\title{
Standard Penetration Test-Based Probabilistic and Deterministic Assessment of Seismic Soil Liquefaction Potential
}

\author{
K. Onder Cetin, M.ASCE${ }^{1}$; Raymond B. Seed, M.ASCE ${ }^{2}$; Armen Der Kiureghian, M.ASCE ${ }^{3}$; \\ Kohji Tokimatsu ${ }^{4}$; Leslie F. Harder Jr., M.ASCE${ }^{5}$; Robert E. Kayen, M.ASCE ${ }^{6}$; and \\ Robert E. S. Moss, M.ASCE ${ }^{7}$
}

\begin{abstract}
This paper presents new correlations for assessment of the likelihood of initiation (or "triggering") of soil liquefaction. These new correlations eliminate several sources of bias intrinsic to previous, similar correlations, and provide greatly reduced overall uncertainty and variance. Key elements in the development of these new correlations are (1) accumulation of a significantly expanded database of field performance case histories; (2) use of improved knowledge and understanding of factors affecting interpretation of standard penetration test data; (3) incorporation of improved understanding of factors affecting site-specific earthquake ground motions (including directivity effects, site-specific response, etc.); (4) use of improved methods for assessment of in situ cyclic shear stress ratio; (5) screening of field data case histories on a quality/uncertainty basis; and (6) use of high-order probabilistic tools (Bayesian updating). The resulting relationships not only provide greatly reduced uncertainty, they also help to resolve a number of corollary issues that have long been difficult and controversial including: (1) magnitude-correlated duration weighting factors, (2) adjustments for fines content, and (3) corrections for overburden stress.
\end{abstract}

CE Database subject headings: Earthquakes; Liquefaction; Seismic hazard; Cyclic loads; Soil penetration tests; In situ tests.

\section{Introduction}

Assessment of the likelihood of "triggering" or initiation of liquefaction is the necessary first step of most projects involving potential seismically induced liquefaction. There are two general types of approaches available for this: (1) use of laboratory testing of "undisturbed" samples, and (2) use of empirical relationships based on correlation of observed field behavior with various in-situ "index" tests.

The use of laboratory testing is complicated by difficulties associated with sample disturbance during both sampling and reconsolidation. It is also difficult and expensive to perform high-

\footnotetext{
${ }^{1}$ Assistant Professor, Dept. of Civil Engineering, Middle East Technical Univ., Ankara, Turkey.

${ }^{2}$ Professor, Dept. of Civil and Environmental Engineering, Univ. of California, Berkeley, CA.

${ }^{3}$ Taisei Professor, Dept. of Civil and Environmental Engineering, Univ. of California, Berkeley, CA.

${ }^{4}$ Professor, Dept. of Architecture and Building Engineering, Tokyo Institute of Technology, Tokyo, Japan.

${ }^{5}$ Chief, Division of Engineering, California Dept. of Water Resources, Sacramento, CA.

${ }^{6}$ Research Civil Engineer, U.S. Geological Survey, Menlo Park, CA.

${ }^{7}$ Project Engineer, Fugro West Inc., Ventura, CA.
}

quality cyclic simple shear testing, and cyclic triaxial testing poorly represents the loading conditions of principal interest for most seismic problems. Both sets of problems can be ameliorated, to some extent, by use of appropriate "frozen" sampling techniques, and subsequent testing in high quality cyclic simple shear or torsional shear apparatus. The difficulty and cost of these delicate techniques, however, places their use beyond the budget and scope of most engineering studies. In addition, permeability conditions in "silty" soils, of clear potential interest with regard to potential liquefaction, can make it impossible to obtain frozen samples without complete disturbance of the soil samples due to ice expansion between particles.

Accordingly, the use of in situ "index" testing is the dominant approach in common practice. As summarized in the recent stateof-the-art paper (Youd et al. 2001), four in situ test methods have now reached a level of sufficient maturity as to represent viable tools for this purpose, and these are: (1) the standard penetration test (SPT); (2) the cone penetration test; (3) measurement of in situ shear wave velocity $\left(V_{s}\right)$; and (4) the Becker penetration test. The oldest, and still the most widely used of these, is the SPT, and this will be the focus of this paper.

\section{Existing Relationships}

The use of SPT as a tool for evaluation of liquefaction potential first began to evolve in the wake of a pair of devastating earthquakes that occurred in 1964; the 1964 Great Alaskan Earthquake $(M=8+)$ and the 1964 Niigata Earthquake $(M \approx 7.5)$, both of which produced significant liquefaction-related damage (e.g., Kishida 1966; Koizumi 1966; Ohsaki 1966; Seed and Idriss 


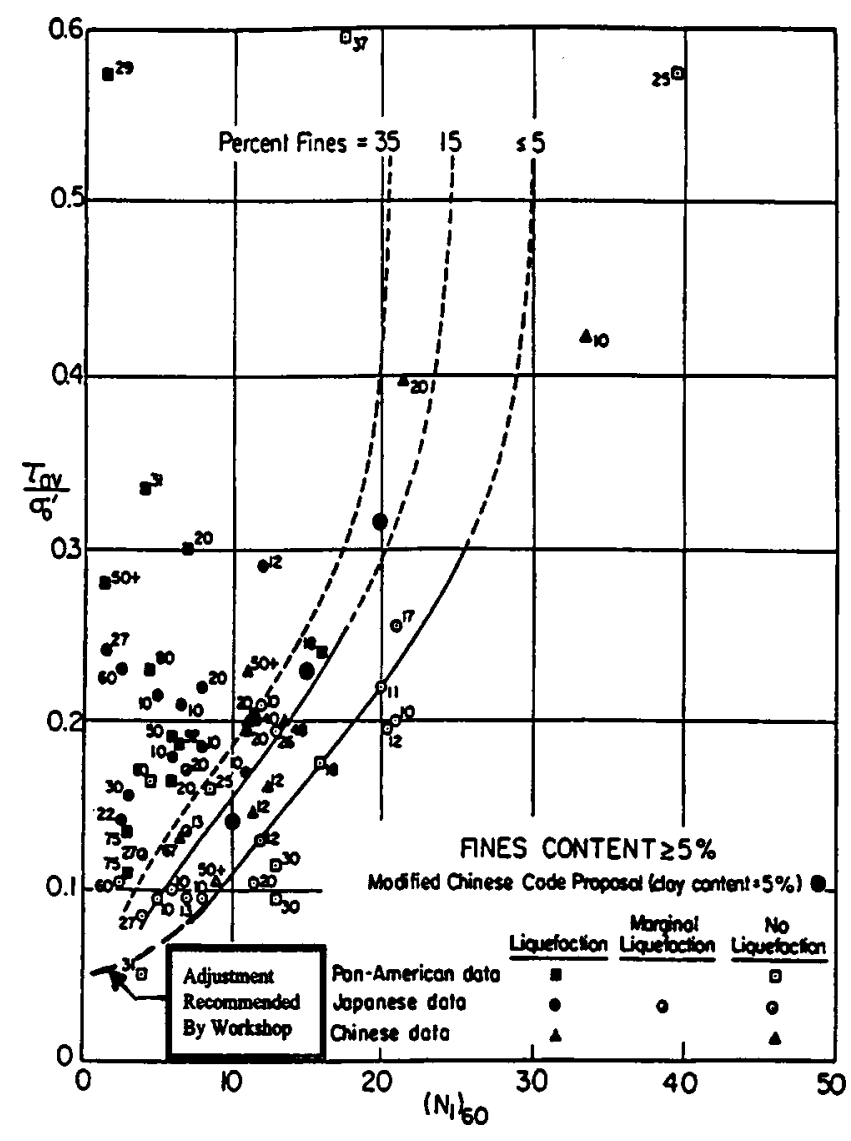

Fig. 1. Correlation between equivalent uniform cyclic stress ratio and standard penetration test $N_{1,60}$ value for events of magnitude $M$ $\approx 7.5$ and for varying fines contents, with adjustment at low cyclic stress ratio as recommended by National Center for Earthquake Engineering Research working group (Seed et al. 1984)

1971). Numerous additional researchers have made subsequent progress, and these types of SPT-based methods continue to evolve today.

As discussed by the NCEER Working Group (NCEER 1997; Youd et al. 2001), one of the most widely accepted and used SPT-based correlations is the "deterministic" relationship proposed by Seed et al. (1984, 1985). Fig. 1 shows this relationship, with minor modification at low cyclic stress ratio (as recommended by the NCEER Working Group; NCEER 1997 and Youd et al. 2001). This familiar relationship is based on comparison between SPT $N$ values, corrected for both effective overburden stress and energy, equipment and procedural factors affecting SPT testing [to $\left(N_{1}\right)_{60}$ values], versus intensity of cyclic loading, expressed as magnitude-weighted equivalent uniform cyclic stress ratio $\left(\mathrm{CSR}_{\mathrm{cq}}^{*}\right)$ or $\tau_{\mathrm{av}} / \sigma_{\mathrm{o}}^{\prime}$ in Fig. 1 . The relationship between corrected $\left(N_{1}\right)_{60}$ values and the intensity of cyclic loading required to trigger liquefaction is also a function of fines content in this relationship, as shown in Fig. 1.

Although widely used in practice, this relationship is somewhat dated, and does not make use of an increasing body of field case history data from seismic events that have occurred since 1984. It is particularly lacking in data from cases wherein peak ground shaking levels were high $(\mathrm{CSR} \geqslant 0.25)$, an increasingly common design range in regions of high seismicity. This correlation also has no formal probabilistic basis, and so provides no insight regarding either uncertainty or probability of liquefaction.

Efforts at development of similar, but formally probabilisti- cally based, correlations have been published by a number of researchers, including Liao et al. (1988) and Liao and Lum (1998), and more recently Youd and Noble (1997) and Toprak et al. (1999). Fig. 2(a) shows the relationship proposed by Liao et al., expressed as contours of probability of triggering of liquefaction for "clean" sands, with the deterministic relationship of Seed et al. from Fig. 1 superposed (dashed lines) for reference. The relationships proposed by Youd and Noble and Toprak et al. are, similarly, presented in Figs. 2(b and c).

The probabilistic relationship proposed by Liao et al. employs a larger number of case history data points than were used by Seed et al. (1984), but this larger number of data points is the result of less severe screening of points for data quality. This relationship was developed using the maximum likelihood estimation method for probabilistic regression (binary regression of logistic models). A largely judgmental correction was made for sampling bias, and this significantly affected the final relationships. Liao et al. sought, but failed to find, a significant impact of fines content on the regressed relationship between SPT penetration resistance and liquefaction resistance, and so developed reliable curves [Fig. 2(a)] only for "clean" sandy soils (soils with less than $12 \%$ fines). This was a landmark effort in its time, and it set high standards for those that followed.

The relationship proposed by Youd and Noble employs a number of field case history data points from earthquakes which have occurred since the earlier relationships were developed, and deletes the most questionable of the data used by Liao et al. The basic methodology employed, maximum likelihood estimation, is the same as that employed by Liao et al. The effects of fines content were judgmentally prescribed, a priori, in these relationships, and so were not developed as part of the regression. This correlation is applicable to soils of variable fines contents (rather than being limited to "clean" sands), and so can be employed for both sandy and silty soils. As shown in Fig. 2(b), however, uncertainty (or variance) is high.

The relationship proposed by Toprak et al. also employs an enlarged and updated field case history database, and deletes the most questionable of the data used by Liao et al. As with the studies of Youd et al., the basic regression tool was binary regression, and the resulting overall uncertainty is again large. Similarly, fines corrections and magnitude correlated duration weighting factors were prescribed a priori, rather than regressed from the field case history data, further decreasing model "fit" (and increasing variance and uncertainty).

Juang et al. (2002) used field performance case history data processed by previous investigators, and developed probabilistically based triggering correlations using a suite of "regression" techniques including logistic regression, Bayesian updating, and other methods. They demonstrated the superior performance of the Bayesian updating methodology in handling the various contributing sources of uncertainty, but their use of data processed by previous researchers resulted in correlations based on a database of variable quality, with some questionable cases included. The processing, however, and especially the application of Bayesian updating methods, was a significant advance.

Finally, all of these previous relationships (the deterministic relationship of Seed et al. 1984, as well as the probabilistic relationships) share two additional, common shortcomings. Inconsistent treatment of effective overburden stress effects ( $K_{\sigma}$ effects) introduces some bias in the assessment of shallow case histories, and these shallow case histories comprise a large portion of the database. All of these correlations also used the same "simplified" $r_{d}$-based assessment of in situ CSR as Seed 


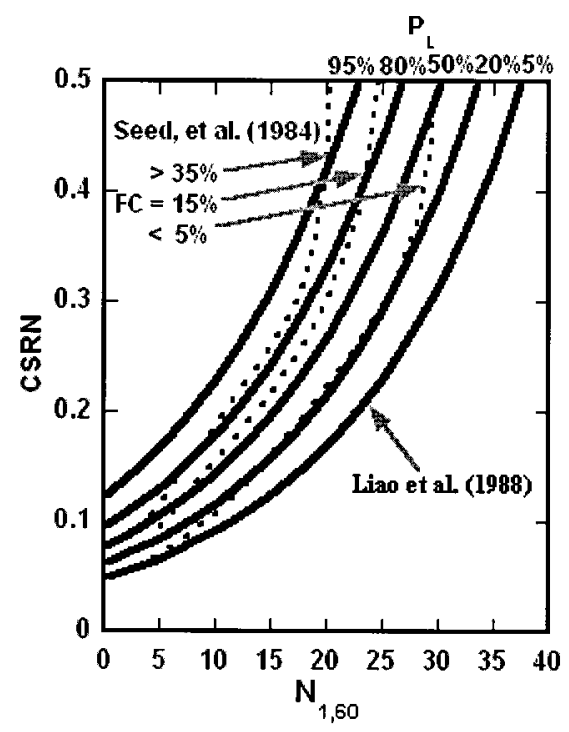

(a) Liao et. al (1988)

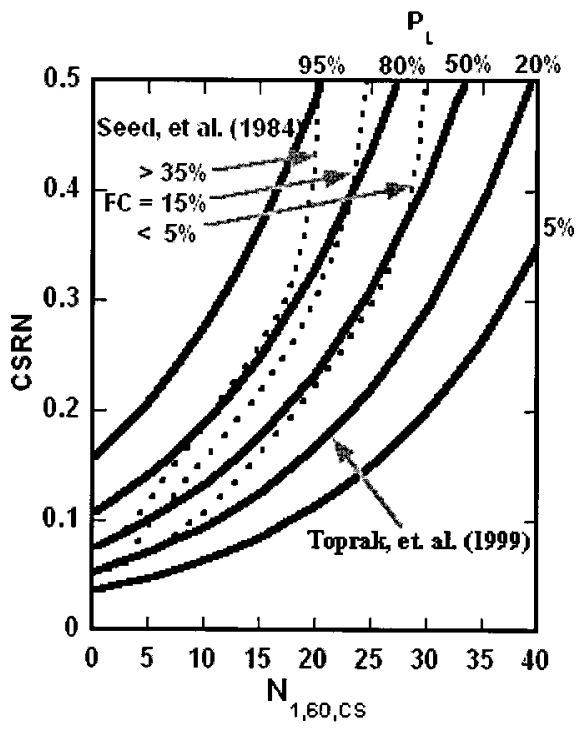

(c) Toprak et. al (1999)

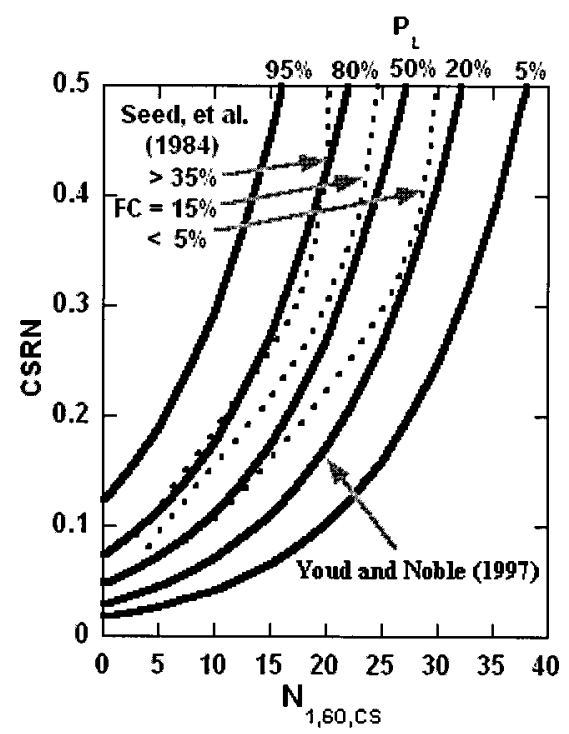

(b) Youd and Noble (1997)

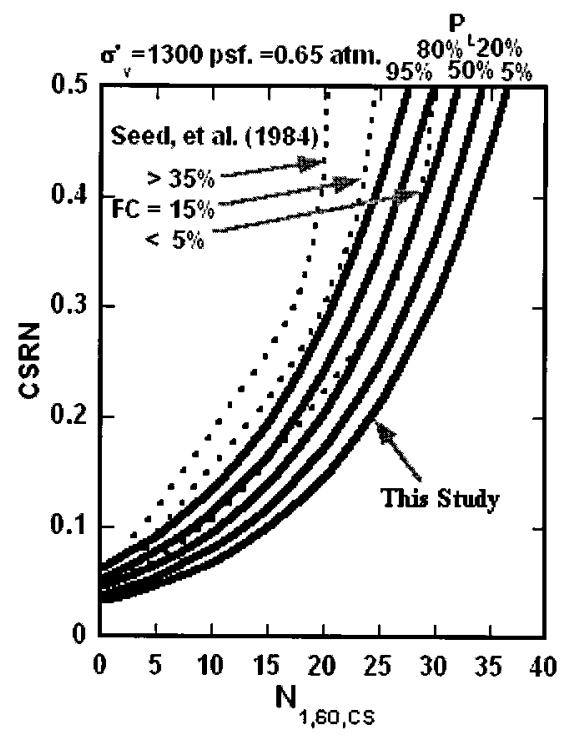

(d) This study

Fig. 2. Comparison among selection of the best available models [(a) Liao et al. (1988), (b) Youd and Noble (1997), (c) Toprak et al. (1999), and (d) this study] for probabilistic assessment of liquefaction initiation likelihood

et al. (1984), and as a result, all suffer from moderately biased estimates of in situ CSR, especially at shallow depths.

Overall, these prior relationships are all excellent efforts, and represent examples of the best of their types. It is proposed that more can now be achieved, however, using more powerful and flexible probabilistic tools, and taking fullest possible advantage of the currently available field case histories and current knowledge affecting the processing and interpretation of these.

\section{Collection and Analysis of Field Case History Data}

As a starting point, all of the field case histories employed in the four previously cited references were obtained and studied. Additional cases were also obtained, including several proprietary data sets. Eventually, approximately 450 liquefaction (or nonliquefaction) field case histories were evaluated in detail, involving well over 600 borings with in situ SPT measurements. A formal rating system was established for evaluating these case histories on the basis of quality and uncertainty, and standards were established for inclusion of field cases in the final data set used to establish the new correlations. In the end, 201 of the field case histories were judged to meet these standards, and were employed in the final development of the proposed new correlations. Processing and back-analysis of field case history data is a key element in development of the types of correlations proposed herein, and it represents a large fraction of the work involved. This is discussed in the sections that follow.

\section{Database of Seed et al. (1984)}

The 126 case history data points employed by Seed et al. (1984) were screened for data quality by the original investigators, and so represented an excellent starting point. These field case histories were reevaluated in detail. New SPT energy, equipment, and procedure corrections were employed, based largely on those rec- 

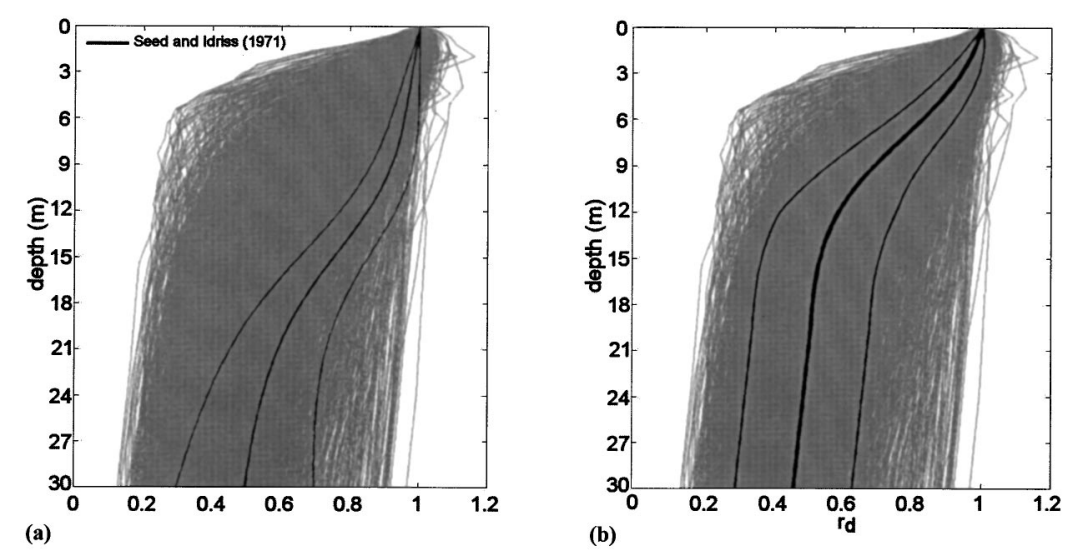

Fig. 3. $r_{d}$ results from response analyses for 2,153 combinations of site conditions and ground motions, superimposed with heavier lines showing: (a) earlier recommendations of Seed and Idriss (1971), and (b) mean and \pm 1 standard deviation values for 2,153 cases analyzed

ommended by the NCEER Working Group (Youd et al. 2001). One particularly significant change from the original work was the use of updated insights regarding rod-length effects on the effective energy transmitted to the SPT sampler at relatively shallow depths, as data from shallow depths are an important component of the case history database.

A second improvement was in the area of evaluation of peak horizontal ground acceleration at each case history site. Specific details are provided by Cetin et al. (2000). Significant improvements here were principally due to improved understanding and treatment of issues such as: (1) fault rupture directivity effects, (2) effects of site conditions on response, and (3) improved attenuation relationships. In these studies, peak horizontal ground acceleration $\left(a_{\max }\right)$ is taken as the geometric mean of two recorded orthogonal horizontal components, a convention selected for internal consistency, as well as for compatibility with many modern attenuation relationships. Whenever possible, a suite of applicable attenuation relationships (suited to the slip mechanism and the regional geologic regime) were calibrated on an earthquakespecific basis, based on local strong ground motion records, significantly reducing uncertainties. In all cases, both local site effects and rupture-mechanism-dependent potential directivity effects were also considered.

A third major improvement was better estimation of in situ CSR within the critical stratum for each of the field case histories. All of the previous studies described so far used the "simplified" method of Seed and Idriss (1971) to estimate CSR at depth (within the critical soil stratum) as

$$
\mathrm{CSR}_{\text {peak }}=\left(\frac{a_{\text {max }}}{g}\right) \cdot\left(\frac{\sigma_{v}}{\sigma_{v}^{\prime}}\right) \cdot\left(r_{d}\right)
$$

where $a_{\max }=$ peak horizontal ground surface acceleration; $g=$ acceleration of gravity; $\sigma_{v}=$ total vertical stress; $\sigma_{v}^{\prime}=$ effective vertical stress; and $r_{d}=$ nonlinear shear mass participation factor.

The original values of the nonlinear shear mass participation factor $\left(r_{d}\right)$ proposed by Seed and Idriss (1971) are shown by the heavy lines in Fig. 3(a). These are the values used in the previous studies by Seed et al. (1984), Liao et al. (1988), Liao and Lum (1998), Youd and Noble (1997), and Toprak et al. (1999).

Recognition that $r_{d}$ is nonlinearly dependent upon a suite of factors led to studies by Cetin and Seed (2004) to develop improved correlations for estimation of $r_{d}$, as discussed in the section that follows. The light gray lines in Figs. 3( $a$ and $b$ ) show the results of 2,153 seismic site response analyses performed to assess the variation of $r_{d}$ over ranges of (1) site conditions and (2) ground motion excitation characteristics. The mean and \pm 1 s.d. values for these 2,153 analyses are shown by the heavy lines in Fig. 3(b). As shown in Figs. 3(a and b), the earlier $r_{d}$ recommendations of Seed and Idriss (1971) understate the variance, and provide biased (generally high) estimates of $r_{d}$ at depths of between 3 and $15 \mathrm{~m}(10-50 \mathrm{ft})$. Unfortunately, it is in this depth range that the critical soil strata for most of the important liquefaction (and nonliquefaction) field performance case histories occur. This, in turn, creates some degree of corresponding bias in relationships developed on this basis.

The best means of estimation of in situ CSR within any given stratum is to directly calculate CSR by means of appropriate sitespecific, and event-specific, seismic site response analyses, when this is feasible. In back-analyses of the field case histories, it was feasible to perform site-specific site response analyses when: (1) sufficient subsurface characterization data were available, and (2) an event-specific and azimuthally appropriate strong motion record was available from which the necessary "input" motion could be developed. For 53 of the case histories eventually employed in these studies, case-specific site response analyses were performed (Cetin 2000; Cetin et al. 2000). For the remaining 148 cases, CSR was evaluated using the new (improved) $r_{d}$ correlations presented in the section that follows. These new correlations provide values of $r_{d}$ that are statistically unbiased relative to results of direct site response analyses.

An additional, and very significant improvement was the evaluation not only of each parameter of interest, but also of the uncertainty or variance of each parameter for each of the field performance case histories studied. This permitted, for the first time, a full treatment of overall uncertainty in the resulting correlations.

\section{New Data (From Events Postdating 1984)}

New case history data were next collected and analyzed, mainly (but not entirely) from events postdating 1984. Data considered here included: (1) all remaining cases from the other studies cited thus far; (2) additional data collected by the authors from a variety of sources; and (3) a set of proprietary data from the 1995 Hyogoken-Nambu (Kobe) earthquake. These data, comprising approximately 300 additional cases, were similarly processed and 


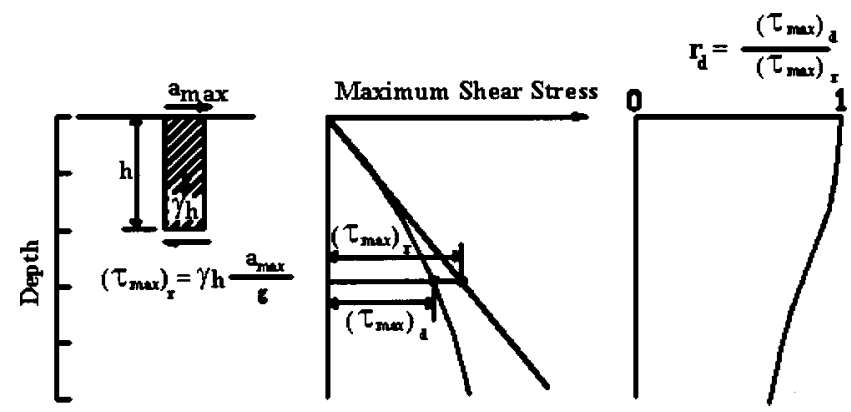

Fig. 4. Schematic illustration of "simplified" procedure for determining maximum cyclic shear stress $\left(\tau_{\max }\right)_{r}$ (after Seed and Idriss 1971)

analyzed as described in the sections that follow. In all cases, both old and new, data processing included assessment of variance or uncertainty in all factors affecting both CSR and corrected SPT $N$ values within the critical soil stratum.

\section{Development of Improved "Simplified" ( $r_{d}$-Based) Cyclic Shear Stress Rate Evaluations}

Evaluation of the in situ cyclic shear stress time history induced within any soil element (or stratum) is a key component of any well-based method for assessment of the likelihood of "triggering" (or initiating) seismically induced soil liquefaction. The seismically induced cyclic shear stress time history is, in most analysis methods, normalized by some measure of the initial normal effective stress in the soil, and the result is the earthquakeinduced in situ CSR.

As the earthquake-induced cyclic shear stress history is a nonlinear function of the interaction between the "input" strong motion characteristics and the characteristics affecting site response (e.g., geometry, stratigraphy, dynamic soil properties, etc.), earthquake-induced CSR time history within a soil element is a site-specific and ground motion-specific issue. Accordingly, it is generally most accurately assessed directly, based on a dynamic response analysis.

In many cases, however, direct response analyses are not performed either: (1) because time and budget do not permit, (2) because necessary information/data for full response analyses are not available, or (3) it is desired to use "simplified" empirical estimates of CSR in order to be fully compatible with the basis employed to develop a given empirical correlation for estimation of in situ liquefaction resistance. Simplified, empirical estimation of CSR is common, both for engineering design studies as well as for back evaluation of earthquake field performance case histories. In both applications, accuracy, lack of systematic error (or bias), and an understanding of uncertainty (or variance) are important.

At most soil sites, the cyclic shear stresses acting on horizontal planes due to seismic loading are largely dominated by cyclic shear stresses induced by vertically propagating, or nearly vertically propagating, shear waves. This gives rise to the "simplified" procedure for evaluation of induced cyclic shear stresses at depth (Seed and Idriss 1971), as illustrated schematically in Fig. 4.

If the soil column above an element of soil at depth $h$ in Fig. 4 behaved as a rigid body, and if the surface peak acceleration was $a_{\text {max }}$, then the full (rigid body) mass of soil above $h$ would impose shear stress at depth $h$, and the maximum shear stress (on a horizontal plane) at depth $h$ would be

$$
\left(\tau_{\text {max }}\right)_{\text {rigid body }}=\gamma \cdot h \cdot \frac{a_{\text {max }}}{g}
$$

where $\gamma=$ total unit weight of the soil; and $g=$ acceleration of gravity.

The soil, however, does not respond as a rigid body. As a result, the actual peak shear stress induced at any depth $h$ is less than that predicted by Eq. (2). The deformable soil mass usually applies less than the "rigid body" shear stress at depth $h$; this reduction is the result of issues such as modal participation, nonlinearity of response, etc.

As the "simplified" method for estimation of CSR begins with estimation of $a_{\max }$, it is conventional to adjust Eq. (2) by the ratio of the actual shear stress induced at any depth versus the theoretical "rigid body" shear stress [from Eq. (2)] as

$$
\left(\tau_{\text {max }}\right)_{\text {deformable soil }}=r_{d} \cdot\left(\tau_{\text {max }}\right)_{\text {rigid body }}
$$

This, in turn establishes the "nonlinear shear mass participation factor" $\left(r_{d}\right)$ at any depth as

$$
r_{d}=\frac{\left(\tau_{\max }\right)_{\text {real }}}{\left(\tau_{\text {max }}\right)_{\text {rigid body }}}
$$

The best way to evaluate earthquake-induced cyclic shear stresses is to perform an appropriate dynamic site response analysis, but it is often either necessary or desirable to estimate cyclic shear stresses at any depth using the "simplified method" as

$$
\tau_{h v, \max }=\frac{a_{\max }}{g} \cdot \gamma \cdot h \cdot r_{d}
$$

A factor of 0.65 is then typically employed to reduce the (single, one time) peak cyclic stress to the "equivalent uniform cyclic shear stress" as

$$
\left(\tau_{h v}\right)_{\mathrm{eq}}=0.65 \cdot \tau_{h v, \max }
$$

When this "equivalent uniform cyclic shear stress" is normalized by the initial effective overburden stress, the result is an estimate of the "equivalent uniform cyclic stress ratio" $\left(\mathrm{CSR}_{\mathrm{eq}}\right)$ as shown (later).

The stress reduction coefficient $r_{d}$ is a function of site stratigraphy, soil properties, and the characteristics of the "input" motions (excitations). It has a value of 1.0 by definition at the ground surface, and tends to decrease with depth. It is also important to note that $r_{d}$ does not vary "smoothly" with depth, but instead may "jump" or transition somewhat sharply, especially at boundaries of substrata of differing stiffnesses. Overall, $r_{d}$ essentially represents a pseudomodal participation factor, and is a function of (nonlinear) system response and harmonics.

Due to the importance of "simplified" methods for assessment of CSR, there have been a number of studies by previous investigators of factors affecting $r_{d}$. It is not reasonable to discuss all of these here (see Cetin and Seed 2004; Cetin 2000). Instead, a limited subset of previous studies and recommendations that provided important insights will be briefly mentioned.

The earliest widely used recommendations for assessment of $r_{d}$ for use in Eqs. (1) and (5), and an equation to follow were proposed by Seed and Idriss (1971), in conjunction with their formal proposal of the "simplified method." Their initial recommendations are shown by the heavy lines in Fig. 3(a).

These early recommendations are important, as they continue to be the most widely used "simplified" basis for estimation of CSR, especially at depths of less than about $12 \mathrm{~m}$ (40 ft). This is despite a number of shortcomings in the limited suite of site re- 
sponse analyses upon which these early recommendations were based. The number of site profiles (stratigraphies) analyzed was very limited, and only a limited number of "input" strong motions were analyzed. These motions were, for the most part, of low to moderate intensity, and these motions did not well span the full ranges of magnitude and intensity currently of interest for seismic engineering applications. In addition, a number of the site soil profiles analyzed were overly uniform, and under-represented the variability of stratigraphy often present at real sites. Nonetheless, this was a landmark early study, and the early recommendations of Seed and Idriss continue to be among the most widely used today.

Ishihara (1977) recognized that $r_{d}$ was a function of site response, and developed a "simplified" method for estimation of $r_{d}$ based on one-dimensional vertical propagation of shear waves in which $r_{d}$ varied as a function of site stiffness and input motion frequency content. Another practical and important set of recommendations regarding the variation of $r_{d}$ with depth were proposed by Iwasaki et al. (1978) based on a series of ground response analyses of two alluvial deposits, each subjected to six earthquake motions. The ranges of the $r_{d}$ values calculated were broader than the range prescribed by Seed and Idriss (1971), suggesting a higher variability in $r_{d}$ estimations. Based on a total of 143 ground response analyses for different site conditions, using five different earthquake motions, Imai et al. (1981) extended the general approach recommended by Ishihara (1977). Again, as with Iwasaki, the 143 site response analyses produced a much broader range of $r_{d}$ values versus depth than the earlier recommendations of Seed and Idriss (1971).

Golesorkhi (1989) investigated the effects of: (1) earthquake magnitude, (2) frequency characteristics of input motion, (3) site stiffness, and (4) site depth on the response and $r_{d}$ behavior of soil sites. Equivalent linear (SHAKE: Schnabel et al. 1972) site response analyses, as well as two types of fully nonlinear site response analyses; lumped mass nonlinear (DESRA), and distributed mass finite difference nonlinear (TESS) site response analyses were performed on idealized soil sites comprised of 30 or $100 \mathrm{~m}$ (100 or $350 \mathrm{ft})$ of uniform sand, with $D_{R}=40$ or $70 \%$. A total of 35 different "input" motions were applied to these hypothetical site conditions. Comparisons between the analytical results by the three different site response analysis tools/methods showed that values of $r_{d}$ calculated by the equivalent linear analyses were typically in good agreement with the results of the two types of fully nonlinear analyses, and were neither consistently high nor low relative to these fully nonlinear analyses. Differences between all three analysis methods were modest, and fully random with no systematic bias.

Based on these site response analysis results, statistically based $r_{d}$ curves were developed for different earthquake magnitude ranges (or "bins"). The initial study by Golesorkhi (1989) has been further extended by Idriss and Golesorkhi (personal communication, 1997), Idriss (1997). The main changes were: (1) the addition of several new soil profiles, and (2) the presentation of Golesorkhi's (1989) findings in a closed form empirical $r_{d}$ correlation for depths of $z \leqslant 24 \mathrm{~m}(80 \mathrm{ft})$ as

$$
\begin{gathered}
\ln \left(r_{d}\right)=\alpha(z)+\beta(z) \cdot M_{w} \\
\alpha(z)=-1.012-1.126 \cdot \sin \left(\frac{z}{38.5}+5.133\right)
\end{gathered}
$$

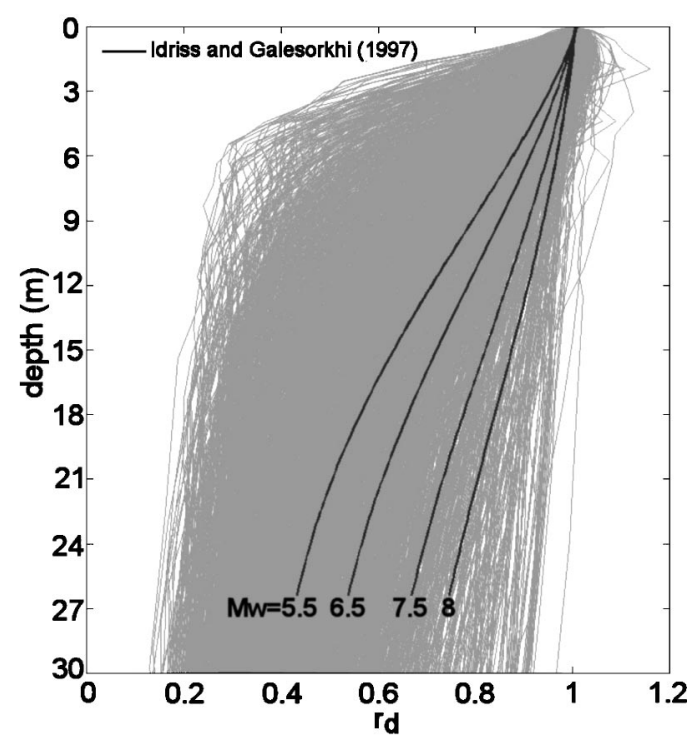

Fig. 5. Improved $r_{d}$ recommendations of Idriss and Golesorkhi (personal communication, 1997) and comparison with calculated values from current study

$$
\beta(z)=0.106+0.118 \cdot \sin \left(\frac{z}{37.0}+5.142\right)
$$

where $z=$ depth in feet.

These recommendations are shown as heavy solid lines in Fig. 5. Also shown with lighter gray lines, for comparison, are the results of the 2,153 site response analyses performed as part of these current studies. As shown in Figs. 3(a) and 5, the proposed $r_{d}$ curve of Idriss and Golesorkhi for earthquakes of moment magnitude $M_{w}=7.5$ is not significantly different than the original Seed and Idriss (1971) $r_{d}$ curve [Fig. 3(a)] over the upper $12 \mathrm{~m}$ (40 ft). These recommendations do, however, address the correlation between $r_{d}$ and earthquake magnitude, and serve to provide improved predictions at magnitudes other than 7.5. As also shown in Fig. 5, however, these recommendations do not yet capture the full variation in $r_{d}$, and continue to provide somewhat biased estimates of $r_{d}$ over most depth ranges.

In these current studies, a total of 2,153 site response analyses were performed on carefully selected sets of site conditions using a carefully selected/developed suite of "input" strong motions. All analyses were one-dimensional seismic response analyses performed by the equivalent linear method using the program SHAKE91 (Idriss and Sun 1992). As demonstrated by Golesorkhi (1989), these analyses, performed with due care and expertise, produce results compatible with fully nonlinear analysis methods for purposes of $r_{d}$ assessment. Details of the site response analyses performed are reported by Cetin (2000), Cetin and Seed (2000), and Cetin and Seed (2004).

One key to the successful consummation of these studies was to develop a suitably balanced and representative suite of realistic site soil profiles for analysis. The sites must be "realistic" to eliminate concerns raised by the use, in many of the previous studies, of overly uniform idealized sites lacking the stratigraphic variation routinely present in sites of interest with respect to potential for liquefaction. Fifty three actual sites were selected from the liquefaction field case history database used to develop correlations for evaluation of liquefaction resistance. The 53 sites selected were each analyzed, using input motions developed from nearby actual strong motion recordings, for purposes of develop- 
ment of liquefaction/nonliquefaction field performance case history data, and the results of these "case-specific" response analyses were included in the overall $r_{d}$ database assembled.

Next, 50 of these sites were selected to develop a suite of sites to be subjected to a broad suite of input motions. Due to the perceived under-representation of relatively shallower sites ( $<100 \mathrm{ft}$. or $<30 \mathrm{~m}), 12$ of the "deep" sites were truncated at the base of the soils of interest and "rock" was added at this depth. For nearly all sites, excepting only those few for which the actual field data indicated otherwise, the transition from soil to "unweathered bedrock" was represented by a transitional zone of weathered rock, typically on the order of about 9-15 m (30-50 ft) in thickness. The unweathered bedrock was modeled as a half space, and in most cases had a shear wave velocity in the range of $V_{s} \approx 900-1,400 \mathrm{~m} / \mathrm{sec}(3,000-4,500 \mathrm{ft} / \mathrm{sec})$.

A suite of 42 strong ground motion recordings were prepared as "input" motions. The characteristics of these motions were developed to provide for suitable and balanced representation of the seismic factors potentially affecting $r_{d}$, including: (1) seismic source mechanism (strike slip or reverse faulting), (2) magnitude, (3) distance, (4) peak ground acceleration $\left(a_{\max }\right)$, (5) near-field versus far-field effects (including directivity, pulse, fling, wave forms, etc.), and (6) spectral content. In addition to 40 actual recordings, scaled and modified as necessary to provide the desired suite of characteristics, two additional synthetic motions were generated for moment magnitude 8.0 strike slip and reverse events. Important characteristics of the resulting suite of 42 "input" motions are summarized in Table 1.

The motions of Table 1 were carefully selected (and scaled and/or modified as necessary) to ensure that the full range of motion characteristics were suitably represented. For example, "near field" motions have relatively high $a_{\max }$, but they also have frequency content, waveforms, etc. (some have near-field directivity effects) representative of near-field motions. Far-field motions, similarly, have low $a_{\max }$, longer-period content, and suitable overall waveforms and characteristics.

Seismic response analyses were then performed using all combinations of the 50 sites and the 42 input motions. The light gray lines in Figs. 3( $a$ and $b$ ) and 5 show the results of the site response analyses for all of the sites and all of the motions. A total of 2,153 site response analyses, representing all combinations of the 50 "prototypical" sites and the input motions from Table 1, plus 53 additional analyses of actual liquefaction field case histories, are presented in these figures.

Fig. 3(b) presents the results of all 2,153 site response analyses, along with the overall mean and mean \pm 1 s.d. values (shown with the heavy lines). This figure, as an overall summary, represents an improved version of the earlier recommendations of Seed and Idriss (1971), based on a much larger and more broadly representative set of response analysis results using carefully selected/developed suites of site conditions and "input" motions.

It is noted that $r_{d}$ is essentially a pseudomodal mass participation factor, and that it is affected by the same factors that affect nonlinear site response. Accordingly, descriptive variables that help to better define the observed $r_{d}$ behavior over the ranges of site conditions and ground motion characteristics analyzed can be evaluated.

Initially, the prospective descriptive variables (parameters that may affect $r_{d}$ ) investigated were: (1) moment magnitude of the earthquake $\left(M_{w}\right) ;(2)$ closest distance to the fault rupture $(D) ;(3)$ depth below the ground surface $(d)$; $(4)$ peak horizontal ground acceleration $\left(a_{\max }\right) ;(5)$ site stiffness, expressed as the representative site shear wave velocity over the top $12 \mathrm{~m}$ (top $40 \mathrm{ft}$ ) as $V_{s, 12 \mathrm{~m}}^{*}\left[V_{s, 12 \mathrm{~m}}^{*}=12 \mathrm{~m}(40 \mathrm{ft})\right.$ divided by $t$, where $t$ is the total

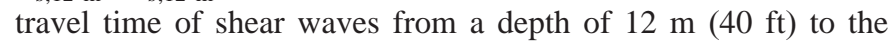
surface]; (6) predominant period of the input motion $T_{p}$; (7) initial fundamental site period at small strains $T_{0}$; (8) final "engineering" site period (site period after earthquake-induced strain softening) $T_{f}$; and (9) total soil depth (to bedrock). For the sake of simplicity, and because of strong cross correlation among some of the parameters listed above, it was decided to reduce the final number of descriptive variables to four, and these were: (1) depth $d$; (2) causative moment magnitude $M_{w}$; (3) intensity of shaking $a_{\max }$; and (4) site stiffness $V_{s, 12 \mathrm{~m}}^{*}$.

To illustrate the variation of $r_{d}$ with these parameters, the results of the 2,153 site response analyses from Fig. 3(b) are subdivided into 12 separate "bins", based on $M_{w}, a_{\max }$, and $V_{s, 12 \mathrm{~m}}^{*}$, as shown in Figs. 6(a-1). It was clearly suggested by the results that $r_{d}$ decreases with increasing $a_{\text {max }}$, and increases with increasing earthquake magnitude and site stiffness. At depths deeper than $\sim 18 \mathrm{~m}(\sim 60 \mathrm{ft})$, the $r_{d}$ curves exhibit a nearly linear decrease with depth. Another interesting observation is that the uncertainty of $r_{d}$ estimations increases with increasing depths (i.e., the range of $r_{d}$ values gets wider with increasing depths) down to a depth of approximately $12 \mathrm{~m}$ (40 ft), and then appears to be nearly constant at greater depths.

Based on these observations, and the results of parametric studies, the predictive limit state function shown in the following equation was developed (using Bayesian updating methods as a "regression" approach) to capture the important aspects of the nonlinear shear mass participation factor. Mean estimates, as well as estimates at various multiples of the standard deviation term, can be expressed as a function of $d, M_{w}, a_{\max }$, and $V_{s, 12 \mathrm{~m}}^{*}$ as $d<20 \mathrm{~m}(\sim 65 \mathrm{ft})$

$$
r_{d}\left(d, M_{w}, a_{\max }, V_{s, 12 \mathrm{~m}}^{*}\right)=\frac{\left[1+\frac{-23.013-2.949 \cdot a_{\mathrm{max}}+0.999 \cdot M_{w}+0.0525 \cdot V_{s, 12 \mathrm{~m}}^{*}}{16.258+0.201 \cdot e^{0.341 \cdot\left(-d+0.0785 \cdot V_{s, 12 \mathrm{~m}}^{*}+7.586\right)}}\right]}{\left[1+\frac{-23.013-2.949 \cdot a_{\max }+0.999 \cdot M_{w}+0.0525 \cdot V_{s, 12 \mathrm{~m}}^{*}}{16.258+0.201 \cdot e^{0.341 \cdot\left(0.0785 \cdot V_{s, 12 \mathrm{~m}}^{*}+7.586\right)}}\right.} \pm \sigma_{\varepsilon_{r_{d}}}
$$

$d \geqslant 20 \mathrm{~m}(\sim 65 \mathrm{ft})$ 
Table 1. Overview of Some Important Characteristics of Seismic Input Motions Used to Develop Improved $r_{d}$ Correlations

\begin{tabular}{|c|c|c|c|c|c|c|c|c|c|}
\hline No. & Event type & Event name & $M w$ & Scaled PGA $(g)$ & PGA $(g)$ & $D(\mathrm{~km})$ & Near field & Mid field & Far field \\
\hline 1 & $?$ & 1985 Michoacan-Ocotito & 8.1 & 0.1 & 0.05 & $337^{\mathrm{a}}$ & - & - & $\mathrm{x}$ \\
\hline 2 & Strike slip & Synthetic Seismograph & 8 & 0.3 & 0.54 & 5 & $\mathrm{x}$ & - & - \\
\hline 3 & Reverse & Synthetic Seismograph & 8 & 0.3 & 0.63 & 5 & $\mathrm{x}$ & - & - \\
\hline 4 & $?$ & 1978 Miyagioki-Ofunato Bochi & 7.4 & 0.15 & 0.22 & $30^{\mathrm{a}}$ & - & - & $\mathrm{x}$ \\
\hline 5 & Reverse & 1978 Tabas-Dayhook & 7.4 & 0.3 & 0.36 & $17^{\mathrm{a}}$ & $\mathrm{x}$ & - & - \\
\hline 6 & Strike slip & 1992 Landers-Lucerne & 7.3 & 0.4 & 0.76 & 1.1 & $\mathrm{x}$ & - & - \\
\hline 7 & Strike slip & 1992 Landers-Silent Valley & 7.3 & 0.09 & 0.045 & 51.3 & - & - & $\mathrm{x}$ \\
\hline 8 & $?$ & 1979 Alaska-Munday Creek & $7.3 ?$ & 0.1 & 0.05 & 72 & - & - & $\mathrm{x}$ \\
\hline 9 & $?$ & 1994 Euroka-Cape Mendocino & 7.2 & 0.05 & 0.03 & $126^{\mathrm{a}}$ & - & - & $\mathrm{x}$ \\
\hline 10 & Strike slip & 1999 Hector Mines-LA City Terrace & 7.1 & 0.08 & 0.04 & $184^{\mathrm{a}}$ & - & - & $\mathrm{x}$ \\
\hline 11 & $?$ & 1971 Adak Alaska-Naval Base & 7.1 & 0.15 & 0.15 & $66.2^{\mathrm{a}}$ & - & $\mathrm{x}$ & - \\
\hline 12 & Reverse & 1992 Cape Mendocino-Cape Mendocino & 7 & 0.55 & 1.25 & $3.8^{\mathrm{a}}$ & $\mathrm{x}$ & - & - \\
\hline 13 & Strike slip & 1989 Loma Prieta-Gilroy \#1 & 7 & 0.3 & 0.44 & 10 & $\mathrm{x}$ & - & - \\
\hline 14 & Strike slip & 1989 Loma Prieta-Lick Lab & 7 & 0.3 & 0.42 & 18 & $\mathrm{x}$ & - & - \\
\hline 15 & Strike slip & 1989 Loma Prieta-Piedmont Jr. High & 7 & 0.15 & 0.075 & 73 & - & - & $\mathrm{x}$ \\
\hline 16 & Strike slip & 1995 Kobe-Chihaya & 6.9 & 0.15 & 0.11 & 48.7 & - & - & $\mathrm{x}$ \\
\hline 17 & Strike slip & 1995 Kobe-Kobe University & 6.9 & 0.3 & 0.31 & 0.2 & $\mathrm{x}$ & - & - \\
\hline 18 & Reverse & 1985 Nahanni-Site 1 & 6.8 & 0.55 & 1.04 & 6 & $\mathrm{x}$ & - & - \\
\hline 19 & Reverse & 1985 Nahanni-Site3 & 6.8 & 0.15 & 0.2 & 16 & - & $\mathrm{x}$ & - \\
\hline 20 & Reverse & 1976 Gazli-Karakyr & 6.8 & 0.35 & 0.66 & 3 & $\mathrm{x}$ & - & - \\
\hline 21 & Strike slip & 1987 Superstition Hills-Superstition Mtn & 6.7 & 0.3 & 0.78 & 4.3 & $\mathrm{x}$ & - & - \\
\hline 22 & Reverse & 1994 Northridge-Lake Hughes \#9 & 6.7 & 0.15 & 0.18 & 28.9 & - & - & $\mathrm{x}$ \\
\hline 23 & Reverse & 1994 Northridge-Vasquez Rocks & 6.7 & 0.15 & 0.14 & 24 & - & - & $\mathrm{x}$ \\
\hline 24 & Reverse & 1971 San Fernando-Cedar Springs & 6.6 & 0.05 & 0.03 & 86.6 & - & - & $\mathrm{x}$ \\
\hline 25 & Reverse & 1971 San Fernando-Carbon Canyon & 6.6 & 0.12 & 0.07 & 66.4 & - & - & $\mathrm{x}$ \\
\hline 26 & Reverse & 1971 San Fernando-Lake Hughes \#4 & 6.6 & 0.25 & 0.17 & 19.6 & - & $\mathrm{x}$ & - \\
\hline 27 & Reverse & 1983 Coalinga-Parkfield Cholame 3E & 6.6 & 0.08 & 0.05 & 38.4 & - & - & $\mathrm{x}$ \\
\hline 28 & Strike slip & 1979 Imperial Valley-Cerro Prieto & 6.5 & 0.25 & 0.163 & 23.5 & - & $\mathrm{x}$ & - \\
\hline 29 & Strike slip & 1979 Imperial Valley-Superstition Mt Cmr & 6.5 & 0.23 & 0.146 & 26 & - & $\mathrm{x}$ & - \\
\hline 30 & Strike slip & 1986 Chalfant Valley-Paradise Lodge & 6.2 & 0.25 & 0.163 & $23^{\mathrm{a}}$ & - & $\mathrm{x}$ & - \\
\hline 31 & Strike slip & 1986 Chalfant Valley-Tinemaha & 6.2 & 0.06 & 0.037 & 40.6 & - & - & $\mathrm{x}$ \\
\hline 32 & Strike slip & 1984 Morgan Hill-Gilroy \#1 & 6.2 & 0.13 & 0.082 & 16.2 & - & - & $\mathrm{x}$ \\
\hline 33 & Strike slip & 1984 Morgan Hill-USCS Lick Observatory & 6.2 & 0.09 & 0.054 & 44.1 & - & - & $\mathrm{x}$ \\
\hline 34 & Reverse & 1986 N. Palm Springs-Silent Valley & 6 & 0.13 & 0.125 & 25.8 & - & $\mathrm{x}$ & - \\
\hline 35 & Reverse & 1986 N. Palm Springs-Murieta Hot Springs & 6 & 0.09 & 0.051 & 63.3 & - & - & $\mathrm{x}$ \\
\hline 36 & Reverse & 1987 Whittier Narrows-Mnt. Wilson & 6 & 0.25 & 0.15 & $28^{\mathrm{a}}$ & - & $\mathrm{x}$ & - \\
\hline 37 & Strike slip & 1980 Victoria-Cerro Prieto & 5.9 & 0.4 & 0.604 & $34.8^{\mathrm{a}}$ & $\mathrm{x}$ & - & - \\
\hline 38 & Dip :80 & 1981 Westmorland-Camera (Sup) & 5.9 & 0.1 & 0.09 & 23.9 & - & $\mathrm{x}$ & - \\
\hline 39 & Reverse & 1983 Coalinga-Oil Fields Fire Station & 5.8 & 0.25 & 0.2 & 10.9 & $\mathrm{x}$ & - & - \\
\hline 40 & Reverse & 1983 Coalinga-Skunk Hollow & 5.8 & 0.25 & 0.3 & 12.2 & $\mathrm{x}$ & - & - \\
\hline 41 & Reverse & 1983 Coalinga-Oil Transmitter Hill & 5.8 & 0.4 & 0.95 & 9.2 & $\mathrm{x}$ & - & - \\
\hline 42 & Strike slip & 1979 Cayote Lake-Gilroy Array \#1 & 5.7 & 0.12 & 0.116 & 9.1 & - & $\mathrm{x}$ & - \\
\hline
\end{tabular}

${ }^{\mathrm{a} E p i c e n t r a l ~ d i s t a n c e . ~}$ 


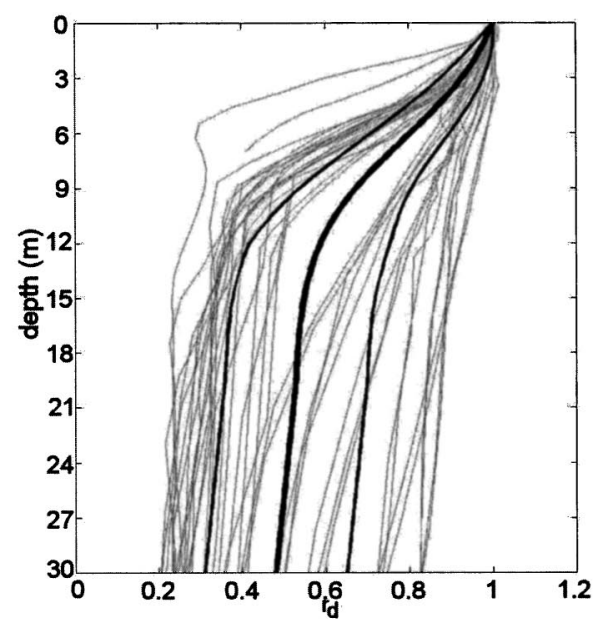

(a) $M_{w} \geq 6.8, a_{\max } \leq 0.12 \mathrm{~g}, V^{*}{ }_{s, 12 \mathrm{~m}} \leq 160 \mathrm{~m} / \mathrm{s}$

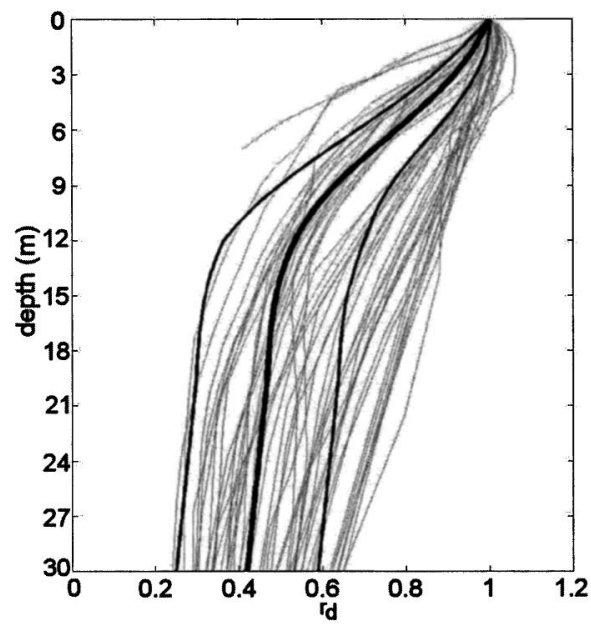

(c) $\mathrm{M}_{\mathrm{w}}<6.8, \mathrm{a}_{\max } \leq 0.12 \mathrm{~g}, \mathrm{~V}_{\mathrm{s}, 12 \mathrm{~m}}^{*} \leq 160 \mathrm{~m} / \mathrm{s}$

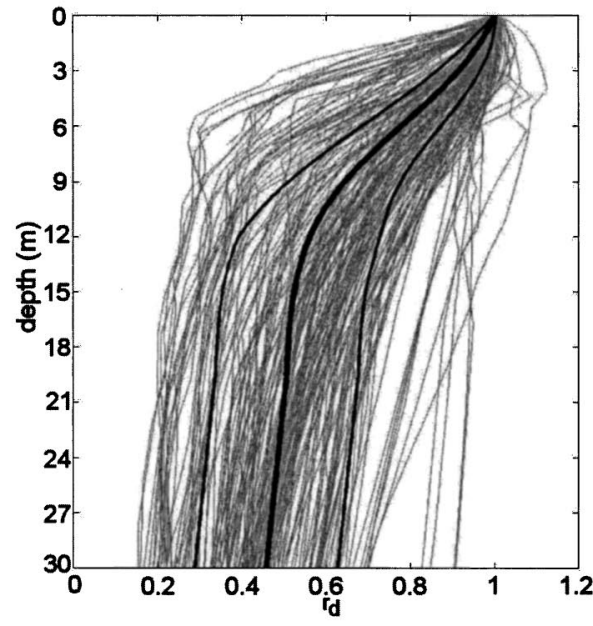

(e) $\mathrm{M}_{\mathrm{w}} \geq 6.8,0.12 \mathrm{~g}<\mathrm{a}_{\max } \leq 0.23 \mathrm{~g}, \mathrm{~V}_{\mathrm{s}, 12 \mathrm{~m}}^{*} \leq 160 \mathrm{~m} / \mathrm{s}$

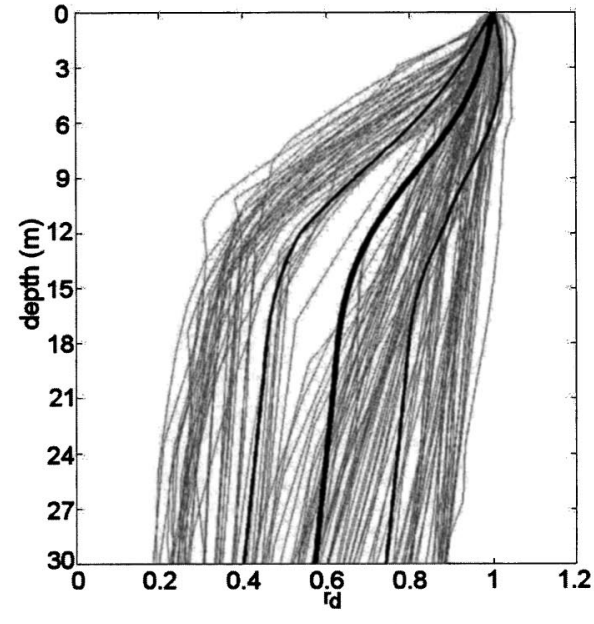

(b) $M_{w} \geq 6.8, a_{\max } \leq 0.12 \mathrm{~g}, V_{s, 12 \mathrm{~m}}^{*}>160 \mathrm{~m} / \mathrm{s}$

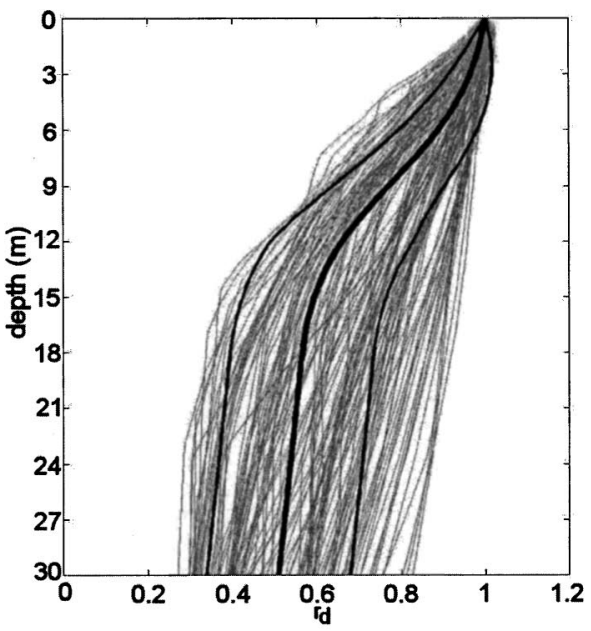

(d) $M_{w}<6.8, a_{\max } \leq 0.12 \mathrm{~g}, V_{s, 12 \mathrm{~m}}^{*}>160 \mathrm{~m} / \mathrm{s}$

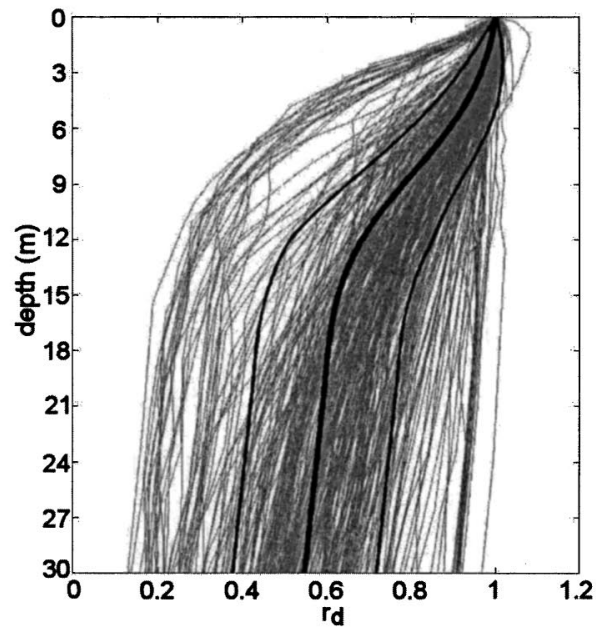

(f) $\mathrm{M}_{\mathrm{w}} \geq 6.8,0.12 \mathrm{~g}<\mathrm{a}_{\max } \leq 0.23 \mathrm{~g}, \mathrm{~V}_{\mathrm{s}, 12 \mathrm{~m}}^{*}>160 \mathrm{~m} / \mathrm{s}$

Fig. 6. $r_{d}$ results for 12 "bins" (based on selected subranges of $a_{\max }, V_{s}$, and $M_{w}$ ) superimposed with predictions based on each bin's mean values of $V_{s}, M_{w}$, and $a_{\max }$ (with \pm 1 standard deviation predictions also shown) 


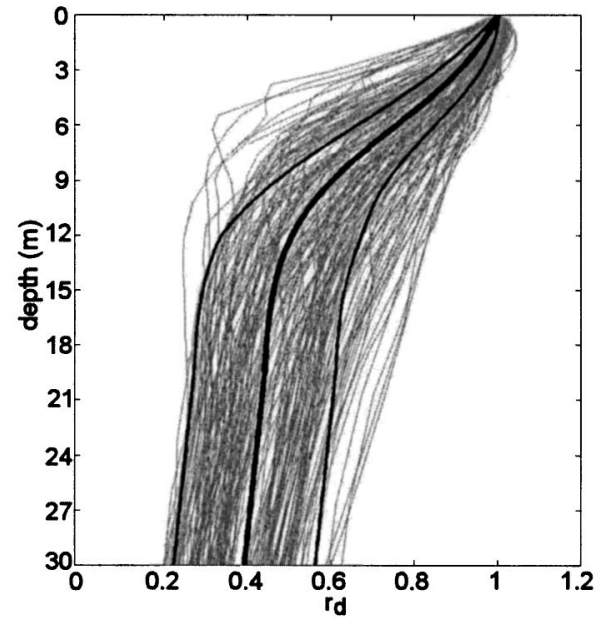

(g) $M_{w}<6.8,0.12 \mathrm{~g}<\mathrm{a}_{\max } \leq 0.23 \mathrm{~g}, \mathrm{~V}_{\mathrm{s}, 12 \mathrm{~m}}^{*} \leq 160 \mathrm{~m} / \mathrm{s}$

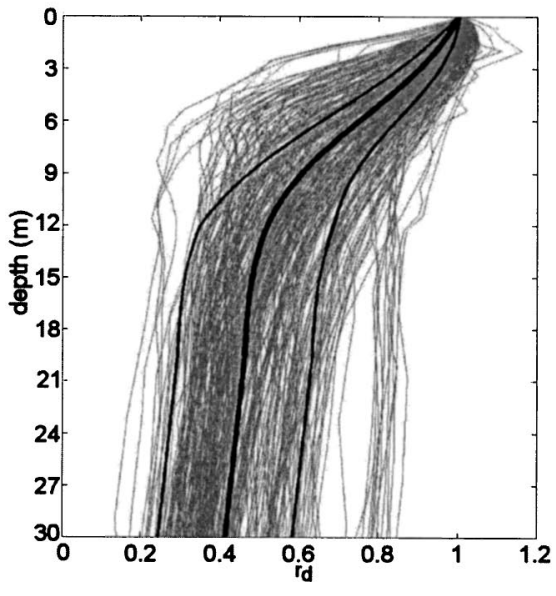

(i) $M_{w} \geq 6.8,0.23 g<a_{\max }, V_{s, 12 m}^{*} \leq 160 \mathrm{~m} / \mathrm{s}$

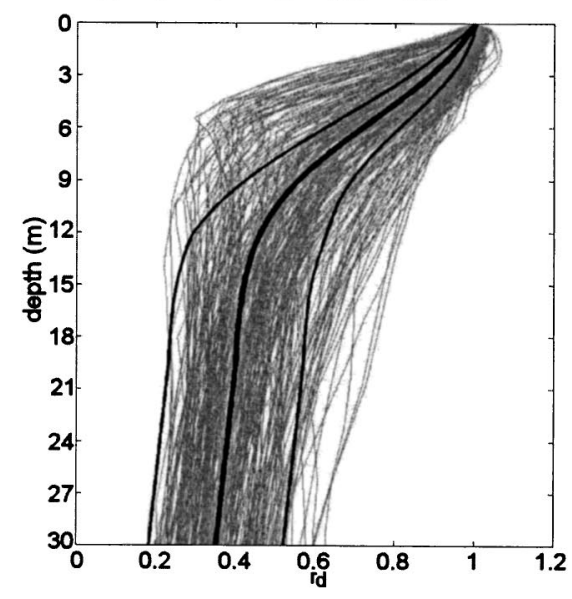

(k) $\mathrm{M}_{\mathrm{w}}<6.8,0.23 \mathrm{~g}<\mathrm{a}_{\max }, \mathrm{V}_{\mathrm{s}, 12 \mathrm{~m}}^{*} \leq 160 \mathrm{~m} / \mathrm{s}$

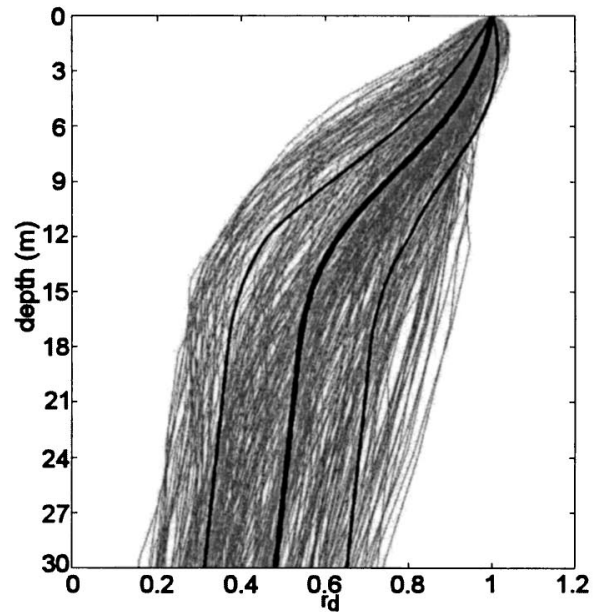

(h) $\mathrm{M}_{\mathrm{w}}<6.8,0.12 \mathrm{~g}<\mathrm{a}_{\max } \leq 0.23 \mathrm{~g}, \mathrm{~V}_{\mathrm{s}, 12 \mathrm{~m}}^{*}>160 \mathrm{~m} / \mathrm{s}$

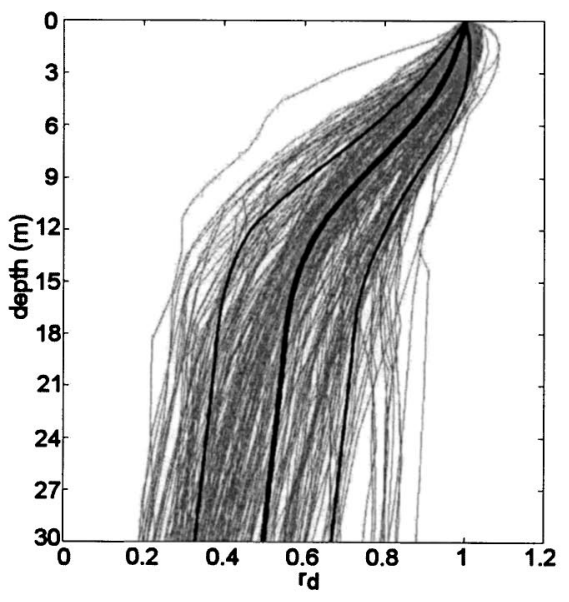

(j) $M_{w} \geq 6.8,0.23 g<a_{\max }, V_{s, 12 m}^{*}>160 \mathrm{~m} / \mathrm{s}$

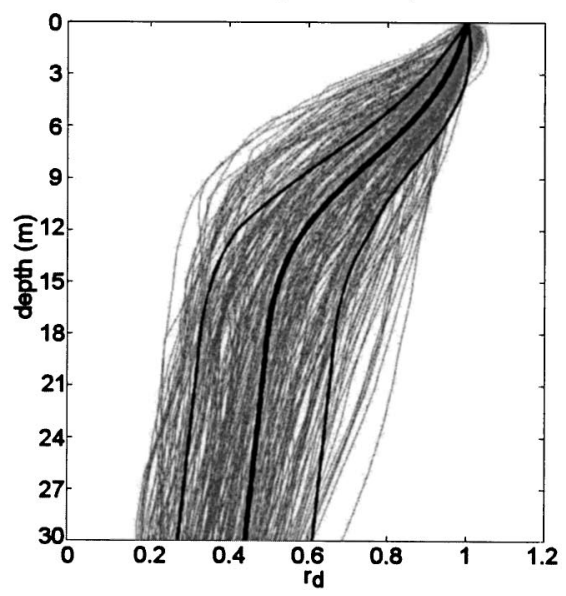

(l) $\mathrm{M}_{\mathrm{w}}<6.8,0.23 \mathrm{~g}<\mathrm{a}_{\max }, \mathrm{V}_{\mathrm{s}, 12 \mathrm{~m}}>160 \mathrm{~m} / \mathrm{s}$

Fig. 6. (Continued). 


$$
r_{d}\left(d, M_{w}, a_{\max }, V_{s, 12 \mathrm{~m}}^{*}\right)=\frac{\left[1+\frac{-23.013-2.949 \cdot a_{\max }+0.999 \cdot M_{w}+0.0525 \cdot V_{s, 12 \mathrm{~m}}^{*}}{16.258+0.201 \cdot e^{0.341 \cdot\left(-20+0.0785 \cdot V_{s, 12 \mathrm{~m}}^{*}+7.586\right)}}\right]}{\left[1+\frac{-23.013-2.949 \cdot a_{\max }+0.999 \cdot M_{w}+0.0525 \cdot V_{s, 12 \mathrm{~m}}^{*}}{16.258+0.201 \cdot e^{0.341 \cdot\left(0.0785 \cdot V_{s, 12 \mathrm{~m}}^{*}+7.586\right)}}\right]}-0.0046 \cdot(d-20) \pm \sigma_{\varepsilon_{r_{d}}}
$$

$d<12 \mathrm{~m}(\sim 40 \mathrm{ft})$

$$
\sigma_{\varepsilon_{r_{d}}}(d)=d^{0.8500} \cdot 0.0198
$$

$d \geqslant 12 \mathrm{~m}(\sim 40 \mathrm{ft})$

$$
\sigma_{\varepsilon_{r_{d}}}(d)=12^{0.8500} \cdot 0.0198
$$

In Eq. (8), $d$ is in meters, $a_{\max }$ is in gravitational acceleration $(g \mathrm{~s}), V_{s, 12 \mathrm{~m}}^{*}$ is in $\mathrm{m} / \mathrm{s}$, and $e=$ exponential symbol.

The mean $r_{d}$ predictions and \pm 1 s.d. ranges predicted by Eq. (8), for 12 different "binned" combinations of $M_{w}, a_{\max }, V_{s, 12 \mathrm{~m}}^{*}$, are shown with heavy lines in Figs. 6(a-1). Also shown, with lighter lines, are the actual calculated results for individual site response analyses falling within the "binned" ranges of each figure. The overall good fit of the predictions, based on the new $r_{d}$ correlations, to the $r_{d}$ values calculated by direct site response analyses shows that the functional form and the selected descriptive variables are capturing the important aspects of the seismically induced shear mass participation problem.

The use of Eq. (8), or Figs. 6(a-1), requires estimation of the site stiffness factor $V_{s, 12 \mathrm{~m}}^{*}$. This can be done using measured $V_{s}$ data, or it can be approximated using estimated $V_{s}$ values for the soil strata of the upper $12 \mathrm{~m}(40 \mathrm{ft})$. There are a number of appropriate empirical correlations available for estimation of shear wave velocity $\left(V_{s}\right)$ as a function of soil type, strength $N_{1,60}$, etc. Finally, if estimation of $V_{s, 12 \mathrm{~m}}^{*}$ is considered difficult for a given case, then $V_{s, 12 \mathrm{~m}}^{*}$ can simply be taken as approximately $150-200 \mathrm{~m} / \mathrm{s}(500-650 \mathrm{ft} / \mathrm{s})$ for most potentially liquefiable sites with adequate accuracy for many engineering applications.

The correlations of Eq. (8) were developed for sites of "typical" stiffness. For the (rare) cases of very soft sites with $V_{s, 12 \mathrm{~m}}^{*}$ of less than $120 \mathrm{~m} / \mathrm{s}(400 \mathrm{ft} / \mathrm{s})$, site response analyses should be performed, or a limiting value of $V_{s, 12 \mathrm{~m}}^{*}=120 \mathrm{~m} / \mathrm{s}$ should be used. Similarly, for very stiff sites (e.g., densely compacted surface fills overlying potentially liquefiable soils) with $V_{s, 12 \mathrm{~m}}^{*}$ of greater than about $250 \mathrm{~m} / \mathrm{s}(820 \mathrm{ft} / \mathrm{s})$, site response analyses should be performed, or a limiting value of $V_{s, 12 \mathrm{~m}}^{*}=250 \mathrm{~m} / \mathrm{s}$ should be used in Eq. (8).

The new $r_{d}$ correlations proposed herein, along with the "simplified" approach of Eq. (1) and an equation to follow, provide significant advantages relative to previously available recommendations in that they:

1. Are developed based on a much higher number of cases $(2,153$ site response analysis cases);

2. Are based on more realistic site stratigraphies adopted from 50 actual liquefied/nonliquefied field case history sites;

3. Are based on site response analysis results using a suite of broadly well-balanced input strong ground motions;

4. Address and incorporate the effects of key seismic source, motion, and soil factors such as moment magnitude of the earthquake, intensity of shaking $\left(a_{\max }\right)$, and site soil stiffness in the estimation of $r_{d}$ values; and

5. Predict the values of the nonlinear shear mass participation factor $\left(r_{d}\right)$ correctly in a mean sense (i.e., they are not biased).

Accordingly, these new $r_{d}$ correlations provide a significantly improved, and unbiased, basis for "simplified" evaluation of CSR for purposes of both (1) back analysis and evaluation of liquefaction field case histories and (2) use in forward engineering analyses for actual projects.

\section{Conventions Used in Analyzing Field Case Histories}

This section presents a concise summary of some of the key elements of the conventions and procedures employed in evaluation of the field performance case histories. A more comprehensive description is provided by Cetin (2000), and by Cetin et al. (2000). More complete summaries of each of the case histories employed in these studies, and citations of source references for these are presented in Cetin et al. (2000). It should be noted that the processing and analysis of the field case histories is one of the most difficult, sensitive and time-consuming elements of the work involved in developing the types of correlations proposed herein. It is also of critical importance, and often requires considerable judgment. Differences between the correlations proposed by different teams of researchers are often due, in no small part, to differences in the interpretations and analyses of the contributing individual field case histories.

All case histories used in these studies were free-field and level ground cases. Cases in which soil/structure interaction might have significantly influenced performance were eliminated. Similarly, cases with ground slopes of more than about 3\%, or cases with a free face (e.g., stream cut, shoreline, etc.) in close enough proximity as to produce a nonzero initial shear stress on horizontal planes in the soil, were eliminated. Any individual case can produce only one performance outcome; sites either liquefied, did not liquefy, or in a few cases were "marginal." Unlike some previous studies, it was not allowed that both "liquefied" and "nonliquefied" data were drawn from the same site, as the onset of liquefaction reduces cyclic shear stresses in both overlying and underlying strata, so that it is not possible to derive meaningful "nonliquefied" data from other strata at a site where one or more strata have liquefied.

Some of the case histories are characterized by a single SPT boring, and at other sites multiple SPT borings are available to characterize a single critical soil stratum. Unlike some previous studies, however, these studies did not assign a "case history" to each valid SPT boring. Instead, multiple borings at a site are generally grouped together to jointly define a stratum, and are then considered en masse as a single case history. Because uncertainty or variance in SPT $N$ values is incorporated directly, cases in which more numerous and extensive characterization data are 
available for a critical stratum intrinsically carry more weight than less well-characterized cases with more limited in situ data.

In these studies, peak ground acceleration estimates $\left(a_{\max }\right)$ were developed using all available information, including source mechanism and geometry, recorded strong motion data, etc. Values of $a_{\max }$ are taken as the geometric mean of the two orthogonal horizontal components of motion. Source mechanism, near-field effects, and local site response effects were all accounted for as fully as possible. In most cases, applicable attenuation relationships were locally calibrated for event-specific and azimuthspecific variations using nearby strong ground motion records. Adjustments for site effects were made either based on judgment or experience, on event-specific data, or were based on performance of full site response analyses. $a_{\max }$ was considered to be $\log$-normally distributed. Uncertainty (or variance) in $a_{\max }$ is directly reflective of the level and quality of data and information available for each case history.

In situ CSR is taken as the "equivalent uniform CSR" equal to $65 \%$ of the single peak CSR as

$$
\mathrm{CSR}_{\mathrm{eq}}=(0.65) \cdot \mathrm{CSR}_{\text {peak }}
$$

In situ $\mathrm{CSR}_{\mathrm{eq}}$ was evaluated directly, based on performance of full seismic site response analyses (using SHAKE 91; Idriss and Sun 1992), for cases where (1) sufficient subsurface data were available and (2) where suitable "input" motions could be developed from nearby strong ground motion records. For cases wherein full seismic site response analyses were not performed, $\mathrm{CSR}_{\mathrm{eq}}$ was evaluated using the estimated $a_{\max }$ and the following equation with $r_{d}$ values estimated using the new empirical correlation of Eq. (8) (or Figs. 6(a-1)):

$$
\operatorname{CSR}_{\mathrm{eq}}=0.65 \cdot\left(\frac{a_{\mathrm{max}}}{g}\right) \cdot\left(\frac{\sigma_{v}}{\sigma_{v}^{\prime}}\right) \cdot\left(r_{d}\right)
$$

where $a_{\max }=$ peak horizontal ground surface acceleration; $g=$ acceleration of gravity; $\sigma_{v}=$ total vertical stress; $\sigma_{v}^{\prime}=$ effective vertical stress; and $r_{d}=$ nonlinear shear mass participation factor.

Factors contributing to overall variance in estimation of $\mathrm{CSR}_{\mathrm{eq}}$ were summed within a reliability framework, and the main contributions to this variance were: (1) uncertainty in $a_{\max }$ and (2) uncertainty in nonlinear shear mass participation (or $r_{d}$ ). Uncertainty in $a_{\max }$ was largest when instrumental recordings in the region of the case history site were sparse, and attenuation projections could not be well calibrated on an event-specific and azimuth-specific basis. Additional variables, which generally contributed slightly to overall variance in estimates of $\mathrm{CSR}_{\mathrm{cq}}$ were, (1) the limits of the critical soil stratum, (2) uncertainty in soil unit weights, and (3) uncertainty regarding the location of the phreatic surface (or "water table depth") at the time of the earthquake.

At each case history site, the critical stratum was identified as the stratum most susceptible to triggering of liquefaction. When possible, collected surface boil materials were also considered, but problems associated with mixing and segregation during transport, and recognition that liquefaction of underlying strata can result in transport of overlying soils to the surface through boils, limited the usefulness of some of these data.

The $N_{1,60}$ values employed were "truncated mean values" within the critical stratum, developed as follows. Measured $N$ values (from one or more points) within a critical stratum were corrected for overburden, energy, equipment, and procedural effects to $N_{1,60}$ values, and were then plotted versus elevation. In many cases, a given soil stratum would be found to contain an identifiable substratum (based on a group of localized low $N_{1,60}$ values) that was significantly more critical than the rest of the stratum. In such cases, the substratum was taken as the "critical stratum." Occasional high values, not apparently representative of the general characteristics of the critical stratum, were considered "nonrepresentative" and were deleted in a number of the cases. Similarly, though less often, very low $N_{1,60}$ values (very much lower than the apparent main body of the stratum, and often associated with locally high fines content) were similarly deleted. The remaining, corrected $N_{1,60}$ values were then used to evaluate both the mean of $N_{1,60}$ within the critical stratum and the variance in $N_{1,60}$.

Based on assessment of the distributions of $N_{1,60}$ in all of the field cases wherein more than five values of $N_{1,60}$ were available to characterize a given stratum, the characteristic distribution of $N_{1,60}$ appeared to be between normally distributed and lognormally distributed. A normal distribution was selected to represent $N_{1,60}$ within each stratum. For the relatively few cases wherein the critical stratum had only one single useful $N_{1,60}$ value, the coefficient of variation $\left(\mathrm{COV}_{N_{1,60}}\right)$ was taken as $20 \%$; a value typical of the larger variances among the cases with multiple $N_{1,60}$ values within the critical stratum (reflecting the increased uncertainty due to lack of data when only a single value was available).

All $N$ values were corrected for overburden effects (to the hypothetical value, $N_{1}$, that "would" have been measured if the effective overburden stress at the depth of the SPT had been 1 atm) $\left[1 \mathrm{~atm} \approx 2,000 \mathrm{lb} / \mathrm{ft}^{2} \approx 1 \mathrm{~kg} / \mathrm{cm}^{2} \approx 14.7 \mathrm{lb} /\right.$ in. $\left.^{2}\right]$ as

$$
N_{1}=N C_{N}
$$

where $C_{N}$ is taken (after Liao and Whitman 1986) as

$$
\begin{gathered}
C_{N}=\left(1 / \sigma_{v}^{\prime}\right)^{0.5} \\
\lim C_{N} \leqslant 1.6
\end{gathered}
$$

where $\sigma_{v}^{\prime}=$ actual effective overburden stress at the depth of the in situ SPT in atmospheres. A maximum (limiting) value of $C_{N}$ $=1.6$ was employed for cases where Eq. (12) resulted in a higher value.

The resulting $N_{1}$ values were then further corrected for energy, equipment, and procedural effects to fully standardized $N_{1,60}$ values as

$$
N_{1,60}=N_{1} C_{R} C_{S} C_{B} C_{E}
$$

where $C_{R}=$ correction for "short" rod length; $C_{S}=$ correction for nonstandardized sampler configuration; $C_{B}=$ correction for borehole diameter; and $C_{E}=$ correction for hammer energy efficiency.

The corrections for $C_{R}, C_{S}, C_{B}$, and $C_{E}$ employed correspond largely to those recommended by the NCEER Working Group (NCEER 1997), and are summarized in Table 2. The correction for "short" rod length between the driving hammer and the penetrating sampler was taken as a nonlinear "curve" as shown in Fig. 7, rather than the stepwise incremental values of the NCEER Workshop recommendations, but the two agree well at all NCEER mid-increments of length. Except for cases where rod "stickup" (protrusion) above the top of the borehole was recorded, rod protrusion of $\sim 1.2 \mathrm{~m}(\sim 4 \mathrm{ft})$ above the top of the borehole was assumed for donut hammers and for the USGS safety hammers, and rod protrusion of $\sim 2.1 \mathrm{~m}(\sim 7 \mathrm{ft})$ was assumed for all other safety hammers.

$C_{S}$ was applied in cases wherein a "nonstandard" (though very common) SPT sampler was used in which the sampler had an internal space for sample liner rings, but the rings were not used. 
$C_{R} \quad$ (See Fig. 7 for Rod Length Correction Factors)

$C_{S}$ For samplers with an indented space for interior liners, but with liners omitted during sampling,

$$
C_{S}=1+\frac{N_{1,60}}{100} \quad(\text { Eq.T-1) }
$$

With limits as $1.10 \leqslant C_{S} \leqslant 1.30$

$C_{B}$

$$
\begin{gathered}
\text { Borehole diameter } \\
\hline 65 \text { to } 115 \mathrm{~mm} \\
150 \mathrm{~mm} \\
200 \mathrm{~mm}
\end{gathered}
$$

$C_{E}$

$$
C_{E}=\frac{E R}{60 \%}
$$

(Eq.T-2)

where ER (efficiency ratio) is the fraction or percentage of the theoretical SPT impact hammer energy actually transmitted to the sampler, expressed as \%

- The best approach is to directly measure the impact energy transmitted with each blow. When available, direct energy measurements were employed.

- The next best approach is to use a hammer and mechanical hammer release system that has been previously calibrated based on direct energy measurements.

- Otherwise, ER must be estimated. For good field procedures, equipment and monitoring, the following guidelines are suggested:

Equipment

$$
\begin{aligned}
& \text {-Safety Hammer }{ }^{\mathrm{a}} \\
& \text {-Donut Hammer }^{\mathrm{a}} \\
& \text {-Donut Hammer }
\end{aligned}
$$

-Automatic-Trip Hammer (Donut or Safety Type)

Approximate $E R$ (see Note ${ }^{c}$ ) 0.4 to 0.75
0.3 to 0.6
0.7 to 0.85
0.5 to 0.8

$C_{E}\left(\right.$ see Note $\left.^{\mathrm{c}}\right)$

0.7 to 1.2

0.5 to 1.0

1.1 to 1.4

0.8 to 1.4

- For lesser quality fieldwork (e.g.: irregular hammer drop distance, excessive sliding friction of hammer on rods, wet or worn rope on cathead, etc.) further judgmental adjustments are needed.

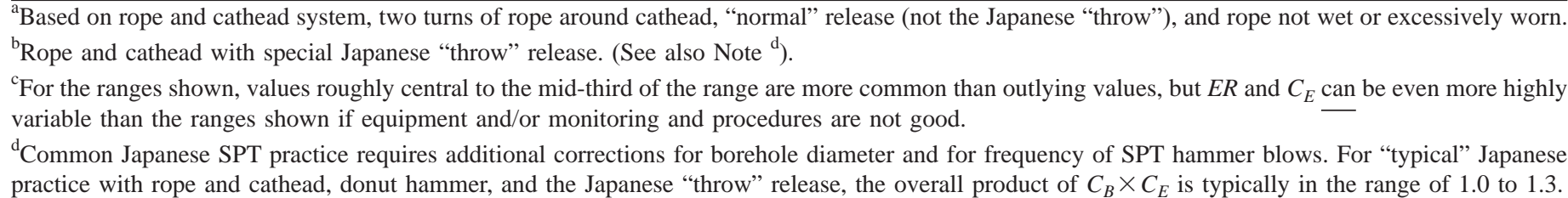

This results in an "indented" interior liner annulus of enlarged diameter, and reduces friction between the sample and the interior of the sampler, resulting in reduced overall penetration resistance (Seed et al. 1984, 1985). The reduction in penetration resistance is on the order of $\sim 10 \%$ in loose soils $\left(N_{1}<10\right.$ blows $\left./ \mathrm{ft}\right)$, and $\sim 30 \%$ in very dense soils $\left(N_{1}>30\right.$ blows/ft $)$, so $C_{S}$ varied from 1.1 to 1.3 over this range.

Borehole diameter corrections $\left(C_{B}\right)$ were as recommended in the NCEER Workshop Proceedings.

Corrections for hammer energy $\left(C_{E}\right)$, which were often significant, were as recommended by the NCEER Working Group, except in those cases where better hammer/system-specific information was available. Cases where better information was available included cases where either direct (instrumented) energy measurements were made during driving of the SPT sampler, or where the hammer and the raising/dropping system had been calibrated by means of direct (instrumented) driving energy measurements.

\section{Data Rating System and Data Quality Assessment}

A rating system was established to evaluate the quality of each field case history. Data were rated as falling into one of five classes (from highest to lowest quality) as follows:
Class A

1. A minimum of 3 or more $N$ values in the critical stratum,

2. Equipment and procedural details affecting SPT data welldefined, and

3. $\mathrm{COV}_{\mathrm{CSR}} \leqslant 0.20$.

\section{Class B}

1. Equipment and procedural details affecting SPT data welldefined, and

2. $0.2<\mathrm{COV}_{\mathrm{CSR}} \leqslant 0.35$, or satisfies Class A but less than $3 \mathrm{~N}$ values in the critical stratum.

\section{Class C}

1. Equipment and procedural details affecting SPT data well defined, and

2. $0.35<\mathrm{COV}_{\mathrm{CSR}} \leqslant 0.5$.

\section{Class D}

1. Equipment and procedural details affecting SPT data not well defined,

2. Seismicity, and/or site effects not well defined $\left(\mathrm{COV}_{\mathrm{CSR}}>0.5\right)$, but some reasonable basis for at least approximate estimation of CSR available, 


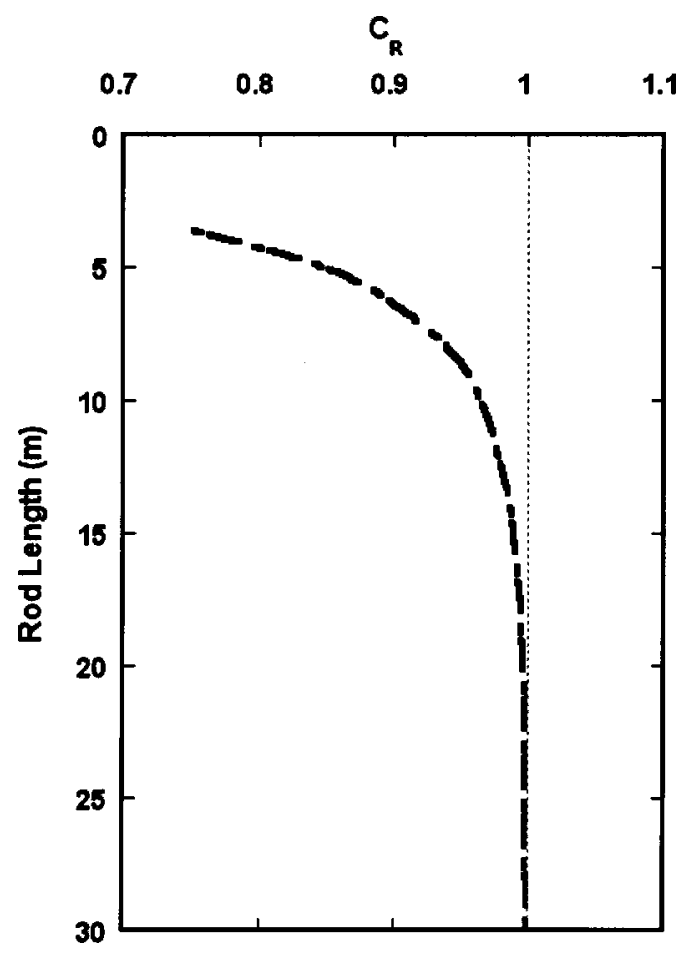

Fig. 7. Recommended $C_{R}$ values (rod length from point of hammer impact to tip of sampler)

3. Poor site performance data/documentation, or

4. Original boring $\operatorname{logs}$ or other important data not directly accessible, etc.

\section{Class E}

1. Cases with one or more clearly fatal flaws.

Case histories where no basis for equipment/procedure corrections of SPT were available, where very poor seismicity data was available for estimation of CSR, or where other important issues were undefined, and data from sites not qualifying as "level ground," etc., were considered to be of lesser quality even than Class D, and were deleted from further consideration (Class E).

The previous studies of Seed et al. (1984) had employed a total of 126 data points, falling into these data classes as shown in Tables 3 and 4. Table 5 presents a summary of the case histories from 1964 to 1984 eventually selected, after full reanalysis of each case, for use in these current studies. Table 6 presents a

Table 3. Field Case History Distribution by Performance as Used in These Studies

\begin{tabular}{lccc}
\hline Database & Liquefied & $\begin{array}{c}\text { Marginal } \\
\text { liquefaction }\end{array}$ & Nonliquefied \\
\hline Seed et al. (1984) modified & 47 & 2 & 41 \\
Seed et al. (1984) Deleted & $(20)$ & $(4)$ & $(12)$ \\
New database & 42 & - & 25 \\
Kobe alluvium & 20 & 1 & 23 \\
Kobe Masado fill & $(25)$ & - & $(36)$ \\
Youd's small magnitude & $(1)$ & - & $(43)$ \\
Data currently used & 109 & 3 & 89 \\
& & Total & 201 \\
\hline
\end{tabular}

Note: Cases in parentheses were not used in final correlation development.
Table 4. Field Case History Data Distribution by Quality Classifications as Used in These Studies

\begin{tabular}{lcccc}
\hline & Class & Class & Class & (Class \\
Database & A & B & C & D) \\
\hline Seed et al. (1984) nonliquefied & 6 & 34 & 1 & - \\
Seed et al. (1984) liquefied & 7 & 38 & 2 & - \\
Seed et al. (1984) marginally & 1 & 1 & - & - \\
liquefied & & & & \\
Seed et al. (1984) deleted & - & - & - & $(36)$ \\
New database nonliquefied & 11 & 13 & 1 & - \\
New database liquefied & 20 & 21 & 1 & - \\
Kobe Alluvium nonliquefied & 4 & 19 & - & - \\
Kobe alluvium liquefied & 12 & 8 & - & - \\
Kobe alluvium marginally & 1 & - & - & - \\
liquefied & & & & - \\
Data currently used & 62 & 134 & 5 & - \\
& & & Total=201 & (Deleted) \\
\hline
\end{tabular}

summary of the 36 cases from the original database of Seed et al. (1984) that were deleted from consideration in these current studies.

The new data collected and processed for these current studies (beyond those used previously by Seed et al. 1984) included a large number of cases of generally higher overall quality, as indicated by Tables 3 and 4 . Based on the availability of a sufficient quantity of relatively high-quality data, it was decided to eliminate all data of Class D or lower, and to employ only data of Class $\mathrm{C}$ or better for these current studies. The result was availability of 201 cases of Class $C$ or better, after deletion of 36 Class D cases from the earlier database of Seed et al. (1984), as shown in Tables 3 and 4.

Table 7 presents a summary of the "new" (post-1984) case histories found to conform to the standards of Classes A, B, or C, and so included in these current studies. Fig. 8(a) shows the mean value locations of the cases deleted on this quality screening basis from the data set of Seed et al. (1984), and Fig. 8(b) shows the "new" (post-1984) data included in these studies. In both Figs. 8(a and b), CSR values have been corrected for magnitudecorrelated duration weighting factors $\left(\mathrm{DWF}_{M}\right)$ based on the final correlations developed herein, and in Fig. 8(b), the $N_{1,60}$ values have been similarly corrected for fines effects [to $\left(N_{1}\right)_{60, \text { cs }}$ values], again based on the final correlations developed.

An additional data set evaluated was a proprietary data set from alluvium sites just inboard of the well-known coastal fills at Kobe, Japan. These data were particularly valuable, as the stiffer underlying soil conditions inboard of the coastal fills were able to sustain higher ground accelerations during the 1995 HyogokenNambu ("Kobe") Earthquake than the coastal fills, so that these data provide good additional coverage of the high CSR range $(\mathrm{CSR}>0.25)$ for which data were previously scarce. Table 8 presents the processed data from this set, and these data are also shown in Fig. 8(b).

\section{Development of Correlations}

Using the field case history data as assessed and presented in Tables 5, 7, and 8, correlations were developed to assess the likelihood of initiation (or "triggering") of liquefaction. The methodology employed was the Bayesian updating method, and the specific formulations and approaches employed are described in 
Table 5. Field Case History Data from Seed et al. (1984) of Classes A, B and C as Reevaluated for These Studies

\begin{tabular}{|c|c|c|c|c|c|c|c|c|c|c|c|c|c|c|c|c|c|c|c|c|c|}
\hline Earthquake & Site & Liquefied? & $\begin{array}{c}\text { Data } \\
\text { class }\end{array}$ & $\begin{array}{c}\text { Critical depth } \\
\text { range (ft) }\end{array}$ & $\begin{array}{c}\text { Depth to } \\
\text { GWT (tt) }\end{array}$ & $\sigma_{o}(\mathrm{psf})$ & $\sigma_{o}^{\prime}(\mathrm{psf})$ & $a_{\max }(\mathrm{g})$ & $V_{s, 40}^{*}{ }^{*}(\mathrm{fps})$ & $r_{d}$ & $\begin{array}{l}\text { Cyclic shear } \\
\text { stress ratio } \\
\text { (CSR) }\end{array}$ & $\begin{array}{l}\text { Eqv. } \\
(M W)\end{array}$ & $D_{50}(\mathrm{~mm})$ & $\%$ Fines & $C_{R}$ & $c_{S}$ & $C_{B}$ & $C_{E}$ & $c_{V}$ & $\left(N_{1}\right)_{60}$ & References \\
\hline 4 Tohr & Ienaga & Yes & B & $8.0-20.0$ & 8. & $0.0 \pm 208.9$ & $985.6 \pm 112.0$ & 60 & 470 & 0.068 & $0.15 \pm 0.048$ & 8 & $0.15 \pm 0.050$ & $25.0 \pm 3.0$ & 0.90 & 1 & 1 & 1.17 & 1.42 & $2.2 \pm 0.8$ & Kishida (1969) \\
\hline 1944 Tohnankai $M=8.0$ & Komei & Yes & B & $6.4-16.4$ & $6.4 \pm 1.0$ & $1,108.1 \pm 173.8$ & $797.8 \pm 98.0$ & $0.20 \pm 0.060$ & 560 & $0.93 \pm 0.057$ & $0.17 \pm 0.055$ & 8 & $0.40 \pm 0.100$ & $13.0 \pm 1.0$ & 0.87 & 1 & 1 & 1.17 & 1.58 & $9.4 \pm 2.9$ & Kishida (1969) \\
\hline 1944 Tohnankai $M=8.0$ & Meiko & Yes & C & $1.6-11.5$ & $1.6 \pm 1.0$ & $645.9 \pm 166.1$ & $340.1 \pm 86.9$ & $0.20 \pm 0.060$ & 380 & $0.89 \pm 0.036$ & $0.22 \pm 0.079$ & 8 & $0.20 \pm 0.050$ & $27.0 \pm 3.0$ & 0.80 & 1 & 1 & 1.17 & 2.00 & $3.6 \pm 1.6$ & Kishida (1969) \\
\hline 1948 Fukui $M=7.3$ & Shonenji Temple & Yes & B & $3.9-18.0$ & $3.9 \pm 1.0$ & $1,110.4 \pm 249.0$ & $672.8 \pm 117.5$ & $0.40 \pm 0.120$ & 600 & $0.95 \pm 0.055$ & $0.41 \pm 0.133$ & 7.3 & $0.40 \pm 0.030$ & $0.0 \pm 0.0$ & 0.86 & 1 & 1 & 1.17 & 1.72 & $6.6 \pm 2.2$ & Kishida (1969) \\
\hline 1948 Fukui $M=7.3$ & Takaya 45 & Yes & B & $12.3-40.0$ & $12.3 \pm 1.0$ & $2,761.3 \pm 542.8$ & $1,897.0 \pm 270.4$ & $0.35 \pm 0.105$ & 620 & $0.79 \pm 0.115$ & $0.26 \pm 0.089$ & 7.3 & $0.50 \pm 0.100$ & $4.0 \pm 1.0$ & 1.00 & 1 & 1 & 1.30 & 1.03 & $21.5 \pm 3.5$ & Kishida (1969) \\
\hline 1964 Nigata $M=7.5$ & Cc17-1 & Yes & B & $16.4-36.1$ & $3.0 \pm 1.0$ & $2,725.9 \pm 372.2$ & $1,275.3 \pm 205.1$ & $0.16 \pm 0.024$ & 510 & $0.65 \pm 0.116$ & $0.15 \pm 0.035$ & 7.5 & $0.20 \pm 0.035$ & $8.0 \pm 2.0$ & 1.00 & 1 & 1 & 1.09 & 1.25 & $12.0 \pm 3.1$ & Kishida (1966) \\
\hline 1964 Nigata $M=7.5$ & Old Town - 1 & No & B & $16.4-32.8$ & $6.0 \pm 1.0$ & $2,832.8 \pm 337.9$ & $1,671.7 \pm 180.9$ & $0.18 \pm 0.027$ & 480 & $0.75 \pm 0.110$ & $0.15 \pm 0.032$ & 7.5 & $0.20 \pm 0.035$ & $8.0 \pm 2.0$ & 0.99 & 1 & 1 & 1.21 & 1.09 & $22.7 \pm 0.7$ & Kishida (1966) \\
\hline 1964 Nigata $M=7.5$ & Old Town -2 & No & в & $32.8-42.7$ & $6.0 \pm 1.0$ & $4,407.6 \pm 236.3$ & $2,427.6 \pm 165.6$ & $0.18 \pm 0.027$ & 560 & $0.55 \pm 0.158$ & $0.12 \pm 0.038$ & 7.5 & $0.20 \pm 0.035$ & $8.0 \pm 2.0$ & 1.00 & 1 & 1 & 1.21 & 0.91 & $27.1 \pm 3.3$ & Koizumi (1964) \\
\hline 1964 Nigata $M=7.5$ & Rail Road-1 & Yes & B & $16.4-32.8$ & $3.0 \pm 1.0$ & $2,553.7 \pm 315.7$ & $1,205.4 \pm 182.9$ & $0.16 \pm 0.024$ & 560 & $0.78 \pm 0.110$ & $0.17 \pm 0.038$ & 7.5 & $0.20 \pm 0.035$ & $8.0 \pm 2.0$ & 0.99 & 1 & 1 & 1.09 & 1.29 & $13.0 \pm 1.6$ & Koizumi (1964) \\
\hline 1964 Nigata $M=7.5$ & Rail Road-2 & No/Yes & B & $29.5-36.1$ & $3.0 \pm 1.0$ & $3,578.9 \pm 216.5$ & $1,718.9 \pm 194.3$ & $0.16 \pm 0.024$ & 580 & $0.65 \pm 0.140$ & $0.14 \pm 0.038$ & 7.5 & $0.20 \pm 0.035$ & $2.0 \pm 2.0$ & 1.00 & 1 & 1 & 1.09 & 1.08 & $18.8 \pm 2.5$ & Koizumi (1964) \\
\hline 1964 Nigata $M=7.5$ & River Site & Yes & B & $13.1-42.7$ & $2.0 \pm 1.0$ & $2,908.5 \pm 527.3$ & $1,291.1 \pm 240.0$ & $0.16 \pm 0.024$ & 580 & $0.60 \pm 0.122$ & $0.14 \pm 0.037$ & 7.5 & $0.43 \pm 0.040$ & $0.0 \pm 0.0$ & 1.00 & 1 & 1 & 1.09 & 1.24 & $11.1 \pm 4.3$ & Ishihara (1979) \\
\hline 1964 Niigata $M=7.5$ & Road Site & No & B & $13.1-29.5$ & $8.2 \pm 1.0$ & $2,222.8 \pm 315.1$ & $1,403.9 \pm 166.7$ & $0.18 \pm 0.027$ & 490 & $0.78 \pm 0.097$ & $0.14 \pm 0.030$ & 7.5 & $0.45 \pm 0.040$ & $0.0 \pm 0.0$ & 0.96 & 1 & 1 & 1.09 & 1.19 & $15.1 \pm 3.9$ & Ishihara (1979) \\
\hline 1964 Nigata $M=7.5$ & Showa $\mathrm{Br} 2$ & Yes & A & $4.5-20.0$ & $0.0 \pm 0.0$ & $1,286.3 \pm 275.6$ & $521.9 \pm 120.5$ & $0.16 \pm 0.024$ & 540 & $0.86 \pm 0.061$ & $0.22 \pm 0.039$ & 7.5 & $0.40 \pm 0.040$ & $10.0 \pm 3.0$ & 0.88 & 1 & 1 & 1.09 & 1.96 & 0.6 & $\begin{array}{l}\text { Ishihara (1979) } \\
\text { I }\end{array}$ \\
\hline 1964 Nigata $M=7.5$ & Showa Br 4 & No & B & $16.4-23.0$ & $4.0 \pm 1.0$ & $2,262.2 \pm 149.5$ & $1,283.5 \pm 99.4$ & $0.18 \pm 0.027$ & 480 & $0.87 \pm 0.091$ & $0.18 \pm 0.034$ & 7.5 & $0.30 \pm 0.030$ & $0.0 \pm 0.0$ & 0.95 & 1 & 1 & 1.21 & 1.25 & $43.0 \pm 3.4$ & Ishihara (1979) \\
\hline 1968 Tokachioki $M=7.9$ & Hachinohe - 2 & No & A & $10.0-26.0$ & $7.0 \pm 1.0$ & $2,180.0 \pm 337.7$ & $1,493.6 \pm 182.9$ & $0.23 \pm 0.025$ & 660 & $0.93 \pm 0.084$ & $0.20 \pm 0.031$ & 7.9 & $0.25 \pm 0.025$ & $5.0 \pm 2.0$ & 0.94 & 1 & & 1.21 & 1.16 & $37.4 \pm 2.8$ & Ohsaki (1970) \\
\hline 1968 Tokachioki $M=7.9$ & Hachinohe - 4 & No & A & $3.0-13.0$ & $3.0 \pm 1.0$ & $875.0 \pm 195.4$ & $563.0 \pm 105.6$ & $0.23 \pm 0.025$ & 580 & $0.96 \pm 0.042$ & $0.22 \pm 0.037$ & 7.9 & $0.25 \pm 0.025$ & $5.0 \pm 2.0$ & 0.82 & 1 & 1 & 1.21 & 1.88 & $26.0 \pm 2.6$ & Ohsaki (1970) \\
\hline 1968 Tokachioki $M=7.9$ & Hachinohe-6 & Yes & A & $6.6-20.0$ & $2.0 \pm 1.0$ & $1,376.5 \pm 251.8$ & $671.4 \pm 141.8$ & $0.23 \pm 0.025$ & 530 & $0.89 \pm 0.065$ & $0.27 \pm 0.047$ & 7.9 & $0.25 \pm 0.025$ & $5.0 \pm 2.0$ & 0.89 & 1 & 1 & 1.09 & 1.73 & $7.6 \pm 0.9$ & Ohsaki (1970) \\
\hline 1968 Tokachioki $M=7.9$ & Nanaehama1-2-3 & Yes & B & $3.0-16.4$ & $3.0 \pm 1.0$ & $955.2 \pm 227.8$ & $537.0 \pm 110.9$ & $0.20 \pm 0.040$ & 560 & $0.95 \pm 0.050$ & $x_{0}+2>$ & 7.9 & & $20.0 \pm 3.0$ & 0.84 & 1 & 1 & 1.17 & 1.93 & 10.4 & Kishida (1970) \\
\hline 1971 San Fernando $M w=6.6$ & Juvenile Hall & Yes & A & $14.4-20.7$ & $14.0 \pm 2.0$ & $1,703.0 \pm 125.1$ & $1,481.3 \pm 127.6$ & $0.45 \pm 0.045$ & 540 & $\begin{array}{l}0.81 \pm 0.082 \\
0.810\end{array}$ & $27 \pm 0.046$ & 6.6 & $\begin{array}{l}0.05 \pm 0.010 \\
0.010\end{array}$ & $\begin{array}{l}50.0 \pm 0.0 \\
55.0 \pm .0\end{array}$ & 0.90 & 1 & 1 & 1.13 & 1.16 & $\begin{array}{r}1.4 .41 .4 \\
4.1 \pm 1.0\end{array}$ & Bennett (1989) \\
\hline 1971 San Fernando $M w=6.6$ & Van Norman & Yes & A & $17.0-24.0$ & $17.0 \pm 2.0$ & $1,982.5 \pm 142.2$ & $1,764.1 \pm 135.2$ & $0.45 \pm 0.045$ & 620 & $0.86 \pm 0.094$ & $28 \pm 0.047$ & 6.6 & $0.06 \pm 0.010$ & $50.0 \pm 5.0$ & 0.93 & 1 & 1 & 1.13 & 1.06 & $8.2 \pm 2.8$ & Bennett (1989) \\
\hline 1975 Haicheng $M s=7.3$ & Panjin Ch. F. P. & Yes & B & $11.5-41.0$ & $5.0 \pm 1.0$ & $2,706.0 \pm 524.2$ & $1,379.4 \pm 233.1$ & $0.13 \pm 0.026$ & 610 & $0.79 \pm 0.116$ & $0.13 \pm 0.034$ & 7.3 & $0.06 \pm 0.010$ & $67.0 \pm 7.0$ & 1.00 & 1 & 1 & 0.83 & 1.20 & $8.2 \pm 1.2$ & Shengcong et al. (1983) \\
\hline 1975 Haicheng $M s=7.3$ & Shuang Tai Zi R. & Yes & B & $19.7-36.1$ & $5.0 \pm 1.0$ & $2,878.3 \pm 302.2$ & $1,449.3 \pm 158.4$ & $0.10 \pm 0.020$ & 610 & $0.77 \pm 0.122$ & $0.10 \pm 0.026$ & 7.3 & $0.07 \pm 0.015$ & $5.0 \pm 2.0$ & 1.00 & 1 & 1 & 1.00 & 1.17 & $11.1 \pm 1.8$ & Shengcong et al. (1983) \\
\hline 1975 Haicheng $M s=7.3$ & Ying Kou G. F. P. & Yes & в & $16.4-29.5$ & $5.0 \pm 1.0$ & $2,451.4 \pm 264.9$ & $1,329.6 \pm 158.5$ & $0.20 \pm 0.040$ & 610 & $0.83 \pm 0.103$ & 020 & 7.3 & $0.08 \pm 0.015$ & $48.0 \pm 5.0$ & 0.98 & 1 & 1 & 1.00 & 1.23 & $14.9 \pm 1.1$ & Shengcong et al. (1983) \\
\hline 1975 Haicheng $M s=7.3$ & Ying Kou P. P. & Yes & B & $14.8-34.4$ & 5. & 4.0 & 1,3 & 40 & 560 & & & 7.3 & & $5.0 \pm 2.0$ & 0.99 & 1 & 1 & 1.00 & 1.24 & & Shengcong et al. (1983) \\
\hline 1976 Guatemala $M=7.5$ & Amatitlan B-1 & Yes & в & $10.0-50.0$ & $5.0 \pm 1.0$ & $2,550.0 \pm 605.5$ & $990.0 \pm 201.6$ & $0.14 \pm 0.015$ & 400 & $0.46 \pm 0.117$ & 330 & 7.5 & $0.80 \pm 0.150$ & $3.0 \pm 1.0$ & 1.00 & 1 & 1 & 0.75 & 1.42 & $4.6 \pm 1.5$ & Seed et al.(1979) \\
\hline 1976 Guatemala $M=7.5$ & Amatitlan B-2 & No/Yes & A & $10.0-20.0$ & $8.0 \pm 1.0$ & $1,110.0 \pm 155.2$ & $673.2 \pm 62.2$ & $0.14 \pm 0.015$ & 420 & $0.75 \pm 0.065$ & $0.11 \pm 0.019$ & 7.5 & $0.80 \pm 0.150$ & $3.0 \pm 1.0$ & 0.88 & 1 & 1 & 075 & 1.72 & $8.5 \pm 1.1$ & Seed et al. (1979) \\
\hline 1976 Guatemala $M=7.5$ & Amatitlan B-3\&4 & No & B & $20.0-45.0$ & $11.0 \pm 2.0$ & $2,595.0 \pm 385.8$ & $1,253.4 \pm 148.6$ & $0.14 \pm 0.015$ & 440 & $47 \pm 0.125$ & $09 \pm 0.026$ & 7.5 & $0.80 \pm 0.150$ & $3.0 \pm 1.0$ & 1.00 & 1 & 1 & 0.75 & 1.26 & $14.1 \pm 1.8$ & Seed et al. (1979) \\
\hline 1976 Tangshan $M s=7.8$ & Coastal Region & Yes & B & $9.8-19.7$ & $4.0 \pm 1.0$ & $1,510.2 \pm 178.5$ & $838.7 \pm 98.7$ & $0.13 \pm 0.026$ & 590 & $0.92 \pm 0.064$ & $14 \pm 0.032$ & 8 & $0.14 \pm 0.030$ & $12.0 \pm 3.0$ & 0.90 & 1 & 1 & 1.00 & 1.54 & $13.2 \pm 3.2$ & Shengcong et al. (1983) \\
\hline 1976 Tangshan $M s=7.8$ & Le Ting L8-14 & Yes & B & $11.5-19.7$ & $3.5 \pm 1.0$ & $1,739.7 \pm$ & & $=0.040$ & 650 & .067 & $J_{2}$ & 8 & & $12.0 \pm 3.0$ & 0.91 & 1 & 1 & 1.00 & 1.42 & $2.8 \pm 2.6$ & \\
\hline 1976 Tangshan $M s=7.8$ & Qing Jia Ying & Yes & B & 14.8 & $3.0 \pm 1.0$ & $2,030.8 \pm 140.8$ & $1,089.1 \pm 96.6$ & $0.35 \pm 0.070$ & 640 & $92 \pm 0.076$ & $0.39 \pm 0.087$ & 8 & .030 & $20.0 \pm 3.0$ & 0.94 & 1 & 1 & 1.00 & 1.36 & $23.2 \pm 2.6$ & Shengcong et al. (1983) \\
\hline 1976 Tangshan $M s=7.8$ & Tangshan City & No & B & $11.5-18.0$ & $9.8 \pm 1.0$ & $1,574.8 \pm 139.9$ & $1,267.7 \pm 87.8$ & $0.50 \pm 0.100$ & 675 & $0.96 \pm 0.064$ & $0.39 \pm 0.084$ & 8 & $0.20 \pm 0.024$ & $10.0 \pm 2.0$ & 0.90 & 1 & 1 & 1.00 & 1.26 & $33.7 \pm 5.8$ & Shengcong et al. \\
\hline 1976 Tangshan $M s=7.8$ & Yao Yuan Village & Yes & B & $11.5-16.4$ & $3.3 \pm 1.0$ & $1,501.0 \pm 101.2$ & $835.6 \pm 79.1$ & $0.20 \pm 0.040$ & 575 & $0.92 \pm 0.061$ & $0.21 \pm 0.048$ & 8 & $0.15 \pm 0.050$ & $5.0 \pm 3.0$ & 0.90 & 1 & 1 & .00 & 1.55 & $11.9 \pm 5.3$ & Shengcong et al. (1983) \\
\hline 1977 Argentina $M=7.4$ & San Juan B-1 & Yes & B & $26.0-28.0$ & $15.0 \pm 1.0$ & $2,745.0 \pm 86.4$ & $1,996.2 \pm 91.7$ & $0.20 \pm 0.015$ & 610 & $78 \pm 0.107$ & 140002 & 7.4 & $0.14 \pm 0.050$ & $20.0 \pm 3.0$ & 0.98 & 1 & 1 & 0.75 & 1.00 & $6.7 \pm 1.5$ & Idriss et al. (1979) \\
\hline 1977 Argentina $M=7.4$ & San Juan B-3 & Yes & B & $33.5-43.0$ & $22.0 \pm 1.0$ & $3,796.3 \pm 199.3$ & $2,782.3=$ & 15 & 580 & & & 7.4 & & 20. & 1.00 & 1 & 1 & 0.75 & 0.85 & 7.3 & Idriss et al. (1979) \\
\hline 1977 Argentina $M=7.4$ & San Juan B-4 & No & B & $4.0-12.0$ & $4.0 \pm 1.0$ & $820.0 \pm 149.2$ & $570.4 \pm 82.4$ & $0.20 \pm 0.015$ & 590 & & $18 \pm 0.027$ & 7.4 & & $4.0 \pm 1.5$ & 0.77 & 1 & 1 & 0.75 & 1.87 & & Idriss et al. (1979) \\
\hline 1977 Argentina $M=7.4$ & San Juan B-5 & No & в & $7.0-12.0$ & $7.0 \pm 1.0$ & $952.5 \pm 102.3$ & $796.5 \pm 67.8$ & $0.20 \pm 0.015$ & 670 & $0.98 \pm 0.044$ & $0.15 \pm 0.019$ & 7.4 & $0.24 \pm 0.025$ & $3.0 \pm 1.0$ & 0.80 & 1 & 1 & 0.75 & 1.58 & $14.5 \pm 0.1$ & Idriss et al. (1979) \\
\hline 1977 Argentina $M=7.4$ & San Juan B-6 & Yes & B & $12.0-18.0$ & $6.0 \pm 1.0$ & $1,530.0 \pm 119.9$ & $968.4 \pm 77.0$ & $0.20 \pm 0.015$ & 63 & $0.94 \pm 0.065$ & $0.19 \pm 0.023$ & 7.4 & $0.10 \pm 0.025$ & $50.0 \pm 5.0$ & 0.87 & 1 & 1 & 0.75 & 1.44 & $5.7 \pm 0.2$ & Idriss et al. (1979) \\
\hline 1978 Miyagiken-Oki $M=6.7$ & Arahama & No & B & $6.6-26.2$ & $3.0 \pm 1.0$ & $1,774.5 \pm 365.2$ & $938.0 \pm 173.6$ & $0.10 \pm 0.020$ & 610 & $91 \pm 0.070$ & & 6.7 & $0.45 \pm 0.080$ & $0.0 \pm 0.0$ & c & 1 & 1 & 1.09 & 1.46 & $14.1 \pm 2.7$ & Tohno et al. (1981) \\
\hline 1978 Miyagiken-Oki $M=6.7$ & Hiyori-1 B & No & B & $8.2-13.1$ & $8.0 \pm 1.0$ & 7.6 & 926. & 28 & 64 & 148 & & 6.7 & 030 & $20.0 \pm 3.0$ & 0.86 & 1 & 1 & 1.09 & 1.47 & $12.5 \pm 2.5$ & Tsuchida et al. $(1979,1980)$ \\
\hline $1978 \mathrm{Mi}$ & Ishinomaki-2 & No & B & $4.6-19.7$ & $4.6 \pm 1.0$ & $1,228.7 \pm 266.6$ & 757.8 & & 520 & & & 6.7 & & & 0.88 & 1 & 1 & 1.0 & 1.62 & $6.2 \pm 0.5$ & Ishihara et al. (1980) \\
\hline 1978 Miyagiken-Oki $M=6.7$ & Kitawabuchi-2 & No & B & $9.8-13.1$ & $9.8 \pm 0.5$ & $1,115.5 \pm 72.9$ & $1,013.1 \pm 53.7$ & $0.14 \pm 0.028$ & 460 & $55 \pm 0.052$ & $.08 \pm 0.018$ & 6.7 & $0.53 \pm 0.100$ & $5.0 \pm 2.0$ & 0.87 & 1 & 1 & 1.00 & 1.41 & $13.5 \pm 2.5$ & Iwasaki (1978) \\
\hline 1978 Miyagiken-Oki $M=6.7$ & Nakajima-18 & No & в & $8.0-20.0$ & $8.0 \pm 1.0$ & $0.0 \pm 235.5$ & $1,115.6 \pm 125.0$ & \pm 0.028 & 50 & $22 \pm 0.061$ & & 6.7 & $0.35 \pm 0.050$ & $3.0 \pm 1.0$ & $\mathrm{c}^{-1}$ & 1 & 1 & 1.09 & 1.34 & $12.6 \pm 5.3$ & suchida et al. $(1979,1980)$ \\
\hline 1978 Miyagiken-Oki $M=6.7$ & amura 4 & 1 & B & 16.4 & $1.6 \pm 1.0$ & $1.5 \pm 124.3$ & $645.0 \pm 84.1$ & \pm 0.024 & 76 & & & 6 & & $5.0 \pm 1.0$ & ( & 1 & 1 & 1.00 & 1.76 & $8.7 \pm 0.7$ & Iwasaki (1978) \\
\hline n-Oki $M=6.7$ & Nakamura 5 & +3 & B & 13.1 & $4.3 \pm 1.0$ & - & 694.7 & & 620 & & & 6 & & $4.0 \pm 1.0$ & 0 & 1 & 1 & 1. & 1.70 & $10.3 \pm 2.0$ & Iwasaki (1978) \\
\hline n-Oki $M=6.7$ & Oiiri-1 & $\mathrm{N}$ & B & $14.0-25.0$ & $14.0 \pm 2.0$ & 27.9 & $1,564.3$ & 24 & 490 & 081 & $0.08 \pm 0.018$ & 6.7 & 100 & $5.0 \pm 3.0$ & 0.95 & 1 & 1 & 1.00 & 1.13 & $9.8 \pm 1.8$ & Iwasaki et al. (1978) \\
\hline & Shiomi-6 & No & A & $9.8-19.7$ & $8.0 \pm 1.0$ & $44.0 \pm 188.0$ & $1,122.0 \pm 107.3$ & 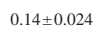 & 60 & & & 6.7 & 150 & $10.0 \pm 2.0$ & 0 & 1 & 1 & 1.0 & 1.34 & 9.7 & Tsuchida et al. $(1979,1980)$ \\
\hline 1978 Miyagiken-Oki $M=6.7$ & Yuriage $\mathrm{Br}-1$ & No & в & $9.8-13.1$ & $5.6 \pm 1.0$ & $1,146.5 \pm 67.0$ & $780.0 \pm 65.9$ & & 60 & & & 6.7 & $0.40 \pm 0.100$ & $5.0 \pm 1.0$ & 0 & . & 1 & 1.00 & 1.60 & $4.1 \pm 1.8$ & Iwasaki et al. (1978) \\
\hline 1978 Miyagiken-Oki $M=6.7$ & Yuriage $\mathrm{I}$ & $\mathrm{s}$ & D & -10.0 & 4. & $797.3 \pm 74.3$ & 3.8 & & & & & $67-7>$ & 2000 & $7.0 \pm 1.0$ & & 1 & 1 & & 1.88 & $19.7 \pm 2.8$ & Iwasaki et al. (1978) \\
\hline 1978 Miyagiken-Oki $M=6.7$ & $\mathrm{Y}$ & $\mathrm{N}$ & B & & $0.9 \pm 0.5$ & $1,024.9 \pm 120.5$ & $464.0 \pm 64.5$ & \pm 0.024 & 62 & \pm 0.045 & & 20 & \pm 0.200 & $12.0 \pm 2.0$ & & 1 & 1 & & 00 & $12.0 \pm 2.1$ & Iwasaki et al. (1978) \\
\hline 1978 Miyagiken-Oki $M=6.7$ & Yuriageka & $\mathrm{s}$ & B & & $5.9 \pm 1.0$ & $1,198.3 \pm 215.4$ & $819.6 \pm 106.4$ & \pm 0.024 & 56 & $22 \pm 0.053$ & 24 & 6.7 & $0.04 \pm 0.010$ & $60.0 \pm 5.0$ & 0.77 & 1 & 1 & 1.00 & 1.56 & $2.8 \pm 1.2$ & Iwasaki et al. (1978) \\
\hline $1978 \mathrm{Mi}$ & Yuriagekami-2 & $\mathrm{N}$ & B & $6.6-18.0$ & & & & & 62 & & & 6.7 & & 0. & 0 & 1 & 1 & 1.0 & 1.73 & 5.2 & Iwasaki et al. (1978) \\
\hline Miyagiken-Oki $M=7.4$ & Nakajima-18 & Yes & B & $8.0-20.0$ & $8.0 \pm 1.0$ & $.0 \pm 235.5$ & $1,115.6 \pm 125.0$ & & 590 & & & 7.4 & 0.050 & $3.0 \pm 1.0$ & 0 & 1 & 1 & 1.09 & 1.34 & $\begin{array}{c} \pm .2 \\
\pm 5.3\end{array}$ & Tsuchida et al. $(1979,1980)$ \\
\hline 1978 Miyagiken-Oki $M=7.4$ & Arahama & $y^{2}$ & в & $6.6-26.2$ & $3.0 \pm 1.0$ & $.5 \pm 365.2$ & & & 610 & & & 7.4 & $5 \pm 0.080$ & $0.0 \pm 0.0$ & 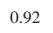 & 1 & 1 & .09 & 1.46 & $13.1 \pm 3.6$ & Tohno et al. (1981) \\
\hline 1978 Miyagiken-Oki $M=7.4$ & & $\mathrm{Y}$ & B & & $8.0 \pm 1.0$ & $92.9 \pm 97.6$ & $926.7 \pm 74.5$ & 0 & & 348 & & 7 & 0.030 & $20.0 \pm 3.0$ & & 1 & 1 & & 47 & $12.5 \pm 2.7$ & Tsuchida et al. $(1979,1980)$ \\
\hline 1978 Miyagiken-Oki $M=7.4$ & 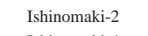 & $\mathrm{Y}$ & B & & & $28.7 \pm 266.6$ & $757.8 \pm 124.4$ & & 52 & & & 7.4 & & $10.0 \pm 2.0$ & 0.88 & 1 & 1 & 1.09 & 1.62 & $6.0 \pm 0.7$ & Ishihara et al. (1980) \\
\hline 1978 Miyagiken-Oki $M=7.4$ & Ishinomaki-4 & No & в & $4.6-23.0$ & $4.6 \pm 1.0$ & $2,786.0 \pm 339.5$ & $2,212.6 \pm 160.2$ & $0.20 \pm 0.040$ & 650 & 060 & 34 & 7.4 & 020 & $10.0 \pm 2.0$ & c & 1 & 1 & 1.21 & 0.95 & $25.2 \pm 2.4$ & Ishihara et al. (1980) \\
\hline & Kitawabuchi-2 & Yes & B & $.8-13.1$ & $9.8 \pm 0.5$ & $. .5 \pm 72.9$ & $1,013.1 \pm 53.7$ & & 460 & & & 7.4 & & $5.0 \pm 2.0$ & 0 & 1 & 1 & 1.00 & 1.41 & 2.9 & Iwasaki et al. (1978) \\
\hline yagiken-Oki $M=7.4$ & Kitawabuchi-3 & No & 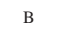 & 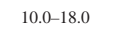 & $10.0 \pm 3.0$ & $.5 \pm 160.1$ & 1, & & 670 & 61 & & 2 & 80 & & 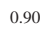 & 1 & 1 & 1.21 & 1.32 & $18.9 \pm 7.3$ & Iwasaki et al. (1978) \\
\hline yagiken-Oki $M=7.4$ & & $\mathrm{r}$ & D & & $8.0=$ & $5.0 \pm 199.4$ & 1,16 & & 6 & & & 7 & 130 & $26.0 \pm 5.0$ & & 1 & 1 & & 1.31 & $15.4 \pm 3.1$ & suchida et al. $(1979,1980)$ \\
\hline 1978 Miyagiken-Oki $M=7.4$ & & $N$ & B & & $3.0 \pm 1.0$ & $1,038.4 \pm 124.9$ & $608.5 \pm 76.5$ & $0.32 \pm 0.064$ & 68 & $98 \pm 0.045$ & $35 \pm 0.079$ & 7.4 & $0.28 \pm 0.040$ & $4.0 \pm 1.0$ & & 1 & 1 & 1.12 & 1.81 & $26.8 \pm 7.2$ & Iwasaki et al. (1978) \\
\hline 1978 Miyagiken-Oki $M=7.4$ & Nakamura 4 & Yes & B & 9.8 & & $1,361.5 \pm 124.3$ & $645.0 \pm 84.1$ & $0.32 \pm 0.064$ & 700 & $0.97 \pm 0.058$ & $43 \pm 0.098$ & 7.4 & & $5.0 \pm 1.0$ & 0.89 & 1 & 1 & 1.00 & 1.76 & $8.7 \pm 0.7$ & Iwasaki et al. (1978) \\
\hline agiken-Oki $M=7.4$ & nura 5 & Yes & B & $9.0-13.1$ & & & $694.7 \pm 68.1$ & & 620 & & & 7.4 & & $7.0 \pm 2.0$ & 0 & 1 & 1 & 1.00 & 1.70 & $10.3 \pm 2.0$ & Iwasaki et al. (1978) \\
\hline & Oiri-1 & Yes & B & $14.0-25.0$ & $=2.0$ & 27.9 & (n) & .048 & 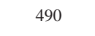 & 0.081 & .035 & 7.4 & $0.34 \pm 0.100$ & 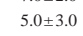 & 0.95 & 1 & 1 & 1.00 & 1.13 & $.8 \pm 2.2$ & Iwasaki et al. (1978) \\
\hline
\end{tabular}


Table 5. (Continued.)

\begin{tabular}{|c|c|c|c|c|c|c|c|c|c|c|c|c|c|c|c|c|c|c|c|c|c|}
\hline Earthquake & Site & Liquefied? & $\begin{array}{l}\text { Data } \\
\text { class }\end{array}$ & $\begin{array}{l}\text { Critical depth } \\
\text { range }(\mathrm{ft})\end{array}$ & $\begin{array}{l}\text { Depth to } \\
\text { GWT (ft) }\end{array}$ & $\sigma_{o}(\mathrm{psf})$ & $\sigma_{o}^{\prime}(\mathrm{psf})$ & $a_{\max }(\mathrm{g})$ & $V_{s, 40^{\prime}}^{*}(\mathrm{fps})$ & $r_{d}$ & $\begin{array}{l}\text { Cyclic shear } \\
\text { stress ratio } \\
\text { (CSR) }\end{array}$ & $\begin{array}{l}\text { Eqv. } \\
(M W)\end{array}$ & $D_{50}(\mathrm{~mm})$ & $\%$ Fines & $C_{R}$ & $C_{S}$ & $C_{B}$ & $C_{E}$ & $c_{V}$ & $\left(N_{1}\right)_{60}$ & References \\
\hline 1978 Miyagiken-Oki $M=7.4$ & Shiomi-6 & Yes & B & $9.8-19.7$ & $8.0 \pm 1.0$ & $1,544.0 \pm 188.0$ & $1,122.0 \pm 107.3$ & $0.24 \pm 0.048$ & 600 & $0.92 \pm 0.064$ & $0.20 \pm 0.044$ & 7.4 & $0.25 \pm 0.050$ & $10.0 \pm 2.0$ & 0.90 & 1 & 1 & 1.09 & 1.34 & $9.7 \pm 2.3$ & Tsuchida et al. $(1979,1980)$ \\
\hline 1978 Miyagiken-Oki $M=7.4$ & Yuriage $\mathrm{Br}-1$ & Yes & B & $9.8-13.1$ & $5.6 \pm 1.0$ & $1,146.5 \pm 67.0$ & $780.0 \pm 65.9$ & $0.24 \pm 0.048$ & 600 & $0.95 \pm 0.051$ & $0.22 \pm 0.048$ & 7.4 & $0.40 \pm 0.100$ & $5.0 \pm 1.0$ & 0.87 & 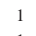 & 1 & 1.00 & 1.60 & $4.1 \pm 1.8$ & Iwasaki et al. (1978) \\
\hline 1978 Miyagiken-Oki $M=7.4$ & Yuriage Br-2 & Yes & B & $6.0-10.0$ & $4.3 \pm 1.0$ & $797.3 \pm 74.3$ & $564.3 \pm 63.8$ & $0.24 \pm 0.048$ & 660 & $0.98 \pm 0.038$ & $0.22 \pm 0.050$ & 7.4 & $1.60 \pm 0.200$ & $7.0 \pm 1.0$ & 0.82 & 1 & 1 & 1.12 & 1.88 & $19.7 \pm 2.8$ & Iwasaki et al. (1978) \\
\hline 1978 Miyagiken-Oki $M=7.4$ & Yuriage $\mathrm{Br}-3$ & Yes & B & $6.6-13.1$ & $0.9 \pm 0.5$ & $1,024.9 \pm 120.5$ & $464.0 \pm 64.5$ & $0.24 \pm 0.048$ & 620 & $0.96 \pm 0.045$ & $0.33 \pm 0.073$ & 7.4 & $1.20 \pm 0.200$ & $12.0 \pm 2.0$ & 0.85 & 1 & 1 & 1.00 & 2.00 & $12.0 \pm 2.1$ & Iwasaki et al. (1978) \\
\hline 1978 Miyagiken-Oki $M=7.4$ & Yuriage Br-5 & No & B & $19.7-29.5$ & $4.3 \pm 1.0$ & $2,744.4 \pm 226.2$ & $1,475.1 \pm 156.3$ & $0.24 \pm 0.048$ & 660 & $0.86 \pm 0.099$ & $0.25 \pm 0.059$ & 7.4 & $0.35 \pm 0.080$ & $17.0 \pm 3.0$ & 0.99 & 1 & 1 & 1.12 & 1.16 & $26.3 \pm 8.6$ & Iwasaki et al. (1978) \\
\hline 1978 Miyagiken-Oki $M=7.4$ & Yuriagekami-1 & Yes & B & $5.9-16.0$ & $5.9 \pm 1.0$ & $1,198.3 \pm 215.4$ & $819.6 \pm 106.4$ & $0.24 \pm 0.048$ & 560 & $0.92 \pm 0.053$ & $0.21 \pm 0.049$ & 7.4 & $0.04 \pm 0.010$ & $60.0 \pm 5.0$ & 0.87 & 1 & 1 & 1.00 & 1.56 & $2.8 \pm 1.2$ & Iwasaki et al. (1978) \\
\hline 1978 Miyagiken-Oki $M=7.4$ & Yuriagekami-2 & Yes & B & $6.6-18.0$ & $2.8 \pm 1.0$ & $1,263.9 \pm 205.1$ & $670.2 \pm 104.7$ & $0.24 \pm 0.048$ & 620 & $0.95 \pm 0.055$ & $0.28 \pm 0.064$ & 7.4 & $0.40 \pm 0.100$ & $0.0 \pm 0.0$ & 0.88 & 1 & 1 & 1.00 & 1.73 & $13.3 \pm 5.2$ & Iwasaki et al. (1978) \\
\hline 1978 Miyagiken-Oki $M=7.4$ & Yuriagekami-3 & No & B & $14.8-24.6$ & $7.1 \pm 1.0$ & $2,122.7 \pm 198.3$ & $1,334.5 \pm 112.2$ & $0.24 \pm 0.048$ & 660 & $0.91 \pm 0.082$ & $0.23 \pm 0.051$ & 7.4 & $0.60 \pm 0.015$ & $0.0 \pm 0.0$ & 0.95 & 1 & 1 & 1.12 & 1.22 & $27.3 \pm 2.5$ & Iwasaki et al. (1978) \\
\hline $\begin{array}{l}1979 \text { Imperial Valley } \\
M L=6.6\end{array}$ & Radio Tower B2 & No & B & $6.6-9.8$ & $6.6 \pm 1.0$ & $746.4 \pm 58.8$ & $644.0 \pm 65.9$ & $0.16 \pm 0.019$ & - & $0.99 \pm 0.020$ & $0.12 \pm 0.019$ & 6.5 & $0.10 \pm 0.020$ & $30.0 \pm 5.0$ & 0.77 & 1 & 1 & 1.13 & 1.76 & $17.0 \pm 2.8$ & Bennett et al. (1984) \\
\hline $\begin{array}{l}1979 \text { Imperial Valley } \\
M L=6.6\end{array}$ & Heber Road A1 & No & B & $5.9-16.4$ & $5.9 \pm 3.0$ & $1,246.7 \pm 233.4$ & $919.2 \pm 160.0$ & $0.47 \pm 0.050$ & - & $0.82 \pm 0.010$ & $0.33 \pm 0.074$ & 6.5 & $0.11 \pm 0.010$ & $25.0 \pm 4.0$ & 0.82 & 1 & 1 & 1.13 & 1.48 & $45.2 \pm 3.6$ & Youd et al. (1983) \\
\hline $\begin{array}{l}1979 \text { Imperial Valley } \\
M L=6.6\end{array}$ & Heber Road A2 & Yes & B & $6.0-15.1$ & $5.9 \pm 3.0$ & $974.1 \pm 147.3$ & $683.4 \pm 181.6$ & $0.47 \pm 0.050$ & - & $0.78 \pm 0.020$ & $0.35 \pm 0.101$ & 6.5 & $0.11 \pm 0.010$ & $29.0 \pm 4.5$ & 0.74 & 1 & 1 & 1.13 & 1.71 & $3.8 \pm 2.4$ & Youd et al. (1983) \\
\hline $\begin{array}{l}1979 \text { Imperial Valley } \\
M L=6.6\end{array}$ & Heber Road A3 & No & B & $5.9-16.1$ & $5.9 \pm 3.0$ & $1,095.0 \pm 183.2$ & $777.7 \pm 175.8$ & $0.47 \pm 0.050$ & - & $0.75 \pm 0.025$ & $0.33 \pm 0.085$ & 6.5 & $0.10 \pm 0.010$ & $37.0 \pm 5.0$ & 0.82 & 1 & 1 & 1.13 & 1.60 & $19.5 \pm 6.1$ & Youd et al.(1983) \\
\hline $\begin{array}{l}1979 \text { Imperial Valley } \\
M L=6.6\end{array}$ & Kornbloom B & No & A & $8.5-17.0$ & $9.0 \pm 1.0$ & $1,248.8 \pm 154.1$ & $1,014.8 \pm 88.9$ & $0.13 \pm 0.010$ & - & $0.83 \pm 0.030$ & $0.09 \pm 0.010$ & 6.5 & $0.05 \pm 0.020$ & $92.0 \pm 10.0$ & 0.85 & 1 & 1 & 1.13 & 1.40 & $7.2 \pm 3.5$ & Bennett et al. (1984) \\
\hline $\begin{array}{l}1979 \text { Imperial Valley } \\
M L=66\end{array}$ & McKim Ranch A & Yes & A & $5.0-13.0$ & $5.0 \pm 1.0$ & $875.0 \pm 135.9$ & $625.4 \pm 80.4$ & $0.51 \pm 0.050$ & 590 & $0.95 \pm 0.042$ & $0.44 \pm 0.072$ & 6.4 & $0.11 \pm 0.003$ & $31.0 \pm 3.0$ & 0.79 & 1 & 1 & 1.13 & 1.79 & $8.5 \pm 4.2$ & Bennett et al. (1984) \\
\hline $\begin{array}{l}1979 \text { Imperial Valley } \\
M L=6.6\end{array}$ & Radio Tower B1 & Yes & B & $9.8-18.0$ & $6.6 \pm 1.0$ & $1,291.8 \pm 135.8$ & $831.2 \pm 82.7$ & $0.18 \pm 0.019$ & - & $0.97 \pm 0.030$ & $0.16 \pm 0.025$ & 6.5 & $0.05 \pm 0.015$ & $75.0 \pm 10.0$ & 0.86 & 1 & 1 & 1.13 & 1.55 & $6.8 \pm 5.2$ & Bennett et al. (1984) \\
\hline $\begin{array}{l}1979 \text { Imperial Valley } \\
M L=6.6\end{array}$ & River Park A & Yes & C & $1.0-5.9$ & $1.0 \pm 0.5$ & $323.0 \pm 78.4$ & $170.0 \pm 40.6$ & $0.16 \pm 0.045$ & - & $0.99 \pm 0.015$ & $0.17 \pm 0.067$ & 6.5 & $0.04 \pm 0.010$ & $80.0 \pm 10.0$ & 0.66 & 1 & 1 & 1.13 & 2.00 & $4.0 \pm 3.4$ & Youd and Wieczorek (1982) \\
\hline $\begin{array}{l}1979 \text { Imperial Valley } \\
M L=6.6\end{array}$ & Wildlife B & No & B & $9.0-22.0$ & $3.0 \pm 1.0$ & $1,520.0 \pm 239.1$ & $740.0 \pm 139.7$ & $0.17 \pm 0.045$ & - & $0.67 \pm 0.035$ & $0.13 \pm 0.039$ & 6.5 & $0.09 \pm 0.005$ & $40.0 \pm 3.0$ & 0.88 & 1 & 1 & 1.13 & 1.64 & $12.8 \pm 5.7$ & Bennett et al. (1984) \\
\hline 1980 Mid-Chiba $M=6.1$ & Owi-1 & No & A & $13.1-23.0$ & $3.0 \pm 1.0$ & $1,879.7 \pm 179.0$ & $940.9 \pm 102.7$ & $0.10 \pm 0.001$ & 490 & $0.75 \pm 0.076$ & $0.09 \pm 0.011$ & 6.1 & $0.18 \pm 0.020$ & $13.0 \pm 1.0$ & 0.86 & 1 & 1 & 1.09 & 1.46 & $6.3 \pm 0.6$ & Ishihara (1981) \\
\hline 1980 Mid-Chiba $M=6.1$ & Owi-2 & No & C & $42.7-52.5$ & $3.0=$ & $4,980.1 \pm 218.9$ & $2,198.8 \pm 162.4$ & $0.10 \pm$ & 490 & $0.33 \pm$ & 0.05 & 6.1 & 0.17 & 27.0 & 1.00 & 1 & 1 & 1.09 & 0.95 & $3.7 \pm 0.6$ & Ishihara (1981) \\
\hline 1981 WestMorland $M L=5.6$ & Kornbloom B & $\mathrm{Y}$ & A & & $9.0 \pm 1.0$ & $1,248.8 \pm 154.1$ & $1,014.8 \pm 88.9$ & $0.19 \pm 0.025$ & - & $0.83 \pm 0.012$ & $0.14 \pm 0.020$ & 5.9 & $0.05 \pm 0.020$ & $92.0 \pm 10.0$ & 0.85 & 1 & 1 & 1.13 & 1.40 & $7.2 \pm 3.5$ & Bennett et al. (1984) \\
\hline 1981 Westmorland $M L=5.6$ & Radio Tower B1 & $\mathrm{Y}$ & B & $9.8-18.0$ & $6.6 \pm 1.0$ & $1,291.8 \pm 134.7$ & $831.2 \pm 80.9$ & $0.17 \pm 0.020$ & - & $0.89 \pm 0.012$ & $0.14 \pm 0.023$ & 5.9 & $0.05 \pm 0.015$ & $75.0 \pm 10.0$ & 0.80 & 1 & 1 & 1.13 & 1.55 & $6.8 \pm 5.2$ & Bennett et al. (1984) \\
\hline 1981 Westmorland $M L=5.6$ & Radio Tower B2 & No & B & $6.6-9.8$ & $6.6 \pm 1.0$ & $746.4 \pm 56.2$ & $644.0 \pm 63.6$ & $0.16 \pm 0.020$ & - & $0.98 \pm 0.010$ & $0.12+0.019$ & 5.9 & $0.10 \pm 0.020$ & $30.0 \pm 5.0$ & 0.77 & 1 & 1 & 1.13 & 1.76 & $17.0 \pm 2.8$ & Bennett et al. (1984) \\
\hline 1981 Westmorland $M L=5.6$ & River Park A & No & B & $1.0-5.9$ & $1.0 \pm 0.5$ & $323.0 \pm 78.4$ & $170.0 \pm 40.6$ & \pm 0.020 & - & $99 \pm 0.003$ & $0.19=$ & 5.9 & $0.04 \pm 0.010$ & $80.0 \pm 10.0$ & 0.66 & 1 & 1 & 1.13 & 2.00 & $4.0 \pm 3.4$ & Youd et al. (1983) \\
\hline 1981 WestMorland $M L=$ & River Park C & $\mathrm{N}$ & A & $11.0-17.0$ & $1.0 \pm$ & $1,520.0 \pm 1$ & 7 & 0 & - & 10 & 0 & 5.9 & 0.15 & 18.0 & 0.86 & 1 & 1 & 1.13 & 1.68 & $20.2 \pm 7.7$ & Youd et al. (1983) \\
\hline 1981 WestMorland $M L=5.6$ & Wildlife B & $\mathrm{Y}$ & A & $9.0-22.0$ & $3.0 \pm$ & $1,520.0 \pm 222.9$ & $740.0 \pm 109.7$ & $0.23 \pm 0.020$ & - & $0.89 \pm 0.013$ & $0.24 \pm 0$ & 5.9 & $0.09 \pm 0.005$ & $40.0 \pm 3.0$ & 0.88 & 1 & 1 & 1.13 & 1.64 & $12.8 \pm 5.7$ & Bennett et al. (1984) \\
\hline 1981 Westmorland $M L=5.6$ & McKim Ranch A & No & B & $5.0-13.0$ & $5.0 \pm 1.0$ & $875.0 \pm 135.9$ & $625.4 \pm 80.4$ & $0.09 \pm 0.023$ & - & $0.93 \pm 0.010$ & $0.08 \pm 0.022$ & 5.9 & $0.11 \pm 0.003$ & $31.0 \pm 3.0$ & 0.79 & 1 & 1 & 1.13 & 1.79 & $8.5 \pm 4.2$ & Bennett et al. (1984) \\
\hline
\end{tabular}


Table 6. Field Case History Data Deleted form Data Set of Seed et al. (1984) as Not Conforming to Class C or Better

\begin{tabular}{|c|c|c|c|c|c|c|}
\hline Earthquake & Site & Liquefied? & $\mathrm{FC}(\%)$ & $\left(N_{1}\right)_{60}$ & CSRN & Explanation \\
\hline 1933 Long Beach $M=6.3$ & Pier A & No & 25 & 8 & 0.165 & Original boring log is not given in the source document \\
\hline 1933 Long Beach $M=6.3$ & Reservation Point & No & 2 & 8.5 & 0.125 & Source document could not be accessed. \\
\hline 1957 San Francisco $M=5.3$ & Lake Merced & Yes & 3 & 5.5 & 0.085 & $\begin{array}{l}\text { Data point is above water table at the time of the earthquake } \\
\text { The side is sloped more than } 30^{\circ}\end{array}$ \\
\hline 1967 Venezuela $M=6.3$ & Caraballeda & Yes & $?$ & 3.5 & 0.07 & $\begin{array}{l}\text { Source document could not be accessed; the critical depth is } \\
3 \mathrm{ft} \text { where soil penetration test values may not be realiable }\end{array}$ \\
\hline 1891 Mino-Owari $M=7.9$ & Ogaki & Yes & 0 & 25.5 & 0.375 & $\begin{array}{l}\text { Not clear if the eruption is due to liquefaction or artesian } \\
\text { conditions; artesian conditions complicated the cyclic shear } \\
\text { stress ratio (CSR) estimations; PGA is estimated from } \\
\text { Kawasumi Intensity scale, poor PGA info. }\end{array}$ \\
\hline 1891 Mino-Owari $M=7.9$ & Ginan & Yes & 5 & 12.5 & 0.33 & $\prime \prime$ \\
\hline 1891 Mino-Owari $M=7.9$ & Unuma & Yes & 3 & 25 & 0.33 & $\prime \prime$ \\
\hline 1891 Mino-Owari $M=7.9$ & Ogase & Yes & 4 & 17 & 0.29 & $\prime \prime$ \\
\hline 1944 Tohnankai $M=8.0$ & Ginan & Yes & 5 & 12.5 & 0.33 & $\prime \prime$ \\
\hline 1923 Kanto $M=7.9$ & Arakawa 7 & Yes & 10 & 11 & 0.17 & $\begin{array}{l}\text { Poor seismic info. PGA is difficult to estimate. No reliable } \\
\text { PGA information. }\end{array}$ \\
\hline 1923 Kanto $M=7.9$ & Arakawa 12 & Yes & 22 & 2.5 & 0.14 & $\prime \prime$ \\
\hline 1923 Kanto $M=7.9$ & Arakawa 21 & Yes & 1 & 20.5 & 0.24 & $\prime \prime$ \\
\hline 1923 Kanto $M=7.9$ & Arakawa 30 & Yes & 5 & 16.5 & 0.23 & $\prime \prime$ \\
\hline 1923 Kanto $M=7.9$ & Arakawa 49 & Yes/No & 20 & 7 & 0.17 & $\prime \prime$ \\
\hline 1948 Fukui $M=7.3$ & Takaya 2 & No & 2 & 40.5 & 0.385 & $\begin{array}{l}\text { Due to the liquefaction of the upper layer, the "nonliquefied" } \\
\text { layer might not have been shaken as severely as the method } \\
\text { assumes. }\end{array}$ \\
\hline 1948 Fukui $M=7.3$ & Agricultural Union. & No & 0 & 29 & 0.45 & $\prime \prime$ \\
\hline 1964 Niigata $M=7.3$ & General Ohsaki & Yes/No & 2 & 12 & 0.18 & $\begin{array}{l}\text { Not a real case history data, adopted from Dr. Koizimu's } \\
\text { "critical" } N \text { value plot versus depth plot after } 1964 \text { Niigata } \\
\text { Earthquake }\end{array}$ \\
\hline 1978 Miyagiken-Oki $M=6.7$ & Oiiri 2 & No & 4 & 9 & 0.115 & Oiiri 2 Site was not mentioned in the referred document. \\
\hline 1978 Miyagiken-Oki $M=7.4$ & Oiiri 2 & Yes & 4 & 9 & 0.22 & Oiiri 2 Site was not mentioned in the referred document. \\
\hline 1978 Miyagiken-Oki $M=7.4$ & Sendaikou 1 & No & 11 & 20 & 0.22 & $\begin{array}{l}\text { Data are summarized on chart. Original boring logs are not } \\
\text { available. }\end{array}$ \\
\hline 1978 Miyagiken-Oki $M=7.4$ & Sendaikou 4 & No & 12 & 20.5 & 0.195 & $\prime \prime$ \\
\hline 1979 Imperial Valley $M=6.6$ & River Park C & Yes & 18 & 16 & 0.24 & $\begin{array}{l}\text { Soil layer above "layer C" has also liquefied. Difficult to } \\
\text { estimate CSR }\end{array}$ \\
\hline 1980 Mid-Chiba $M=6.1$ & Owi-1 & Yes/No & 13 & 7 & 0.135 & $\begin{array}{l}\text { Cyclic TX test results on frozen samples were used to } \\
\text { estimate the level of shaking that will cause 5\% double } \\
\text { amplitude strain level; poor CSR basis. }\end{array}$ \\
\hline 1980 Mid-Chiba $M=6.1$ & Owi-2 & Yes/No & 27 & 4 & 0.12 & $\prime \prime$ \\
\hline 1975 Haicheng $M=7.3$ & Shuangtaihe E. B. & No & Fine sand & 11 & 0.095 & $\begin{array}{l}\text { Obtained the source reference. However the data are } \\
\text { summarized in table; no specific boring log info was } \\
\text { available. }\end{array}$ \\
\hline 1975 Haicheng $M=7.3$ & Shenglitang & No & Sand & 11.5 & 0.09 & $\prime \prime$ \\
\hline 1975 Haicheng $M=7.3$ & Ligohe Ch. F. P. & Yes & Sand & 6.5 & 0.1 & $\prime \prime$ \\
\hline 1975 Haicheng $M=7.3$ & Nanheyan Irr. S. & Yes & Sand & 6.5 & 0.095 & $\prime \prime$ \\
\hline 1975 Haicheng $M=7.3$ & Shuiyuan Comm & Yes & Sand & 8 & 0.195 & $\prime \prime$ \\
\hline 1975 Haicheng $M=7.3$ & Yingkou Gate & Yes & Sand & 8 & 0.19 & $\prime \prime$ \\
\hline 1976 Tangshan $M=7.6$ & Weigezhuang & Yes & Fine sand & 13.5 & 0.17 & $\begin{array}{l}\text { Obtained the source reference. However the data are } \\
\text { summarized in table; no specific boring log info was } \\
\text { available. }\end{array}$ \\
\hline 1976 Tangshan $M=7.6$ & Lujiatuo Mine & Yes & Fine sand & 4.5 & 0.405 & $\prime \prime$ \\
\hline 1976 Tangshan $M=7.6$ & Ma Feng & No & 1 & 11.5 & 0.06 & $\prime \prime$ \\
\hline 1976 Tangshan $M=7.6$ & Wang Zhuang & Yes & 2 & 12.5 & 0.21 & $\prime \prime$ \\
\hline
\end{tabular}

detail by Cetin (2000), and Cetin et al. (2002). These Bayesian analyses serve essentially the same purpose as multidimensional "regression" analyses, but (1) allow for separate and more appropriate treatment of various contributing sources of aleatory and epistemic uncertainty, and (2) facilitate treatment of more descriptive variables/parameters than have been attempted in most pre- vious, similar studies while also permitting monitoring of parameter interactions and covariances.

Within the Bayesian updating analyses, which were performed using a modified version of the program BUMP (Geyskens et al. 1993), all data were modeled not as "points," but rather as distributions, with variances in both CSR and $N_{1,60}$, as well as vari- 
Table 7. New Field Case History Data of Classes A, B, and C as Developed for These Studies

\begin{tabular}{|c|c|c|c|c|c|c|c|c|c|c|c|c|c|c|c|c|c|c|c|c|c|}
\hline Earthquake & Site & Liquefied? & $\begin{array}{l}\text { Data } \\
\text { class }\end{array}$ & $\begin{array}{c}\text { Critical depth } \\
\text { range (ft) }\end{array}$ & $\begin{array}{l}\text { Depht to } \\
\text { GWT (ft) }\end{array}$ & $\sigma_{o}(\mathrm{psf})$ & $\sigma_{o}^{\prime}(\mathrm{psf})$ & $a_{\max }(\mathrm{g})$ & $V_{s, 40^{\prime}}^{*}(\mathrm{fps})$ & $r_{d}$ & $\begin{array}{l}\text { Cyclic shear } \\
\text { stres ratio } \\
\text { (SSR) }\end{array}$ & $\begin{array}{l}\text { Eqv. } \\
(M W)\end{array}$ & $D_{50}(\mathrm{~mm})$ & $\%$ Fines & $C_{R}$ & $c_{S}$ & $C_{B}$ & $C_{E}$ & $C_{V}$ & $\left(N_{1}\right)_{60}$ & References \\
\hline 4 Niigata $M=7.5$ & Arayamotomachi & Yes & в & $6.6-14.8$ & $3.3 \pm 1.0$ & $1,103.2 \pm 147.2$ & 77.9 & $0.09 \pm 0.018$ & 490 & .054 & $0.09 \pm 0.021$ & 7.5 & $0.15 \pm 0.070$ & $5.0 \pm 2.0$ & 0.86 & & 1 & 1.22 & 1.76 & & suda and Tohno (19 \\
\hline 1964 Nigata $M=7.5$ & Cc17-2 & Yes & B & $11.5-23.0$ & $3.0 \pm 1.0$ & 1.778 .6 & 30.4 & $0.16 \pm 0.024$ & 480 & $0.78 \pm 0.081$ & $0.16 \pm 0.032$ & 7.5 & $0.20 \pm 0.035$ & $\begin{array}{l}5.0 \pm 2.0 \\
8.0 \pm 2.0\end{array}$ & 0.93 & & & 1.09 & 1.50 & $\begin{array}{c}4.8 \pm \pm 2.6 \\
12.0 \pm 2.1\end{array}$ & Kishida (1966) \\
\hline 1968 Tokachi-Oki $M=7.9$ & Aomori Station & Yes & A & $13.1-24.6$ & $\begin{array}{l}3.0 \pm 1.0 \\
0.0 \pm 1.0\end{array}$ & $\begin{array}{l}1,7 / 8.0 \pm 219.3 \\
1,980.8 \pm 214.9\end{array}$ & $\begin{array}{l}89.1001103 .4 \\
803.6 \pm 122.8\end{array}$ & $\begin{array}{l}0.10 \pm 0.024 \\
0.21 \pm 0.030\end{array}$ & 520 & $\begin{array}{l}0.8 \pm 0.0081 \\
0.80 \pm 0.087\end{array}$ & $\begin{array}{l}0.10 \pm 0.032 \\
0.27 \pm 0.054\end{array}$ & 7.8 & $\begin{array}{l}0.25 \pm 0.023 \\
0.25 \pm 0.020\end{array}$ & $\begin{array}{l}8.0 \pm 2.0 \\
3.0 \pm 1.0\end{array}$ & 0.94 & & 1 & 1.22 & 1.58 & $\begin{array}{l}12.0 \pm \pm 2.1 \\
16.3 \pm 1.6\end{array}$ & Yasuda and Tohno (1988 \\
\hline 1976 Tangshan $M s=7.8$ & Luan Nan-L1 & No & B & $4.9-18.0$ & $3.6 \pm 1.0$ & $1,287.7 \pm 265.9$ & $796.4 \pm 135.9$ & $0.22 \pm 0.044$ & 640 & $0.96 \pm 0.052$ & $0.22 \pm 0.050$ & 8 & $0.17 \pm 0.060$ & $5.0 \pm 3.0$ & 0.87 & & 1 & 1.00 & 1.58 & $26.5 \pm 3.6$ & Shengcong and Tatsuoka (1983) \\
\hline 1976 Tangshan $M s=7.8$ & Luan Nan-L2 & Yes & B & 4. & $3.6 \pm 1.0$ & $1,169.6 \pm 232.5$ & $678.3 \pm 112.4$ & $0.22 \pm 0.044$ & 640 & $0.96 \pm 0.052$ & $0.24 \pm 0.055$ & 8 & $0.17 \pm 0.060$ & $3.0 \pm 2.0$ & 0.87 & 1 & 1 & 1.00 & 1.72 & $8.8 \pm 0.9$ & Shengcong and $\mathrm{T}$ \\
\hline 1983 Nihonkai-Chubu $M=7.1$ & Arayamotomachi & No & B & $3.3-24.6$ & $3.3 \pm 1.0$ & $1,447.7 \pm 375.9$ & $782.3 \pm 168.0$ & $0.15 \pm 0.030$ & 490 & $0.84 \pm 0.061$ & $0.15 \pm 0.036$ & 7.1 & $0.15 \pm 0.070$ & $15.0 \pm 4.0$ & 0.90 & & & 1.22 & 1.60 & $8.9 \pm 4.9$ & Yasuda and Tohno (1988) \\
\hline 1983 Nihonkai-Chubu $M=7.1$ & & No & B & $26.2-34.4$ & $3.3 \pm 1.0$ & $3,305.4 \pm 186.0$ & $1,616.5 \pm 137.4$ & $0.15 \pm 0.030$ & 550 & $0.63 \pm 0.118$ & $0.13 \pm 0.035$ & 7.1 & $0.42 \pm 0.100$ & $0.0 \pm 1.0$ & 1.00 & 1 & & 1.22 & 1.11 & $17.7 \pm 4.5$ & Yasuda and Tohno (1988) \\
\hline 1983 Nihonkai-Chubu $M=7.1$ & Takeda Elementary Sch. & Yes & B & $8.2-21.3$ & $1.1 \pm 1.0$ & $1,544.5 \pm 236.1$ & $694.8 \pm 122.3$ & $0.12 \pm 0.022$ & 470 & $0.80 \pm 0.064$ & $0.14 \pm 0.031$ & 7.1 & $0.24 \pm 0.020$ & $0.0 \pm 1.0$ & 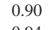 & & & 1.22 & 1.70 & $14.6 \pm 1.6$ & Yasuda and Tohno (1988) \\
\hline 1983 Nihonkai-Chubu $M=7.7$ & Aomori Station & $\begin{array}{l}\text { Yes } \\
\text { Yes }\end{array}$ & $B$ & 4.6 & $0.0 \pm 1.0$ & $1,980.8 \pm 214.9$ & $803.6 \pm 122.8$ & $0.12 \pm 0.018$ & 520 & $0.80 \pm 0.079$ & $0.15 \pm 0.030$ & 7.7 & $0.25 \pm 0.020$ & $3.0 \pm 1.0$ & 0.94 & 1 & & 1.22 & 1.58 & $16.3 \pm 1.6$ & Yasuda and Tohn \\
\hline 1983 Nihonkai-Chubu $M=7.7$ & $\begin{array}{l}\text { Arayamotomachi } \\
\text { Gaike Whar } B \text {-2 }\end{array}$ & $\begin{array}{l}\text { Yes } \\
\text { Yes }\end{array}$ & B & 3. & $3.3 \pm 1.0$ & $1,447.7 \pm 375.9$ & $782.3 \pm 168.0$ & $0.20 \pm 0.040$ & 490 & $0.85 \pm 0.061$ & $0.20 \pm 0.048$ & 7.7 & $0.15 \pm 0.070$ & $15.0 \pm 4.0$ & 0.90 & 1 & & 1.22 & 1.60 & $8.9 \pm 4.9$ & suda and Tohn \\
\hline $\begin{array}{l}1983 \text { Nihonkai-Chubu } M=7.7 \\
1093 \text { NhhonkaiaCCubu } M=7.7\end{array}$ & $\begin{array}{l}\text { Gaiko Wharf B-2 } \\
\text { Noshiro Section N-7 }\end{array}$ & $\begin{array}{l}\text { Yyes } \\
\text { Yes }\end{array}$ & $\begin{array}{l}\mathrm{B} \\
\mathrm{B}\end{array}$ & $\begin{array}{l}8.2-41.0 \\
6.6-16.4\end{array}$ & $1.3 \pm 1.0$ & $2,570.9 \pm 581.8$ & $\begin{array}{c}1,115.3 \pm 256.4 \\
7\end{array}$ & $\begin{array}{l}0.23 \pm 0.035 \\
0250.055\end{array}$ & $\begin{array}{l}550 \\
560\end{array}$ & $\begin{array}{l}0.74 \pm 0.099 \\
0.930 .052\end{array}$ & $0.25 \pm 0.054$ & $\begin{array}{l}7.7 \\
7.7 \\
\end{array}$ & $0.25 \pm 0.020$ & $\begin{array}{l}1.0 \pm 1.0 \\
10+10\end{array}$ & $\begin{array}{l}0.99 \\
087\end{array}$ & & 1 & 1.22 & $\begin{array}{l}1.34 \\
1.59\end{array}$ & $12.3 \pm 2.9$ & $\begin{array}{l}\text { Hamada and O'Rourke (1992) } \\
\text { Hamada and O'Rourke (1992) }\end{array}$ \\
\hline $\begin{array}{l}1983 \text { Nihonkaia-Chubu } M=7.7 \\
1983 \text { Nihonkai-Chubu } M=7.7\end{array}$ & $\begin{array}{l}\text { Nosinio section N-1 } \\
\text { Takeda Elementary Sch. }\end{array}$ & $\begin{array}{l}\text { res } \\
\text { Yes }\end{array}$ & $\begin{array}{l}\mathrm{B} \\
\mathrm{A}\end{array}$ & $\begin{array}{l}6.6-10.4 \\
8.2-21.3\end{array}$ & $\begin{array}{l}5.7 \pm 1.0 \\
1.1 \pm 1.0\end{array}$ & $\begin{array}{l}1,148.3 \pm \pm 756.6 \\
1,544.5 \pm 236.1\end{array}$ & $\begin{array}{l}790.0 .933 .2 \\
694.8122 .3\end{array}$ & $\begin{array}{l}0.25 \pm 0.055 \\
0.28 \pm 0.040\end{array}$ & $\begin{array}{l}360 \\
470\end{array}$ & $\begin{array}{l}0.93 \pm 0.052 \\
0.081 \pm 0.064\end{array}$ & $\begin{array}{l}0.22 \pm 0.054 \\
0.32 \pm 0.062\end{array}$ & 7.7 & $\begin{array}{l}0.25 \pm 0.020 \\
0.24 \pm 0.020\end{array}$ & $\begin{array}{l}1.0 \pm 1.0 \\
0.0 \pm 1.0\end{array}$ & $\begin{array}{l}0.81 \\
0.90-250\end{array}$ & & & $\begin{array}{l}1.22 \\
1.22\end{array}$ & $\begin{array}{l}1.59 \\
1.70\end{array}$ & $\begin{array}{l}16.4 \pm 3.6 \\
146 \pm 16\end{array}$ & $\begin{array}{l}\text { Hamada and Kourke (1992) } \\
\text { Yasuda and Tohno (1988) }\end{array}$ \\
\hline 1987 Elmore Ranch $M w=6.2$ & Radio Tower B1 & No & B & & $6.6 \pm 1.0$ & $1,291.8 \pm 134.7$ & $831.2 \pm 80.9$ & $\begin{array}{l}0.2010 .040 \\
0.09 \pm 0.025\end{array}$ & - & $\begin{array}{l}0.97 \pm 0.032 \\
0.972\end{array}$ & $\begin{array}{l}0.09 \pm 0.0026 \\
0.0926\end{array}$ & 6.2 & $0.05 \pm 0.015$ & $75.0 \pm 10.0$ & 0.86 & & & 1.13 & 1.55 & $\begin{array}{r}14.0 \pm 1.0 \\
6.8 \pm 5.2\end{array}$ & nett et al. ( \\
\hline 1987 Elmore Ranch $M w=6.2$ & Wildlife B & No & A & $9.0-22.0$ & $3.0 \pm 1.0$ & $1,520.0 \pm 222.9$ & $740.0 \pm 109.7$ & $0.00 \pm 0.005$ & - & $0.75 \pm 0.035$ & $0.10 \pm 0.011$ & 6.2 & $0.09 \pm 0.000$ & $40.0 \pm 3.0$ & 0.88 & 1 & & 0.00 & 1.64 & $12.8 \pm 5.7$ & Bennett et al. (1984) \\
\hline 1987 Supersitition Hills $M w=6.7$ & Radio Tower B1 & No & B & $9.8-18.0$ & $6.6 \pm 1.0$ & $1,291.8 \pm 134.7$ & $831.2 \pm 80.9$ & $0.20 \pm 0.040$ & - & $0.94 \pm 0.032$ & $0.18 \pm 0.042$ & 6.6 & $0.05 \pm 0.015$ & $75.0 \pm 10.0$ & 0.86 & 1 & & 1.13 & 1.55 & $6.8 \pm 5.2$ & Bennett et al. (1984) \\
\hline 1988 Superstition Hills $M w=6.7$ & Wildlife B & Yes & A & $9.0-22.0$ & $3.0 \pm 1.0$ & $1,520.0 \pm 222.9$ & $740.0 \pm 109.7$ & $0.18 \pm 0.005$ & - & $0.84 \pm 0.035$ & $0.20 \pm 0.021$ & 6. & $0.09 \pm 0.005$ & & 0.88 & 1 & & 1.13 & 1.64 & $12.8 \pm 5.7$ & ennett et 2 \\
\hline 1987 Superstition Hills $M w=6.7$ & Heber Road A1 & No & $B$ & $5.9-16.4$ & $5.9 \pm 3.0$ & $1,246.7 \pm 233.4$ & $919.2 \pm 160.0$ & $0.16 \pm 0.020$ & - & $0.82 \pm 0.022$ & $0.12 \pm 0.026$ & 6.7 & $0.11=$ & $25.0 \pm 4.0$ & 0.82 & 1 & & 1.13 & 1.48 & $44.0 \pm 3.6$ & Youd and Bennett (1983) \\
\hline 1987 Superstition Hills $M w=6.7$ & $\begin{array}{l}\text { Heber Road A2 } \\
\text { Heber Road A3 }\end{array}$ & $\begin{array}{l}\text { No } \\
\text { No }\end{array}$ & ${ }_{\mathrm{B}}^{\mathrm{B}}$ & 6.0-15.1 & $5.9 \pm 3.0$ & $974.1 \pm 156.2$ & $683.4 \pm 188.9$ & $0.15 \pm 0.020$ & - & $0.78 \pm 0.024$ & $0.12 \pm 0.034$ & 6.7 & $0.11 \pm 0.010$ & $29.0 \pm 4.5$ & 0.81 & & & 1.13 & 1.71 & $3.8 \pm 2.4$ & Youd and Bennett (1983) \\
\hline $\begin{array}{l}1987 \text { Supersstition Hills } M w=6.7 \\
1987 \text { Superstition Hills } M w=6.7\end{array}$ & $\begin{array}{l}\text { Heber Rood A3 } \\
\text { Kornbloom B }\end{array}$ & $\begin{array}{l}\text { No } \\
\text { No }\end{array}$ & $\begin{array}{l}\mathrm{B} \\
\mathrm{A}\end{array}$ & $\begin{array}{l}5.9-16.1 \\
8.5-17.0\end{array}$ & $5.9 \pm 3.0$ & $1,095.0 \pm 183.2$ & $\begin{array}{r}777.7 \pm 175.8 \\
1048+88.9\end{array}$ & $\begin{array}{l}0.13 \pm 0.020 \\
0.170 .020\end{array}$ & $=$ & $\begin{array}{l}0.75 \pm 0.025 \\
0.830 .023\end{array}$ & $0.11 \pm 0.026$ & $\begin{array}{l}6.7 \\
6.7\end{array}$ & $\begin{array}{l}0.10 \pm 0.010 \\
0.050\end{array}$ & $\begin{array}{l}37.0 \pm 5.0 \\
920+100\end{array}$ & $\begin{array}{l}0.82 \\
0.85\end{array}$ & & 1 & $\begin{array}{l}1.13 \\
1.13\end{array}$ & $\begin{array}{l}1.60 \\
1.40\end{array}$ & $19.5 \pm 6.1$ & Youd and Bennett (1983) \\
\hline $\begin{array}{l}1987 \text { Superstition Hinls } M w=6 \text {. } \\
1987 \text { Superstition Hills } M w=6 .\end{array}$ & $\begin{array}{l}\text { Kornbloom B } \\
\text { McKim Ranch A }\end{array}$ & No & A & $\begin{array}{l}8.5-17.0 \\
5.0-13.0\end{array}$ & $\begin{array}{l}9.0 \pm 1.0 \\
5.0 \pm 1.0\end{array}$ & $\begin{array}{l}1,248.8 \pm 154.1 \\
875.0+135.9\end{array}$ & $\begin{array}{l}1,014.8 \pm 88.9 \\
625.4+8.4\end{array}$ & $\begin{array}{l}0.17 \pm 0.020 \\
0.16+0.020\end{array}$ & $=$ & $\begin{array}{l}0.83 \pm 0.030 \\
0.95+0.025\end{array}$ & $\begin{array}{l}0.13 \pm 0.017 \\
0.14+0.024\end{array}$ & $\begin{array}{l}6.7 \\
6.7\end{array}$ & $\begin{array}{l}0.05 \pm 0.020 \\
011+0.03\end{array}$ & $92.0 \pm 10.0$ & $\begin{array}{l}0.83 \\
0.79\end{array}$ & & & $\begin{array}{l}1.13 \\
1.13\end{array}$ & $\begin{array}{l}1.40 \\
1.79\end{array}$ & $\begin{array}{l}7.2 \pm 3.5 \\
85+42\end{array}$ & $\begin{array}{l}\text { Bennentt et al. (1994) } \\
\text { Bennett et al. (1984) }\end{array}$ \\
\hline 1987 Superstition Hills $M w$ & Radio Tower B2 & No & B & $6.6-9.8$ & $6.6 \pm 1.0$ & $\begin{array}{l}746.4 \pm 66.7 \\
74.09\end{array}$ & $\begin{array}{l}62.254 .480 .4 \\
644.0 \pm 73.0\end{array}$ & $\begin{array}{l}0.116 \pm 0.020 \\
0.18 \pm 0.020\end{array}$ & $=$ & $\begin{array}{l}0.99 \pm 0.025 \\
0.99 \pm 0.20\end{array}$ & $\begin{array}{l}0.1 .1 \pm 0.024 \\
0.13 \pm 0.021\end{array}$ & $\begin{array}{l}0.1 \\
6.7 \\
\end{array}$ & $\begin{array}{l}0.11 \pm 0.003 \\
0.10 \pm 0.020\end{array}$ & $\begin{array}{l}31.0 \pm 3.0 \\
30.0 \pm 5.0\end{array}$ & & & & 1.13 & & $8.5 \pm 4.2$ & nnett et al. (1984) \\
\hline 1987 Superstition Hills $M w=$ & River Park A & No & C & $1.0-5.9$ & $1.0 \pm 1.0$ & $323.0 \pm 78.5$ & $170.0 \pm 64.2$ & $0.19 \pm 0.020$ & - & $\begin{array}{l}0.99 \pm 0.020 \\
0.99 \pm 0.010\end{array}$ & $\begin{array}{l}0.13 \pm 0.021 \\
019+0.088\end{array}$ & $\begin{array}{l}6.1 \\
6.7\end{array}$ & $\begin{array}{l}0.10 \pm 0.020 \\
004+0.010\end{array}$ & $\begin{array}{l}30.0 \pm 5.0 \\
800+100\end{array}$ & & & & & & $\begin{array}{l}0.2 .8 \\
0.34\end{array}$ & $\begin{array}{l}\text { ennett et al. (1984) } \\
\text { and Bennett (1983) }\end{array}$ \\
\hline 1987 Supersitition Hills $M w=6.7$ & River Park C & No & A & $11.0-17.0$ & $1.0 \pm 0.5$ & $1,520.0 \pm 122.1$ & $708.8 \pm 73.7$ & & & $\begin{array}{l}0.99 \pm 0.010 \\
0.97 \pm 0.025\end{array}$ & $\begin{array}{l}0.1 .1 \pm 0.088 \\
0.24 \pm 0.031\end{array}$ & 6.7 & $\begin{array}{l}0.04 \pm 0.0 .010 \\
0.15 \pm 0.008\end{array}$ & $\begin{array}{l}80.0 \pm 10.0 \\
18.0 \pm 3.0\end{array}$ & & & & 1.1 & & & Youd and Bennett (1983) \\
\hline 1989 Loma Prieta $M w=7$ & Alameda BF Dike & & & & $9.8 \pm 3.0$ & $2,616.5 \pm 92.5$ & $1,8999 \pm 185.7$ & & 60 & $\begin{array}{l}0.95 \pm 0.0087 \\
0.057\end{array}$ & 034 & 7 & & & & & & 0.92 & & 18 & 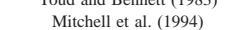 \\
\hline Prieta $M w=7$ & Farris Farm & & B & & $8 \pm 3.0$ & & & & - & & & & & & & & & & & $\begin{array}{l}42.0 \pm \pm \\
10.9 \pm\end{array}$ & Holzer et al. (1994) \\
\hline Prieta $M w=7$ & Hall Avenue & $\mathrm{N}$ & A & $11.5-18.9$ & 2.0 & & $1,190.7 \pm 118.6$ & $0.14 \pm 0.013$ & - & & 0.08 & 7 & & $30.0 \pm 7.0$ & & & & 0.92 & 1.30 & $\begin{array}{l}50.9 \pm \pm .9 \\
5.3 \pm 3.7\end{array}$ & Mitchell et al. (1994) \\
\hline $\begin{array}{l}\text { tat } M w=7 \\
\text { tas }\end{array}$ & Marine Laboratory UC-B1 & Yes & B & $7.9-18.0$ & $\begin{array}{l}11.0 \pm 2.0 \\
7.9 \pm 3.0\end{array}$ & $1,282.0 \pm 184.3$ & $964.7 \pm 177.0$ & $\begin{array}{l}0.14 \pm 0.013 \\
0.24 \pm 0.025\end{array}$ & - & 0.98 & $0.20 \pm 0.046$ & 7 & & $30 \pm 1.0$ & 0.85 & & & 1.00 & 1.44 & $\begin{array}{l}3.0 \pm \pm .7 \\
12.5 \pm 0.9\end{array}$ & Boulager et al. (1997) \\
\hline 99 Loma Prieta $M w=7$ & MBARI NO:3 EB-1 & No & B & $6.6-9.8$ & $6.6 \pm 1.0$ & $820.2 \pm 75.2$ & $717.8 \pm 55.9$ & $0.24 \pm 0.025$ & - & $0.99 \pm 0.007$ & $0.18 \pm 0.024$ & 7 & $0.60 \pm 0.100$ & $1.0 \pm 2.0$ & 0.69 & & & 00 & 1.67 & 23.9 & al. (1997) \\
\hline 1989 Loma Prieta $M w=7$ & ARI NO:31 & No & A & & $5.9 \pm 1.0$ & $1,428.8 \pm 292.5$ & $957.9 \pm 144.1$ & $0.27 \pm 0.025$ & - & $0.99 \pm 0.007$ & $0.24 \pm 0.033$ & 7 & $0.60 \pm 0.100$ & $1.0 \pm 2.0$ & 0.86 & & & 1.00 & 1.44 & 18.7 & ger et al. ( \\
\hline 1989 Loma Prieta $M w=7$ & Sandho & Yes & B & & $5.5 \pm 1.0$ & $885.0 \pm 110.2$ & $669.6 \pm 72.8$ & $0.26 \pm 0.025$ & - & $0.99 \pm 0.008$ & $0.23 \pm 0.032$ & 7 & $0.80 \pm 0.100$ & $2.0 \pm 2.0$ & 79 & & & 25 & & $16.1 \pm 1.0$ & \\
\hline 1989 Loma Prieta $M w=7$ & Mille & $\mathrm{Yc}_{\mathrm{c}}$ & B & & $13.1 \pm 1.0$ & $1,804.5 \pm 216.0$ & $1,395.0 \pm 108.7$ & $0.42 \pm 0.050$ & - & $0.84 \pm 0.017$ & $0.32 \pm 0.043$ & 7 & $0.16 \pm 0.020$ & $22.0 \pm 3.0$ & & 1 & & & & $10.0 \pm 4.4$ & 1) \\
\hline 1989 Loma Prieta $M w=7$ & Miller Farm CMF10 & $\mathrm{Y}$ & B & & $9.8 \pm 1.0$ & $2,600.1 \pm 176.3$ & $1,474.1 \pm 113.6$ & 0. & - & & & 7 & & & & & & & & & \\
\hline 1989 Loma Prieta $M w=7$ & & $\begin{array}{c}\mathrm{Y} \\
\mathrm{Y}\end{array}$ & A & & $18.7 \pm 3.0$ & 2,016 & 1,827 & 0 & - & & & 7 & & & & & & & & & \\
\hline 1989 Lor & Miller Farm CV & $\begin{array}{c}\mathrm{Y} \\
\mathrm{Y}\end{array}$ & B & $\begin{array}{l}18.0-27.9 \\
164-262\end{array}$ & $15.4 \pm 1.0$ & $2,409.8 \pm 201.3$ & $1,938.9 \pm 120.0$ & $0.41 \pm 0.050$ & - & $0.90 \pm 0.016$ & $0.29 \pm 0.039$ & 7 & & $13.0 \pm 2.0$ & & & & & 1.02 & $21.9 \pm 3.5$ & 1995) \\
\hline 1989 Loma Prieta $M w=7$ & $\begin{array}{l}\text { Miller Farm CMF } 8 \\
\text { St tate Beach UC-B1 }\end{array}$ & 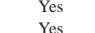 & B & $\begin{array}{l}16.4-26.2 \\
59-120\end{array}$ & $\begin{array}{c}16.1 \pm 1.0 \\
50+10\end{array}$ & $2,052.2 \pm 177.5$ & $1,724.6 \pm 108.1$ & $0.46 \pm 0.050$ & - & $0.73 \pm 0.013$ & $0.25 \pm 0.032$ & 7 & $0.20=$ & $15.0 \pm 2.0$ & 0.94 & & 1 & 13 & 1.08 & $10.3 \pm 1.0$ & Bennett an \\
\hline $\begin{array}{l}\text { 1989 Loma Prirta } M w=7 \\
\text { 1989 Loma Prieta } M w=7\end{array}$ & $\begin{array}{l}\text { ttate Beach UC-B1 } \\
\text { State Beach UC-B2 }\end{array}$ & $Y$ & A & $\begin{array}{l}5.9-12.0 \\
9.0-22.0\end{array}$ & $\begin{array}{l}5.9 \pm 1.0 \\
90+10\end{array}$ & $\begin{array}{r}865.7 \pm 105.1 \\
5825+2318\end{array}$ & $\begin{array}{l}675.6 \pm 73.9 \\
1169+1174\end{array}$ & $\begin{array}{l}0.29 \pm 0.025 \\
0.024025\end{array}$ & - & $\begin{array}{l}0.95 \pm 0.010 \\
090+0.113\end{array}$ & $0.24 \pm 0.032$ & $\begin{array}{l}7 \\
7\end{array}$ & $0.26 \pm 0.100$ & $2.0 \pm 2.0$ & 0.79 & & 1 & 5 & $\begin{array}{l}1.72 \\
1.30\end{array}$ & $\begin{array}{l}8.5 \pm 1.6 \\
10 \pm 2\end{array}$ & $\begin{array}{l}\text { Boulanger et al. (1997) } \\
\text { Boulanger et al. (1997) }\end{array}$ \\
\hline $\begin{array}{l}1989 \text { Loma Printa } M w=7 \\
1989 \text { Loma Prieta } M w=7\end{array}$ & & $\begin{array}{l}\mathrm{Y} \\
\mathrm{Y}\end{array}$ & A & 18. & $\begin{array}{l}9.0 \pm 1.0 \\
9.8 \pm 2.0\end{array}$ & $\begin{array}{l}1,582.5 \pm 231.8 \\
2,320.4 \pm 9.7\end{array}$ & $\begin{array}{l}1,1766.9 \pm 117.4 \\
1,675.5 \pm 142.2\end{array}$ & $\begin{array}{l}0.24240 .025 \\
0.22 \pm 0.010\end{array}$ & $=$ & $\begin{array}{l}0.99 \pm 0.013 \\
0.05 \pm 0.018\end{array}$ & $\begin{array}{l}0.21 \pm 0.028 \\
0.17 \pm 0.014\end{array}$ & 1 & $\begin{array}{l}0.40 \pm 0.100 \\
0.030 \pm 0.030\end{array}$ & $\begin{array}{l}1.0 \pm 2.0 \\
3.0 \pm 1.0\end{array}$ & & & & & & $\begin{array}{l}19.0 \pm 2.5 \\
13.0 \pm 3.1\end{array}$ & Mitchell et al. (1994) \\
\hline 1989 Loma Prieta $M w=7$ & & $\mathrm{Y}$ & B & & $9.8 \pm 1.0$ & $2,452.4 \pm 87.3$ & $1,735.9 \pm 91.5$ & $0.22 \pm$ & - & & 0.16 & 7 & & $5.0 \pm 1.0$ & & 1 & & & & $13.2 \pm 4.1$ & \\
\hline 1989 Loma Prieta $M v$ & & $\mathrm{Y}$ & A & & $11.5 \pm 1.0$ & $1,388.1 \pm 101.2$ & 1,102 & 13 & - & .017 & 0.09 & 7 & 010 & $50.0 \pm 5.0$ & 89 & 1 & & & & $3.8 \pm 1.2$ & \\
\hline $1989 \mathrm{~L}$ & 然 & Y & A & & $9.8 \pm 1.0$ & $2,460.6 \pm 118.0$ & 1,795 & & - & & & 7 & & & & te & & & & $8.1 \pm 2.2$ & \\
\hline 1989 & W & Y & -1 & & $3.3 \pm 1.0$ & 557.7 & & & - & & & 7 & & & & & & & & & 7) \\
\hline 1989 Loma Pr & Marine Laboratory UC & $x^{*}$ & A & & $8.2 \pm 1.0$ & & \pm 66.7 & $0.26 \pm$ & - & & & 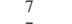 & & 3.0 & & & & & & & Boulanger ef \\
\hline 1989 Loma Prieta $M w=7$ & Treasure Islan & $\begin{array}{r}Y \\
N\end{array}$ & A & & $4.9 \pm 2.0$ & & $\left\{\begin{array}{l}1515.7 \\
\end{array}\right.$ & & - & & & & & & & & & & & $7.6=$ & Youd an \\
\hline 16 & $\mathrm{C}$ & $\mathrm{N}$ & A & & & & & & 610 & & & 7.6 & & & 0.92 & & & & & 3 & Wak \\
\hline & & & & & & & & & & & & 7.6 & & & & & & & & 14.0 & \\
\hline & & & & & & & 4,1 & & & & & 8 & & $10.0 \pm 3.0$ & & & & & & & \\
\hline 1993 & & $\mathrm{Y}$ & A & & 6. & & \pm 100.2 & & 70 & & & 8 & & & & 1 & & & & $17.1 \pm 4.2$ & \\
\hline 1993 & & N & B & & $5.2 \pm 1.0$ & & 2,30 & & 715 & & & 8 & & & & 1 & & & & & \\
\hline & & 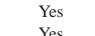 & A & & $23.6 \pm 2.0$ & & & & - & & & 6 & & & & 1 & & & 2 & & \\
\hline & & 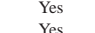 & A & & 12 & & & & & & & & & & & & & & & & \\
\hline $1994 \mathrm{~N}$ & $\mathrm{P}$ & $\begin{array}{rl}\mathrm{Y}_{\mathrm{Y}} & \mathrm{Y} \\
\mathrm{Y}\end{array}$ & A & & 1.0 & & & & 25 & & & 6 & & 5.0 & 0. & 1 & 1 & & 4 & 0.7 & \\
\hline 1994 Norr & $\begin{array}{l}\text { Ave. U } \\
\text { A (Mar }\end{array}$ & $\mathrm{N}$ & ${ }_{\mathrm{A}}^{\mathrm{A}}$ & & $\begin{array}{l}1 \pm 1.0 \\
5+10\end{array}$ & $2,3,3$ & & & 650 & & & 6. & & $38.0 \pm 23.0$ & 00 & $\begin{array}{l}1 \\
1\end{array}$ & 1 & & & $=1.6$ & \\
\hline goken-Nambu $M L=$ & & $N$ & A & & & $\begin{array}{l}2,9 \\
1.8\end{array}$ & $\begin{array}{l}0.2 \\
2.1\end{array}$ & & & & & 0.9 & & $\begin{array}{r}2.0 \pm 1.0 \\
180 \pm 4.0\end{array}$ & 93 & 1 & 1 & $\frac{2}{2}$ & & $\begin{array}{l}31.3 \pm 5.9 \\
216+7.1\end{array}$ & $\begin{array}{l}\text { et al. (1996) } \\
\text { et al. (1996) }\end{array}$ \\
\hline & & & B & & & & & & & & & & & & & & & & & & o) \\
\hline & & $\mathrm{Y}$ & c & & & & & & & & & & & & & & & & & & \\
\hline & & $\mathrm{Y}$ & A & & & & & & & & & 6 & & & & & & & & & \\
\hline & & No & A & & 16.4 & & & & 6 & & & 9 & & & & & & & & & \\
\hline 2 & & No & B & & $16.4 \pm 1.0$ & & & & 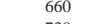 & & & & & & & & & & & & \\
\hline be N Nomer & ind & No & & & $16.4 \pm 1.0$ & & 3200 & & & & & & & & & 1 & & & & 32.2. & et al. (1996) \\
\hline & & & & & & & & & & & & & & & 1.00 & 1 & 1 & 2 & & 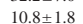 & 6) \\
\hline & & $y$ & $A$ & & & & & & & & & 6.9 & & & 99 & 1 & 1 & & & & \\
\hline lyogoken-Nambu $M$ & & $\mathrm{Yc}$ & B & & & $4,396.3 \pm 990.6$ & $2.860 .9 \pm 488.3$ & & 6 & & & 6.9 & & & 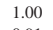 & 1 & & 1.22 & & $12.2 \pm 3.5$ & 996) \\
\hline 1995 Hyogoken-Nambu $M L=7.2$ & Torishima Dikc & Yes & A & $9.8-21.3$ & $0.0 \pm 1.0$ & $1,714.2 \pm 219.8$ & $741.8 \pm 122.2$ & $0.25 \pm 0.040$ & 560 & $0.87 \pm 0.067$ & $0.33 \pm 0.065$ & 6.9 & $0.20 \pm 0.100$ & $20.0 \pm 7.0$ & 0.91 & 1 & & 1.22 & 1.64 & $15.5 \pm 3.5$ & Matsuo (1996 \\
\hline
\end{tabular}




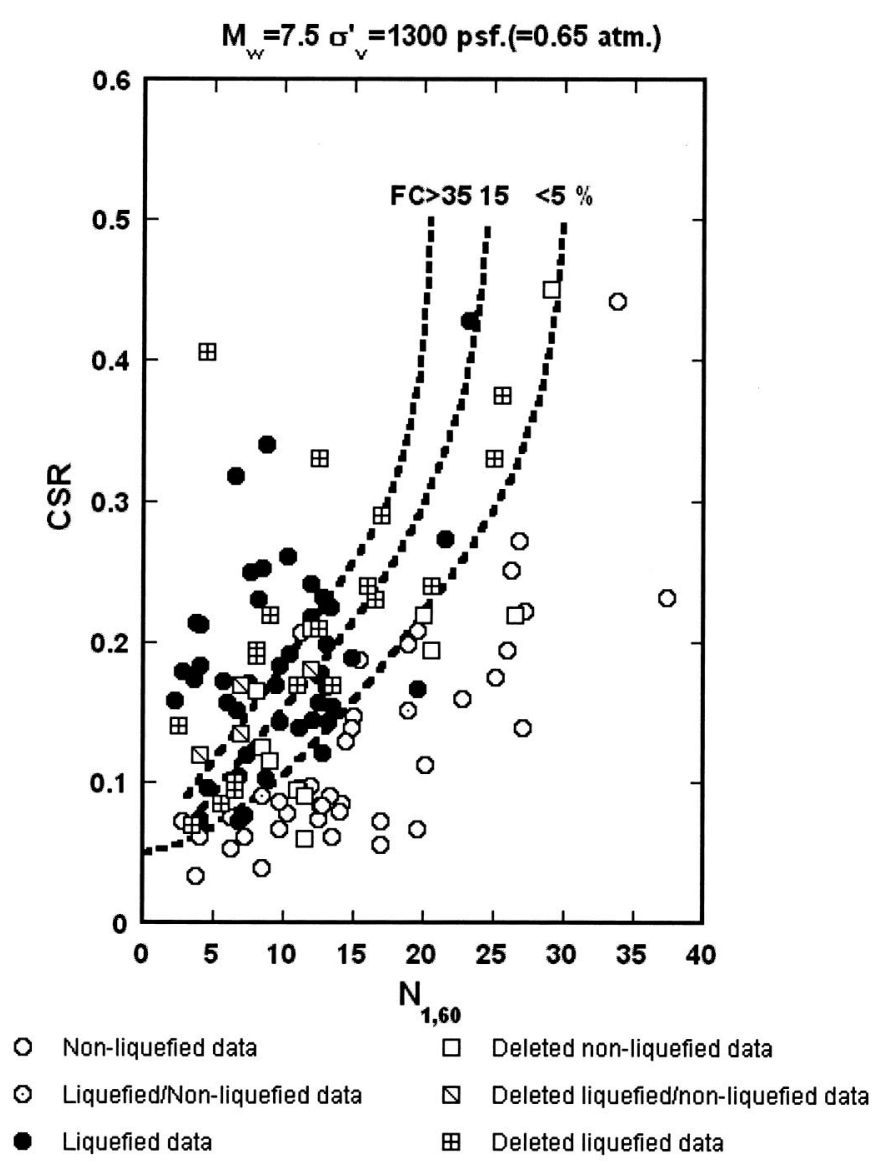

(a)

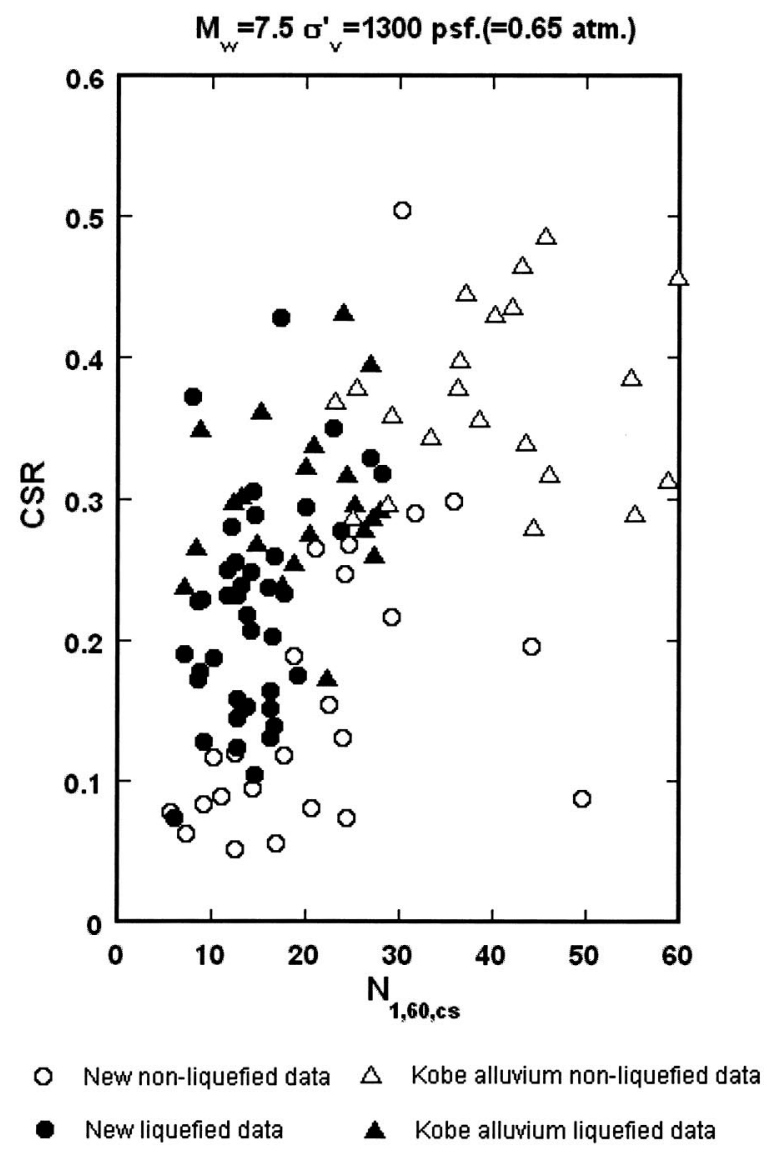

(b)

Fig. 8. (a) Reevaluated case histories from database of Seed et al. (1984), showing data cases deleted and (b) post-1984 field case histories used in these studies

ances in other key parameters (e.g., fines content, etc.), all carried forward. Details of the formulation and performance of these regression analyses are reported in Cetin et al. (2002).

These regression-type analyses were simultaneously applied to a number of contributing variables, and the results are illustrated in Figs. 9-14, and are expressed in the remaining equations.

Fig. 9(a) shows the resulting proposed probabilistic relationship between duration-corrected equivalent uniform cyclic stress ratio $\left(\mathrm{CSR}_{\mathrm{eq}}^{*}\right)$, and fines-corrected penetration resistances $\left(N_{1,60, \mathrm{cs}}\right)$ with the correlations as well as all field data shown normalized to an effective overburden stress of $\sigma_{v}^{\prime}=0.65 \mathrm{~atm}\left(1,300 \mathrm{lb} / \mathrm{ft}^{2}\right)$. The contours shown (solid lines) are for probabilities of liquefaction of $P_{L}=5,20,50,80$, and $95 \%$. All "data points" shown actually represent median values of distributions of $\mathrm{CSR}_{\text {eq }}^{*}$ and $N_{1,60 \text {,cs }}$, also corrected for duration and fines. These are superposed (dashed lines) with the relationship proposed by Seed et al. (1984) for reference.

As shown in this figure, the "clean sand" (fines content $\leqslant 5 \%$ ) line of Seed et al. (1984) appears to correspond roughly to $P_{L}$ $\approx 50 \%$. This is actually not the case, however, as the Seed et al. (1984) line was based on biased values of CSR (as a result of biased $r_{d}$ at shallow depths, as discussed earlier). The new correlation uses actual event-specific seismic site response analyses for evaluation of in situ CSR in 53 of the back-analyzed case histories, and the new (and statistically unbiased) empirical estimation of $r_{d}$ (as a function of level of shaking, site stiffness, and earth- quake magnitude) of Eq. (8) for the remaining 148 cases. The new estimates of in situ CSR tend to be slightly lower, typically on the order of $\sim 5-15 \%$, at the shallow depths that are critical in most of the case histories. Accordingly, the CSRs of the new correlation are also, correspondingly, lower by about $5-15 \%$, and a fully direct comparison between the new correlation and the earlier recommendation of Seed et al. (1984) cannot be made.

It should be noted that the use of slightly biased (high) values of $r_{d}$ was not problematic in the earlier correlation of Seed et al. (1984), so long as the same biased $\left(r_{d}\right)$ basis was also employed in forward application of this correlation to field engineering works. It was a problem, however, when forward applications involved direct, response-based calculation of in situ CSR, as often occurs on major analyses of earth dams, etc. As shown in Figs. 3(a and b), the earlier $r_{d}$ recommendations produced CSR values that were biased to the low side (typically $\sim 5-15 \%$ low at the shallow depths that dominate the field performance case history database), so that all previous correlations (which were based on these lowered values) are unconservatively biased if used in conjunction with CSR values based on direct project-specific dynamic response analyses.

It was Seed's intent that the recommended (1984) boundary should represent approximately a $10-15 \%$ probability of liquefaction, and with allowance for the "shift" in (improved) evaluation of CSR, the 1984 deterministic relationship for clean sands $(<5 \%$ fines) does correspond to approximately $P_{L} \approx 10-40 \%$, except at 
Table 8. Field Case History Data from Proprietary Alluvial Sites Near Kobe, Japan

\begin{tabular}{|c|c|c|c|c|c|c|c|c|c|c|c|c|c|c|c|c|c|c|c|c|c|}
\hline Earthquake & $\begin{array}{c}\text { Kobe } \\
\text { Alluvial } \\
\text { site } \\
\text { number }\end{array}$ & Liquefied? & $\begin{array}{l}\text { Data } \\
\text { class }\end{array}$ & $\begin{array}{l}\text { Critical depth } \\
\text { range (ft) }\end{array}$ & $\begin{array}{l}\text { Depth to } \\
\text { GWT (tt) }\end{array}$ & $\sigma_{o}(\mathrm{psf})$ & $\sigma_{o}^{\prime}(\mathrm{psf})$ & $a_{\max }(\mathrm{g})$ & $V_{s, 40^{\prime}}^{*}(\mathrm{fps})$ & $r_{d}$ & $\begin{array}{l}\text { Cyclic Shear } \\
\text { stress ratio }\end{array}$ & $\begin{array}{l}\text { Eqv. } \\
(M W)\end{array}$ & $D_{50}(\mathrm{~mm})$ & $\%$ Fines & $C_{R}$ & $c_{S}$ & $C_{B}$ & $C_{E}$ & $c_{V}$ & $\left(N_{1}\right)_{60}$ & References \\
\hline$M L=7.2$ & 1 & No & в & $16.4-23.0$ & 7. & 4 & $1,439.4 \pm 96.4$ & $0.40 \pm 0.060$ & 700 & $3 \pm 0.082$ & $0.37 \pm 0.066$ & 6.9 & $\mathrm{NA}$ & $4.0 \pm 1.5$ & 0.95 & 1 & 1 & 1.22 & 1.18 & $.7 \pm 3.2$ & Kobe City Office (personal communication, 1999) \\
\hline 995 Hyogoken-Nambu $M L=7.2$ & 2 & No & в & $16.4-39.4$ & $9.5 \pm 1.0$ & $112.2 \pm 448.0$ & $63.7 \pm 223.9$ & $0.40 \pm 0.060$ & 680 & $33 \pm 0.110$ & 71 & 6.9 & $\mathrm{NA}$ & $15.0 \pm 5.0$ & 1.00 & 1 & 1 & 1.22 & 1.01 & & Kobe City Office (personal communication, 1999) \\
\hline 1995 Hyogoken-Nambu $M L=7.2$ & 3 & No & в & $11.5-24.6$ & $\begin{array}{l}8.0 \pm 1.0 \\
8.2 \pm 1.0\end{array}$ & $1,993.1 \pm 256.9$ & $1,378.9 \pm 136.4$ & $\begin{array}{l}0.40 \pm 0.0000 \\
0.40 \pm 0.060\end{array}$ & 650 & $0.91 \pm 0.076$ & $0.34 \pm 0.063$ & 6.9 & NA & $\begin{array}{l}3.0 \pm \pm .0 \\
4.0 \pm 1.0\end{array}$ & 0.94 & 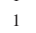 & 1 & 1.22 & 1.20 & $54.2 \pm 7.2$ & Kobe City Office (personal communication, 1999) \\
\hline 1995 Hyogoken-Nambu $M L=7.2$ & 4 & No & B & $9.8-21.3$ & $6.7 \pm 1.0$ & $1,602.7 \pm 205.9$ & $1,049.9 \pm 109.2$ & $0.40 \pm 0.060$ & 600 & $0.90 \pm 0.067$ & $0.36 \pm 0.066$ & 6.9 & $\mathrm{NA}$ & $4.0 \pm 1.0$ & 0.91 & 1 & 1 & 1.22 & 1.38 & $\begin{array}{l}54.2 \pm \pm .2 \\
43.5 \pm 5.3\end{array}$ & Kobe City Office (personal communication, 1999) \\
\hline 1995 Hyogoken-Nambu $M L=7.2$ & 5 & Yes & B & $21.3-36.1$ & $9.9 \pm 1.0$ & $3,251.8 \pm 295.5$ & $2,078.7 \pm 165.1$ & $0.35 \pm 0.045$ & 600 & $0.71 \pm 0.113$ & $0.25 \pm 0.053$ & 6.9 & $\mathrm{NA}$ & $\begin{array}{l}2.0 \pm 1.0 \\
2.0 \pm 1.0\end{array}$ & 1.00 & 1 & 1 & 1.22 & 0.98 & $6.9 \pm 1.6$ & Kobe City Office (personal communication, 1999) \\
\hline 1995 Hyogoken-Nambu $M L=7.2$ & 6 & Yes & A & $14.1-24.0$ & $7.5 \pm 1.0$ & $2,150.6 \pm 196.6$ & $1,434.1 \pm 117.3$ & $0.40 \pm 0.060$ & 580 & $0.84 \pm 0.079$ & $0.33 \pm 0.061$ & 6.9 & $\mathrm{NA}$ & $25.0 \pm 3.0$ & 0.95 & 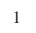 & 1 & 1.22 & 1.18 & $22.7 \pm 3.9$ & Kobe City Office (personal communication, 1999) \\
\hline 1995 Hyogoken-Nambu $M L=7.2$ & 7 & Yes & A & $14.1-27.2$ & $10.4+1.0$ & $2,325.1 \pm 258.3$ & $1,682.3 \pm 141.2$ & $0.40 \pm 0.060$ & 580 & $0.81 \pm 0.085$ & $0.29 \pm 0.056$ & 6.9 & $\mathrm{NA}$ & $0.0 \pm 0.0$ & 0.96 & 1 & 1 & 1.22 & 1.09 & $27.3 \pm 1.7$ & Kobe City Office (personal communication, 1999) \\
\hline 1995 Hyogoken-Nambu $M L=7.2$ & 8 & Yes & A & $13.1-19.7$ & $9.7 \pm 1.0$ & $1,674.0 \pm 124.2$ & $1,254.4 \pm 87.7$ & $0.50 \pm 0.075$ & 600 & $\begin{array}{l}0.81 \pm 0.083 \\
0.89 \pm 0.070\end{array}$ & $\begin{array}{l}0.29 \pm 0.030 \\
0.39 \pm 0.069\end{array}$ & 6.9 & $\mathrm{NA}$ & $\begin{array}{l}0.0 \pm 0.0 \\
0.0 \pm 0.0\end{array}$ & 0.92 & 1 & 1 & 1.22 & 1.26 & $24.5 \pm 2.9$ & Tokimatsu (personal communication, 2000) \\
\hline 1995 Hyogoken-Nambu $M L=7.2$ & 9 & Yes & A & $10.8-17.4$ & $9.1 \pm 1.0$ & $1,531.5 \pm 132.8$ & $1,218.3 \pm 88.2$ & $0.50 \pm 0.075$ & 570 & $0.89 \pm 0.061$ & $0.37 \pm 0.064$ & 6.9 & $\mathrm{NA}$ & $3.0 \pm 1.0$ & 0.90 & 1 & 1 & 1.22 & 1.28 & $12.1 \pm 5.3$ & Kobe City Office (personal communication, 1999) \\
\hline 1995 Hyogoken-Nambu $M L=7.2$ & 10 & No & B & $19.7-29.5$ & $14.6 \pm 1.0$ & $2,633.5 \pm 193.9$ & $2,011.2 \pm 120.0$ & $0.60 \pm 0.090$ & 0 & $0.75 \pm 0.099$ & $0.38 \pm 0.078$ & 6.9 & $\mathrm{NA}$ & $9.0 \pm 1.0$ & 0.99 & 1 & 1 & 1.22 & 1.00 & $27.7 \pm 4.2$ & Tokimatsu (personal communication, 2000) \\
\hline 1995 Hyogoken-Nambu $M L=7.2$ & 11 & Yes & в & $12.3-32.0$ & $4.8 \pm 1.0$ & $2,301.5 \pm 352.0$ & $1,216.5 \pm 167.4$ & $0.50 \pm 0.075$ & 20 & $0.70 \pm 0.090$ & $0.43 \pm 0.090$ & 6.9 & $\mathrm{NA}$ & $5.0 \pm 1.0$ & 0.97 & 1 & 1 & 1.22 & 1.28 & $8.3 \pm 2.3$ & Tokimatsu (personal communication, 2000) \\
\hline 1995 Hyogoken-Nambu $M L=7.2$ & 12 & No & A & $14.1-20.7$ & $10.5 \pm 1.0$ & $1,773.3 \pm 125.4$ & $1,343.4$ & $50 \pm 0.075$ & 50 & $83 \pm 0.073$ & $0.36 \pm 0.065$ & 6.9 & $\mathrm{NA}$ & $13.0 \pm 3.0$ & 0.92 & 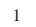 & 1 & 1.22 & 1.22 & $26.7 \pm 1.3$ & Kobe City Office (personal communication, 1999) \\
\hline n-Nambu $M L=$ & 13 & Yes & A & $16.4-26.2$ & $7.5 \pm 1.0$ & $2,201.4 \pm 183.4$ & $1.341 .6=$ & $50 \pm 0.075$ & 590 & $31 \pm 0.087$ & $43 \pm 0.083$ & 6.9 & $\mathrm{NA}$ & $18.0 \pm 3.0$ & 0.96 & 1 & 1 & 1.22 & 1.22 & $13.3 \pm 1.5$ & Tokimatsu (personal communication, 2000) \\
\hline 1995 Hyogoken-Nambu $M L=7.2$ & 14 & No & A & $14.1-17.4$ & $10.2 \pm 1.0$ & $1,602.7 \pm 74.0$ & $1,254.7 \pm 77.4$ & $0.50 \pm 0.075$ & 540 & $0.84 \pm 0.068$ & $0.35 \pm 0.062$ & 6.9 & $\mathrm{NA}$ & $\begin{array}{l}10.0 \pm \pm .0 \\
18.0\end{array}$ & 0.91 & 1 & 1 & 1.22 & 1.26 & $\begin{array}{l}13.3 .5 \pm 1.3 \\
22.5 \pm 2.3\end{array}$ & Kobe City Office (personal communication, 1999) \\
\hline 1995 Hyogoken-Nambu $M L=7.2$ & 15 & Yes & A & $15.3-22.6$ & $12.0 \pm 1.0$ & $1,929.5 \pm 140.7$ & $1,494.5 \pm 95.5$ & $0.50 \pm 0.075$ & 20 & $0.76 \pm 0.079$ & $0.32 \pm 0.061$ & 6.9 & $\mathrm{NA}$ & $5.0 \pm 2.0$ & 0.94 & 1 & 1 & 1.22 & 1.16 & $19.9 \pm 4.4$ & Kobe City Office (personal communication, 1999) \\
\hline 1995 Hyogoken-Nambu $M L=7.2$ & 16 & No/Yes & A & $13.1-16.4$ & $8.0 \pm 1.0$ & $1,510.0 \pm 71.3$ & $1,090.3 \pm 74.8$ & $0.60 \pm 0.090$ & 0 & $93 \pm 0.064$ & $0.50 \pm 0.088$ & 6.9 & $\mathrm{NA}$ & $5.0 \pm 1.0$ & 0.90 & 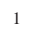 & 1 & 1.22 & 1.35 & $26.1 \pm 1.5$ & Tokimatsu (personal communication, 2000) \\
\hline 1995 Hyogoken-Nambu $M L=7.2$ & 17 & Yes & A & $9.8-19.7$ & $\begin{array}{l}8.0 \pm 1.0 \\
2.5 \pm 1.0\end{array}$ & $1,537.9 \pm 179.5$ & $770.2 \pm 103.4$ & $\begin{array}{l}0.50 \pm 0.0075 \\
0.075\end{array}$ & 630 & $\begin{array}{l}0.93 \pm 0.0004 \\
0.964\end{array}$ & $\begin{array}{l}0.30 \pm 0.00 .112 \\
0.600\end{array}$ & 6.9 & $\mathrm{NA}$ & $\begin{array}{r}5.0 \pm 1.0 \\
5.0 \pm 1.0\end{array}$ & 0.90 & 1 & 1 & 1.22 & 1.61 & $\begin{array}{r}20.11 \pm .5 \\
23.2 \pm 7.9\end{array}$ & Tokimatsu (personal communication, 2000) \\
\hline 1995 Hyogoken-Nambu $M L$ & 18 & No & в & $29.5-39.4$ & $25.1 \pm 1.0$ & $3,836.1 \pm 217.0$ & $3,252.7 \pm$ & $0 \pm 0.105$ & 630 & $2 \pm 0.131$ & & 6.9 & $\mathrm{NA}$ & & 1.00 & 1 & 1 & 1.22 & 0.78 & & Tokimatsu (personal communication, 2000) \\
\hline 995 Hyogoken-Nambu $M L=7.2$ & 19 & No & B & 23 & $20.0 \pm 1.0$ & $\begin{array}{l}3,830.1121,60 \\
2,629.6 \pm 103.9\end{array}$ & $\begin{array}{l}3,252.1 \pm \pm 49.1 \\
2,343.0 \pm 101.6\end{array}$ & $\begin{array}{l}0.10 \pm 0.103 \\
0.60 \pm 0.090\end{array}$ & 680 & 199 & 0.38 & 6.9 & $\mathrm{NA}$ & & 0.99 & 1 & 1 & 1.22 & 0.92 & & Tokimatsu (personal communication, 2000) \\
\hline 1995 Hyogoken-Nambu $M L=7.2$ & 20 & No & B & $13.1-26.2$ & $6.6 \pm 1.0$ & $2,198.2 \pm 258.5$ & $1,379.3 \pm 139.4$ & $0.55 \pm 0.090$ & & $0.93 \pm 0.082$ & $0.53 \pm 0.102$ & 6.9 & Yot & $0.0 \pm 0.0$ & 0.95 & 1 & 1 & 1.22 & 1.20 & $64.3 \pm 2.0$ & Tokimatsu (personal communit \\
\hline 1995 Hyogoken-Nambu $M L=7.2$ & 21 & $\mathrm{~N}$ & B & $9.8-13.1$ & $5.4 \pm 1.0$ & $1,266.4 \pm 71.5$ & $887.7 \pm 68.1$ & $0.60 \pm 0.090$ & 650 & $0.96 \pm 0.052$ & $0.53 \pm 0.093$ & 6.9 & $\mathrm{NA}$ & $0.0 \pm 0.0$ & 0.87 & 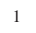 & 1 & 1.22 & 1.50 & $36.4 \pm 3.2$ & Tokimatsu (personal communication, 2000) \\
\hline oken-Nambu $M L=7.2$ & 22 & $\mathrm{~N}$ & B & $13.1-26.2$ & $7.9 \pm 1.0$ & $2,185.0 \pm 258.1$ & $1,448.0$ & $0.60 \pm 0.090$ & 620 & $86 \pm 0.082$ & & 6.9 & $\mathrm{NA}$ & $6.0 \pm 2.0$ & 0.88 & 1 & 1 & 1.22 & 1.18 & $40.8 \pm 12.2$ & Tokimatsu (personal communication, 2000) \\
\hline - & 23 & No & A & $13.1-19.7$ & & $1,788.1 \pm 134.7$ & 1,378 & 0 & 0 & & & 6.9 & $\mathrm{NA}$ & & 0.92 & 1 & 1 & 1.22 & 1.20 & & Tokimatsu (personal communication, 2000) \\
\hline 995 Hyogoken-Nambu 1 & 24 & Yes & в & $9.8-13.1$ & $7.7 \pm 1.0$ & $1,243.4=$ & 1,008 & $0 \pm 0$ & 640 & & & 6.9 & $\mathrm{NA}$ & & 0.87 & 1 & 1 & 1.22 & 1.41 & & Tokimatsu (personal communication, 2000) \\
\hline 1995 Hyogoken-Nambu $M L=7.2$ & 25 & No & B & $9.8-13.1$ & $7.1 \pm 1.0$ & $1,250.0 \pm 71.9$ & $973.6 \pm 68.4$ & $0.70 \pm 0.105$ & 660 & $0.96 \pm 0.052$ & $0.56 \pm 0.097$ & 6.9 & $\mathrm{NA}$ & $\begin{array}{l}0.0 \pm 0.0 \\
4.0 \pm 1.0\end{array}$ & 0.76 & 1 & 1 & 1.22 & 1.43 & $39.4 \pm 1.2$ & Tokimatsu (personal communication, 2000) \\
\hline 1995 Hyogoken-Nambu $M L=7.2$ & 26 & No & в & $9.8-13.1$ & $3.0 \pm 1.0$ & $1,248.4 \pm 70.3$ & $716.1 \pm 72.6$ & $0.60 \pm 0.090$ & 690 & $77 \pm 0.052$ & $0.66 \pm 0.120$ & 6.9 & $\mathrm{NA}$ & $0.0 \pm 0.0$ & 0.87 & 1 & 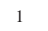 & 1.22 & 1.67 & $43.1 \pm 6.8$ & Tokimatsu (personal communication, 2000) \\
\hline en-Nambu $M L$ & 27 & No & B & $6.6-9.8$ & & & & & & & & 6.9 & $\mathrm{NA}$ & $10.0 \pm 2.0$ & 0.82 & 1 & 1 & 1. & 1.91 & & Tokimatsu (personal communication, 2000) \\
\hline $1995 \mathrm{~F}$ & 28 & Yc & в & 13.1 & & $1,521.5$ & 92 & 0 & & 64 & & 6.9 & $\mathrm{NA}$ & $10.0 \pm 2.0$ & 0.90 & 1 & 1 & 1.22 & 1.44 & & Tokimatsu (personal communication, 2000) \\
\hline & 29 & Yes & A & $9.8-14.8$ & $6.6 \pm 1.0$ & & $929.5 \pm$ & & 610 & & & 6.9 & $\mathrm{NA}$ & & 0.88 & 1 & 1 & 1.22 & 1.4 & & Tokimatsu (personal communication, 2000) \\
\hline 1995 Hyogoken-Nambu $M L=7.2$ & 30 & № & в & $23.0-32.8$ & $\begin{array}{l}6.0 \pm 1.0 \\
4.9 \pm 1.0\end{array}$ & $\begin{aligned} & 1,287.1 \pm 1.2 \\
& 2,903.5 \pm 196.3\end{aligned}$ & $\begin{array}{l}92,9.514 .1 \\
1,470.5 \pm 130.4\end{array}$ & 0.6 & (5) & 110 & 123 & 6.9 & $\mathrm{NA}$ & $\begin{array}{l}0.0 \pm 0 \pm 0 \\
10.0 \pm 1.0\end{array}$ & 1.00 & 1 & 1 & 1.22 & 1.17 & $\begin{array}{l}18.8 \pm \pm .4 \\
43.4 \pm 6.6\end{array}$ & Tokimatsu (personal communication, 2000) \\
\hline 1995 Hyogoken-Nambu $M L=7.2$ & 31 & No & A & $9.8-16.4$ & $3.9 \pm 1.0$ & 27.2 & $831.0=$ & & & & & 6.9 & $\mathrm{NA}$ & $0.0 \pm 0.0$ & 0.89 & 1 & t & 1.22 & 1.55 & $\begin{array}{l}43.40 .0 . \\
59.8 \pm 6.3\end{array}$ & Tokimatsu (personal communication, 2000) \\
\hline oken-Nar & 32 & $\mathrm{~N}$ & B & & & 4 & 695. & & & & & 6.9 & $\mathrm{NA}$ & $6.0 \pm 2.0$ & 0.8 & & 1 & & & 32.2 & Tokimatsu (personal communication, 2000) \\
\hline $1995 \mathrm{l}$ & 33 & No & в & & & .8 & $1,494.8$ & 5 & & 04 & & 6.9 & $\mathrm{~N} A$ & $50.0 \pm 5.0$ & 1.00 & & 1 & 1.22 & 1.16 & & Tokimatsu (personal communication, 2000) \\
\hline 1995 Hyogoken-Nambu 1 & 34 & Yes & B & $13.1-32.8$ & $5.9 \pm$ & $\begin{array}{l}2,3231 \\
2,381\end{array}$ & $\begin{array}{l}1,194,8.2 \\
1,317.3\end{array}$ & $0.40=$ & 55 & 93 & 1 & 6.9 & $\mathrm{NA}$ & $9.0 \pm 1.0$ & 0.98 & 1 & 1 & 1.22 & 1.23 & 25.8 & Tokimatsu (personal communication, 2000) \\
\hline & 35 & Yes & A & $9.8-19.7$ & $6.7 \pm 1.0$ & $1,516.6 \pm 177.3$ & $1,015.0 \pm 99.7$ & $0.50 \pm 0.075$ & 540 & & & 6. & $\mathrm{NA}$ & & 0.90 & 1 & 1 & 1.22 & 1.4 & 2.6 & Tokimatsu (personal communication, 2000) \\
\hline ogoken-Nambu $M L=7$ & 36 & № & в & $9.8-13.1$ & $3.1 \pm 1.0$ & $1,190.3 \pm 67.8$ & $666.2 \pm 71.5$ & & & & & 6.9 & $\mathrm{NA}$ & & 0. & 1 & t & 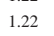 & 1.73 & & Tokimatsu (personal communication, 2000) \\
\hline oken-Nan & 37 & $y_{0}$ & A & & $13.1 \pm 1.0$ & $1,312.3 \pm 235.6$ & $1,312.3 \pm 121.4$ & 0.3 & & & & 6. & $\mathrm{~N}$ & $0.0 \pm 0.0$ & 烈 & 1 & 1 & & & 3.1 & Tokimatsu (personal communication, 2000) \\
\hline 995 Hyogoken-Nambu $M L=7.2$ & 38 & $\mathrm{Yc}_{\mathrm{C}}$ & B & & & $2,706.7 \pm 242.1$ & $1,683.1 \pm 133.5$ & 0.5 & & 104 & & 6.9 & $\mathrm{~N}$ & & 1. & 1 & 1 & 1.22 & 1. & & Tokimatsu (personal communication, 2000) \\
\hline 1995 Hyogoken-Nambu $M L=7.2$ & 39 & No & в & $13.1-1$ & $\begin{array}{l}8.0 \pm 1.0 \\
8.5 \pm 1.0\end{array}$ & $1,612.5 \pm 76.4$ & $1,223.6 \pm 73.2$ & $0.60 \pm 0.090$ & ${ }^{2}$ & 64 & $0.49 \pm$ & 6.9 & $\mathrm{NA}$ & 0.0 & 0.9 & 1 & 1 & 1.22 & 1.28 & & Tokimatsu (personal communication, 2000) \\
\hline & 40 & No & B & $9.8-1$. & & & & & 680 & & & 6.9 & $\mathrm{NA}$ & & 0.8 & 1 & 1 & 1.22 & 1.33 & 0.8 & Tokimatsu (personal communication, 2000) \\
\hline 1-Nam & 41 & Yes & A & 7.4-19.7 & & & & & 600 & & & 6.9 & $\mathrm{NA}$ & & 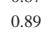 & $x^{2}$ & ${ }^{2}$ & 1.22 & 1. & & Tokimatsu (personal communication, 2000) \\
\hline 1995 Hyogoken-Nambu $M L=$ & 42 & $\mathrm{Ye}$ & A & & & $1,621.6 \pm 121.5$ & & & & & & 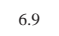 & $\mathrm{NA}$ & & & 1 & 1 & 1.22 & & & Tokimatsu (personal communication, 2000) \\
\hline 1995 Hyogoken-Nambu $M L=7.2$ & 43 & Yes & B & & $7.1 \pm 1.0$ & $1,566.6 \pm 72.1$ & $1,054.8 \pm 75.6$ & $35 \pm 0.050$ & 60 & $1 \pm 0.066$ & 553 & 6.9 & $\mathrm{~N} A$ & 20 & & & 1 & 1.2 & 1.3 & 15. & tstu (personal communicati) \\
\hline 1995 Hyogoken-Nambu $M L=7.2$ & 44 & Yes & B & $9.8-16.4$ & $5.1 \pm 1.0$ & $1,286.9 \pm 115.9$ & $785.3 \pm 80.2$ & $0.40 \pm 0.060$ & 520 & $0.87 \pm 0.058$ & $0.37 \pm 0.068$ & 6.9 & $\mathrm{NA}$ & $5.0 \pm 1.0$ & 0.89 & 1 & 1 & 1.22 & 1.60 & $8.0 \pm 2.0$ & Tokimatsu (personal communication, 2000) \\
\hline
\end{tabular}



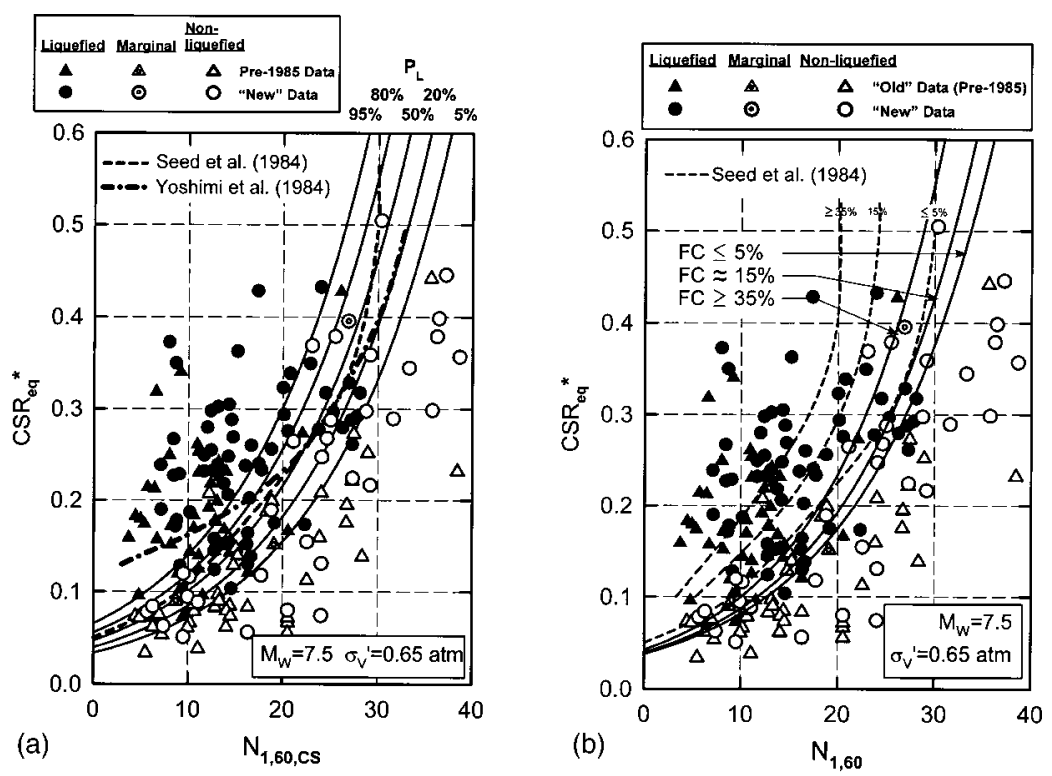

Fig. 9. (a) Recommended probabilistic standard penetration test-based liquefaction triggering correlation for $M_{w}=7.5$ and $\sigma_{v}^{\prime}=0.65$ atm, and relationship for "clean sands" proposed by Seed et al. (1984) and (b) recommended "deterministic" standard penetration test-based liquefaction triggering correlation for $M_{w}=7.5$ and $\sigma_{v}^{\prime}=0.65 \mathrm{~atm}$, with adjustments for fines content shown

very high CSR $(\mathrm{CSR}>0.3)$, a range in which data was previously scarce

Also shown in Fig. 9(a) is the boundary curve proposed by Yoshimi et al. (1994), based on high quality cyclic testing of frozen samples of alluvial sandy soils. The line of Yoshimi et al. is arguably unconservatively biased at very low densities (low $N$ values) as these loose samples densified during laboratory thawing and reconsolidation prior to cyclic testing. Their testing provides potentially valuable insight, however, at high $N$ values where reconsolidation densification was less significant. In this range, the new proposed correlation provides slightly better agreement with the test data than does the earlier relationship proposed by Seed et al. (1984).

The new correlation is also presented in Fig. 2(d), where it can be compared directly with the earlier probabilistic relationships of Figs. 2(a-c). Here, again, the new correlation is normalized to $\sigma_{v}^{\prime}=0.65 \mathrm{~atm}$ in order to be compatible with the basis of the other relationships shown. As shown in this figure, the new correlation provides a significant reduction in overall uncertainty (or variance); to such an extent that the principal remaining uncertainty is now concentrated not in the correlation itself, but rather in the engineer's ability to assess the necessary project-specific loading and soil characterization parameters.

\section{Adjustments for Fines Content}

The new (probabilistic) boundary curve for $P_{L}=15 \%$ (again normalized to an effective overburden stress of $\sigma_{v}^{\prime}=0.65 \mathrm{~atm}$ ) represents a suitable basis for illustration of the new correlation's regressed correction for the effects of fines content, as shown in Fig. 9(b). In this figure, both the correlations as well as the mean values (CSR and $N_{1,60}$ ) of the field case history data are shown not corrected for fines [this time with the $N$ value axis not corrected for fines content effects, so that the $\left(P_{L}=15 \%\right)$ boundary
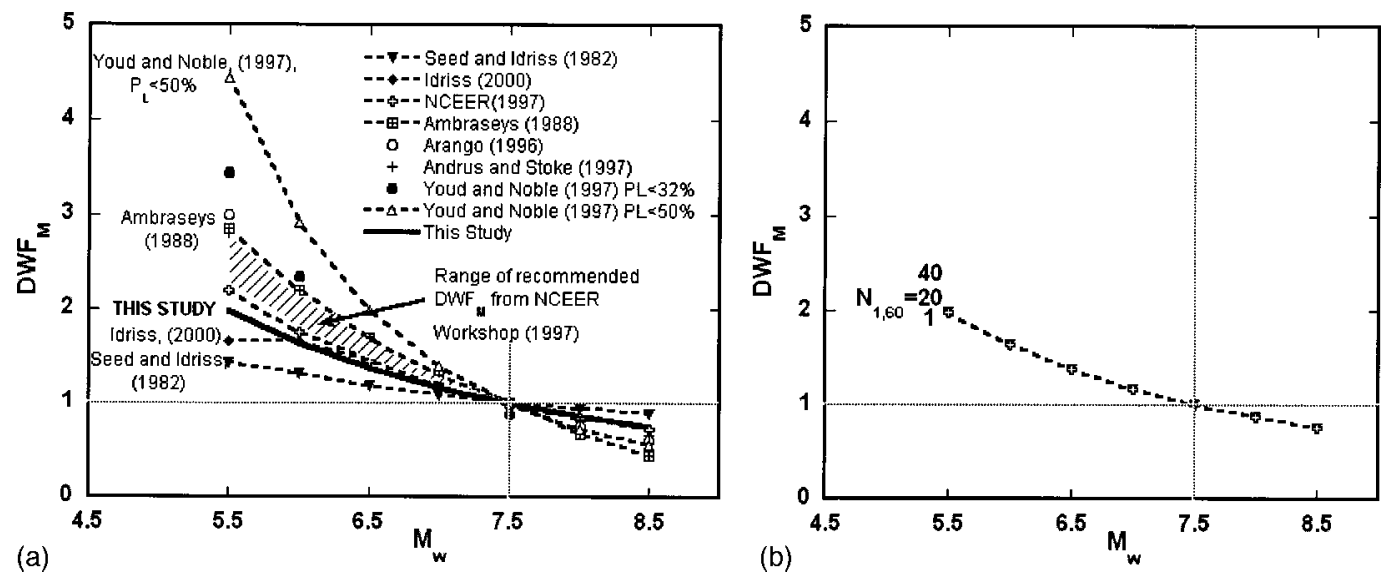

Fig. 10. (a) Previous recommendations for magnitude-correlated duration weighting factor, with recommendations from current studies and (b) recommended magnitude-correlated duration weighting factor as function of $N_{1,60}$ 


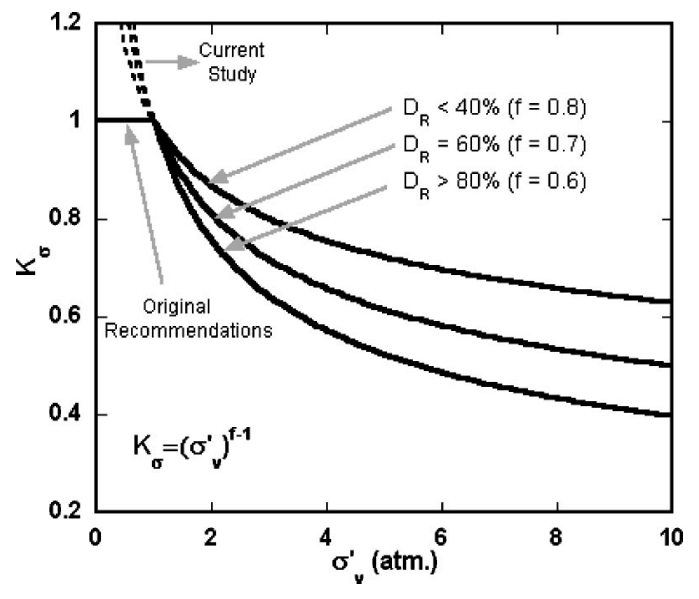

Fig. 11. Previous National Center for Earthquake Engineering Research working group recommendations regarding $K_{\sigma}$ (after Youd et al. 2001)
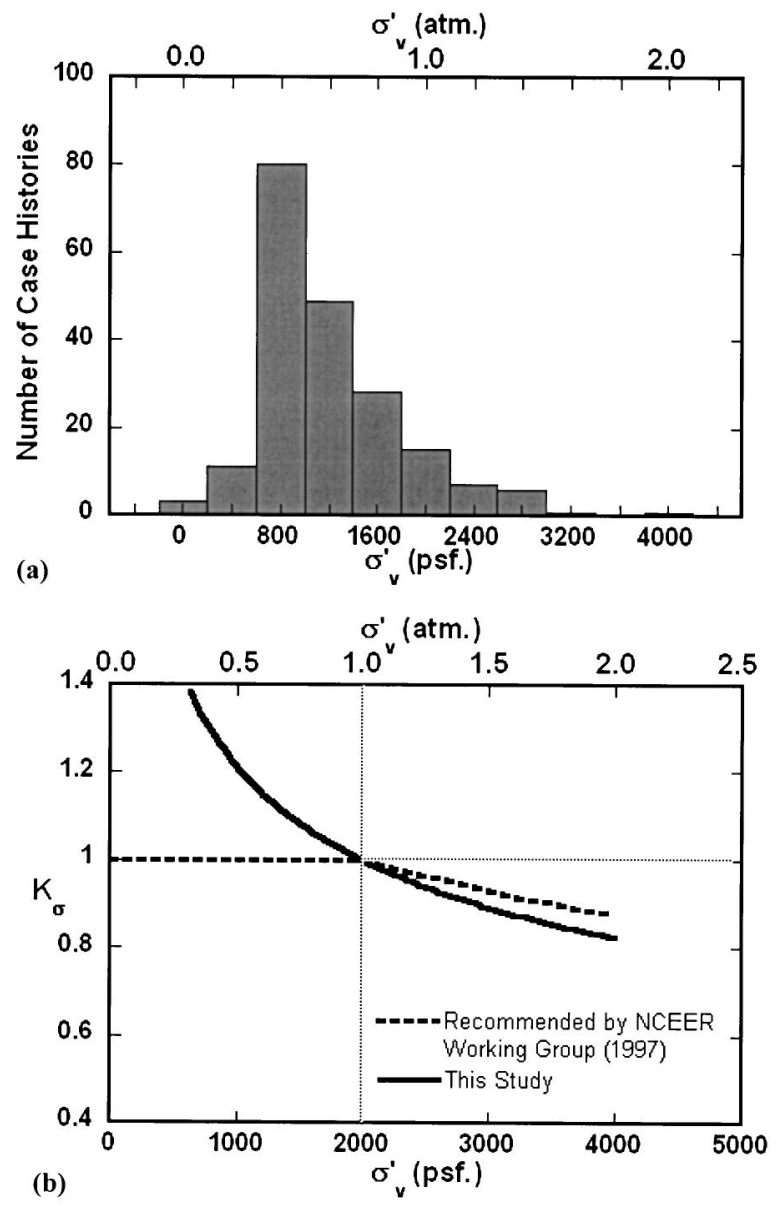

Fig. 12. (a) Range of $\sigma_{v}^{\prime}$ in case history database; and (b) values of $K_{\sigma}$ developed and used in these studies, and National Center for Earthquake Engineering Research working group recommendations (for $n=0.7, D_{R} \approx 60 \%$ ) for comparison

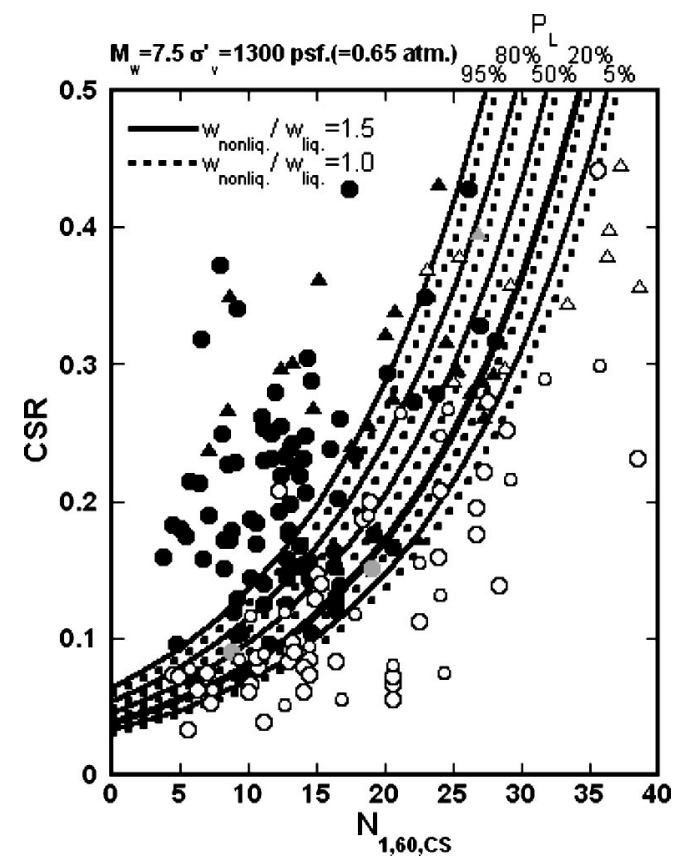

Fig. 13. Effect of weighting of nonliquefied field case histories to address sampling disparity

curves are, instead, offset to account for varying fines content]. In this figure, the earlier correlation proposed by Seed et al. (1984) is also shown, with dashed lines, for approximate comparison.

In these current studies, based on the overall (regressed) correlation, the energy, procedure, and overburden-corrected $N$ values $\left(N_{1,60}\right)$ are further corrected for fines content as

$$
N_{1,60, \mathrm{CS}}=N_{1,60} \cdot C_{\mathrm{FINES}}
$$

where the fines correction (FC) was "regressed" as a part of the overall Bayesian updating analyses. The fines correction is equal to approximately 1.0 (a null adjustment) for fines contents of $\mathrm{FC} \leqslant 5 \%$, and reaches a maximum (limiting) value for $\mathrm{FC}$ $\geqslant 35 \%$. As illustrated in Fig. 9(b), the maximum fines correction results in an increase of $N$ values of about +6.5 blows $/ \mathrm{ft}$ (at FC $\geqslant 35 \%$, and high CSR). As illustrated in this figure, this maximum fines correction is somewhat smaller than the earlier maximum correction of +10 blows/ft proposed by Seed et al. (1984).

The relationship for $C_{\text {FINES }}$ can be expressed as a close approximation as

$$
\begin{aligned}
C_{\mathrm{FINES}}= & (1+0.004 \cdot \mathrm{FC})+0.05 \cdot\left(\frac{\mathrm{FC}}{N_{1,60}}\right), \\
& \lim : 5 \% \leqslant \mathrm{FC} \leqslant 35 \%
\end{aligned}
$$

where $\mathrm{FC}=$ percent fines content (by dry weight) expressed as an integer (e.g., 27\% fines is represented as $\mathrm{FC}=27.0$ ). At fines contents of less than $5 \%$, a value of $\mathrm{FC}=0$ is used, and similarly a value of $\mathrm{FC}=35$ is used when fines content exceeds $35 \%$.

\section{Magnitude-Correlated Duration Weighting}

Both the probabilistic and "deterministic" (based on $P_{L}=15 \%$ ) new correlations presented in Figs. 9(a and b) are based on correction of "equivalent uniform cyclic stress ratio" $\left(\mathrm{CSR}_{\mathrm{eq}}\right)$ for duration (or number of equivalent cycles) to $\mathrm{CSR}_{\text {eq }}^{*}$, representing 

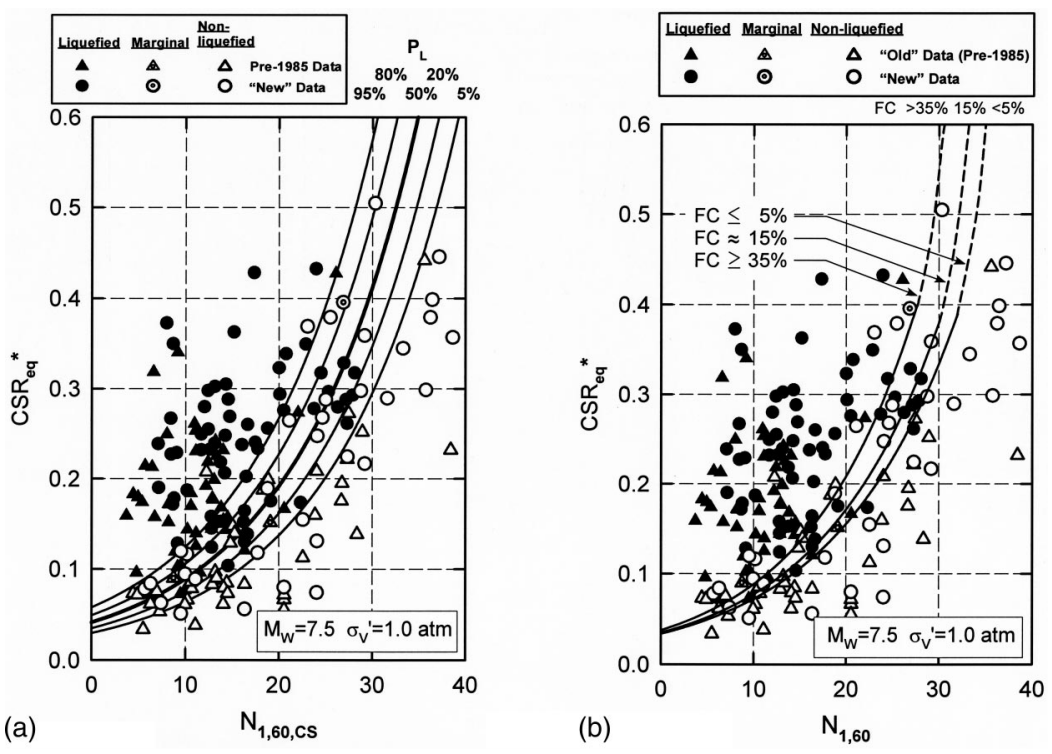

Fig. 14. (a) Recommended probabilistic standard penetration test-based liquefaction triggering correlation for $M_{w}=7.5$ and $\sigma_{v}^{\prime}=1.0$ atm and (b) recommended "deterministic" standard penetration test-based liquefaction triggering correlation for $M_{w}=7.5$ and $\sigma_{v}^{\prime}=1.0$ atm, with adjustments for fines content shown

the equivalent $\mathrm{CSR}_{\mathrm{eq}}$ for a duration typical of an "average" event of $M_{W}=7.5$. This was done by means of a magnitude-correlated $\mathrm{DWF}_{M}$ as

$$
\mathrm{CSR}_{\mathrm{eq}}^{*}=\mathrm{CSR}_{\mathrm{eq}} / \mathrm{DWF}_{M}
$$

This duration weighting factor has been somewhat controversial, and has been developed by a variety of different approaches (using cyclic laboratory testing and/or field case history data) by a number of investigators. Fig. 10(a) summarizes a number of recommendations, and shows (shaded zone) the recommendations of the NCEER Working Group (NCEER 1997; Youd et al. 2001). In these current studies, this important and controversial factor could be derived as a part of the overall regression analyses. Moreover, the factor $\left(\mathrm{DWF}_{M}\right)$ could also be investigated for possible dependence on density (correlation with $N_{1,60}$ ). Figs. 10(a and b) show the resulting values of $\mathrm{DWF}_{M}$, as a function of varying corrected $N_{1,60}$ values. As shown in Fig. 10(b), the dependence on density, or $N_{1,60}$ values, was found to be relatively minor.

The duration weighting factors shown in Figs. 10(a and b) fall slightly below those recommended by the NCEER Working group, and slightly above (but very close to) recent recommendations of Idriss (personal communication, 2000). Idriss' recommendations are based on a judgmental combination of interpretation of high-quality cyclic simple shear laboratory test data and empirical assessment of "equivalent" numbers of cycles from recorded strong motion time histories. The close agreement of this very different (and principally laboratory data based) approach, and the careful probabilistic assessments of these current studies, are strongly mutually supportive.

\section{Adjustments for Effective Overburden Stress}

An additional factor not directly resolved in prior studies based on field case histories is the increased susceptibility of soils to cyclic liquefaction, at the same CSR, with increases in effective overburden stress. [This is in addition to the normalization of $N$ values for overburden effects as per Eqs. (11) and (12)].
The additional effect of reduction of normalized liquefaction resistance with increased effective initial effective overburden stress $\left(\sigma_{v}^{\prime}\right)$ has been demonstrated by means of laboratory testing, and is a manifestation of "critical state" type of behavior (suppression of dilatency at increased effective confining stress). Fig. 11 shows the recommendations of the NCEER Working group (Youd et al. 2001) regarding the correction factor $K_{\sigma}$ to be used to correct the normalized resistance to liquefaction at an initial effective overburden stress of $1 \mathrm{~atm}$. $\left(\mathrm{CSR}_{\mathrm{liq}, 1 \mathrm{~atm}}\right)$, as

$$
\mathrm{CSR}_{\mathrm{liq}}=\mathrm{CSR}_{\mathrm{liq}, 1 \mathrm{~atm}} \cdot K_{\sigma}
$$

These current studies were not very sensitive to $K_{\sigma}$, as the range of $\sigma_{v}^{\prime}$ in the case history data base was largely between $\sigma_{v}^{\prime}=30$ and $130 \mathrm{kPa}\left(600-2,600 \mathrm{lb} / \mathrm{ft}^{2}\right)$, as shown in Fig. 12(a), but it was possible to "regress" $K_{\sigma}$ as part of the overall Bayesian updating analyses. The results are shown in Fig. 12, over the range of $\sigma_{v}^{\prime} \approx 30-180 \mathrm{kPa}\left(600-3,600 \mathrm{lb} / \mathrm{ft}^{2}\right)$ for which they are considered valid. These are in good agreement with the earlier recommendations of Fig. 11, and it is recommended that $K_{\sigma}$ can be estimated as

$$
K_{\sigma}=\left(\sigma_{v}^{\prime}\right)^{f-1}
$$

where $f \approx 0.6-0.8$ (as a function of $N_{1,60 \text {,cs }}$ varying from about 5 to 40 blows/ft). The field case history data of these current studies are not a sufficient basis for extrapolation of $K_{\sigma}$ to much higher values of $\sigma_{v}^{\prime}$, and the authors recommend continued use of Fig. 11 for $\sigma_{v}^{\prime}>2$ atm at this time.

The earlier relationships proposed by Seed et al. (1984), Liao et al. (1988), and Liao and Lum (1998), Youd and Noble (1997), and Toprak et al. (1999) were all stated to be normalized to an effective overburden stress of approximately $\sigma_{v}^{\prime}$ $=1 \mathrm{~atm}\left(2,000 \mathrm{lb} / \mathrm{ft}^{2}\right)$. The correlation of Seed et al. (1984) was never formally corrected to $\sigma_{v}^{\prime}=1 \mathrm{~atm}$, however, as it was noted the field case histories of the database were "shallow" and approximately in this range. The database was, however, not centered at $\sigma_{v}^{\prime}=1 \mathrm{~atm}$, but rather at lesser overburden (mean $\sigma_{v}^{\prime}$ $\approx 1,300 \mathrm{lb} / \mathrm{ft}^{2}$, or $65 \mathrm{kPa}$ ), and this proves to render the earlier 
relationship of Seed et al. $(1984,1985)$ slightly unconservative if taken as normalized to $\sigma_{v}^{\prime}=1 \mathrm{~atm}$. (The same is true of all of the other, similar, previous relationships discussed.) It should be noted, however, that this unconservatism is minimized if the correlations are applied at shallow depths.

For correctness, and to avoid ambiguity, both the earlier relationship of Seed et al. (1984), and the correlations developed in these current studies, need to be formally normalized to $\sigma_{v}^{\prime}$ $=1 \mathrm{~atm}$. Accordingly, in these studies, all data are corrected for $K_{\sigma}$ effects [by Eqs. (17) and (18)]; not just those data for which $\sigma_{v}^{\prime}$ were greater than $1 \mathrm{~atm}$. A recommended limit is $K_{\sigma} \leqslant 1.5$ (at very shallow depths). Figs. 14(a and b) again show the proposed new correlations, this time fully normalized to $\sigma_{v}^{\prime}=1 \mathrm{~atm}$.

\section{Sources of Potential Bias}

A number of earthquakes contributed disproportionally to the database, and this posed a risk of biasing the results. This was addressed by means of a number of adjustments. Case histories from the 1989 Loma Prieta Earthquake experienced unusually short durations of shaking due to the relatively symmetric nature of the event's bilateral rupture mechanism. Accordingly, the "magnitude" representing this event was judgmentally downgraded to $M_{W}=6.5$ for purposes of evaluating the magnitude-correlated duration weighting factor $\left(\mathrm{DWF}_{M}\right)$. Similarly, rupture directivity effects compressed the arriving energy pulses in the Port region at Kobe during the 1995 Kobe Earthquake, so the assigned magnitude in the Port region was downgraded slightly to $M_{W}=6.7$. Finally, owing to the similarity of seismic excitation in a relatively close proximity, the seismic loading (CSR) data for the Kobe Port region and the Loma Prieta data sets were analytically treated as internally correlated, with assigned correlation factors based on judgment. The analyses were then repeated, without modeling this internal correlation, and the results were found not to differ significantly. The uncorrelated model (requiring no a priori judgmental assignment of internal correlation) was used as the final basis for the studies presented herein.

A final, and very difficult, issue was the fact that the data sets assembled overrepresented "liquefied" sites relative to "nonliquefied" sites. The final data set contained roughly twice as many liquefied as nonliquefied cases, and most large data sets assembled by prior researchers were found to have similar ratios. The problem is that this represents a sampling disparity problem, and is not an unbiased reflection of actual field occurrences. Simply put, postearthquake field investigators are more inclined to perform borings and tests at liquefied sites, than at sites where no apparent liquefaction occurred. Given finite research budgets, it would be asking too much to expect researchers to randomly space their SPT borings at nonliquefied sites in the hope of encountering nonliquefied soils of potentially liquefiable type.

This unavoidable sampling disparity produces a bias in the results, as the artificially disproportionate number of "liquefied" data push against the under represented "nonliquefied" data. Two approaches were invoked to address this problem, and these are described in Cetin et al. (2002). The first was to consult with experts, and to attempt to develop expert consensus regarding a weighting factor that can be applied to eliminate this bias. All experts consulted agreed that the bias was real, and that a corrective weighting factor $\left(W_{N L}\right)$ for the nonliquefied data should be greater than 1.0. The most common range recommended was on the order of $W_{N L}=1.5-2$.

The second approach was to treat the weighting factor as a variable in the Bayesian regression analyses performed, and to assess the weighting factor that provided the best overall model "fit." This was found to be a factor of about 1.5. Finally a sensitivity study was performed, and it was found that a weighting factor of 1.5 produced only a modest shift in the correlations, as illustrated in Fig. 13, and that it would be potentially overconservative to leave the sampling disparity problem unaddressed. Accordingly, all "nonliquefied" data were scaled by a weighting factor of $W_{N L}=1.5$. This was not done, however, simply by weighting the nonliquefied data by this factor, as that would have increased the "apparent" amount of overall case history data, and would have produced biased (reduced) estimates of overall model uncertainty. Instead, all "liquefied" data were weighted by a factor of $W_{L}=0.8$, and all "nonliquefied" data were weighted by a factor of $W_{N L}=1.2$, resulting in a ratio of $W_{N L} / W_{L}=1.5$ without significantly increasing or decreasing the "apparent" overall number of cases or amount of data.

\section{Overall Correlation}

The overall correlation can be expressed in parts, as in the previous sections [and Eqs. (14)-(18) and the equations to follow, and Figs. 9-14]. It can also be expressed concisely as a single, composite relationship as

$$
P_{L}\left(N_{1,60}, \mathrm{CSR}_{\mathrm{eq}}, M_{w}, \sigma_{v}^{\prime}, \mathrm{FC}\right)=\Phi\left(-\frac{\left(N_{1,60} \cdot(1+0.004 \cdot \mathrm{FC})-13.32 \cdot \ln \left(\mathrm{CSR}_{\mathrm{eq}}\right)-29.53 \cdot \ln \left(M_{w}\right)-3.70 \cdot \ln \left(\frac{\sigma_{v}^{\prime}}{P_{a}}\right)+0.05 \cdot \mathrm{FC}+16.85\right)}{2.70}\right)
$$

where $P_{L}=$ probability of liquefaction in decimals (i.e., $P_{L}=30 \%$ is represented as 0.30 ); CSR eq is not "adjusted" for magnitude or duration effects (correction for duration effects occurs within the equation itself); FC = percent fines content (by dry weight) expressed as an integer (e.g., $12 \%$ fines is expressed as $\mathrm{FC}=12$ ) with the limit of $5 \leqslant \mathrm{FC} \leqslant 35$ as explained previously in Eq. (15); $P_{a}=$ atmospheric pressure $(=1 \mathrm{~atm}, \approx 100 \mathrm{kPa}, \approx 2,000 \mathrm{psf})$ in the same units as the in situ vertical effective stress $\left(\sigma_{v}^{\prime}\right)$; and $\Phi=$ standard cumulative normal distribution. Also the cyclic resistance ratio for a given probability of liquefaction can be expressed as

$$
\operatorname{CRR}\left(N_{1,60}, M_{w}, \sigma_{v}^{\prime}, \mathrm{FC}, P_{L}\right)=\exp \left[\frac{\left(N_{1,60} \cdot(1+0.004 \cdot \mathrm{FC})-29.53 \cdot \ln \left(M_{w}\right)-3.70 \cdot \ln \left(\frac{\sigma_{v}^{\prime}}{P_{a}}\right)+0.05 \cdot \mathrm{FC}+16.85+2.70 \cdot \Phi^{-1}\left(P_{L}\right)\right)}{13.32}\right]
$$


where $\Phi^{-1}\left(P_{L}\right)=$ inverse of the standard cumulative normal distribution (i.e., mean $=0$, and standard deviation $=1$ ). For spreadsheet construction purposes, the command in Microsoft Excel for this specific function is "NORMINV $\left(P_{L}, 0,1\right)$."

\section{Recommended Use of New Correlations}

The proposed new probabilistic correlations can be used in either of two ways. They can be used directly, all at once, as summarized in Eqs. (19) and (20). Alternatively, they can be used "in parts" as has been conventional for most previous, similar methods. To do this, measured $N$ values must be corrected to $N_{1,60}$ values, using Eqs. (11)-(13). The resulting $N_{1,60}$ values must then be further corrected for fines content to $N_{1,60, c s}$ values, using Eqs. (14) and (15) [or Figs. 9(b) and 13]. Similarly, in situ equivalent uniform $\mathrm{CSR}_{\mathrm{eq}}$ must be evaluated [either based on direct response analyses, or using Eq. (10) and the new $r_{d}$ relationships proposed herein], and this must then be adjusted by the magnitudecorrelated $\mathrm{DWF}_{M}$ using Eq. (16) [and Fig. 10(a)] as

$$
\mathrm{CSR}_{\mathrm{eq}, M=7.5}=\mathrm{CSR}_{\mathrm{eq}} / \mathrm{DWF}_{M}
$$

The new $\mathrm{CSR}_{\mathrm{eq}, M=7.5}$ must then be further adjusted for effective overburden stress by the inverse of Eq. (17) as

$$
\mathrm{CSR}_{\mathrm{eq}, M=7.5,1 \mathrm{~atm}}=\mathrm{CSR}_{\mathrm{eq}, M=7.5} / K_{\sigma}=\mathrm{CSR}_{\mathrm{eq}}^{*}
$$

The resulting, fully adjusted and normalized values of $N_{1,60, \mathrm{cs}}$ and $\mathrm{CSR}_{\mathrm{eq}}^{*}$ can then be used, with Fig. 14(a) to assess probability of initiation of liquefaction.

For "deterministic" evaluation of liquefaction resistance, largely compatible with the intent of the earlier relationship proposed by Seed et al. (1984), the same steps can be undertaken (except for the fines adjustment) to assess the fully adjusted and normalized $\mathrm{CSR}_{\mathrm{eq}, M=7.5,1 \mathrm{~atm}}$ values, and normalized $N_{1,60}$ values, and these can then be used in conjunction with the recommended "deterministic" relationship presented in Fig. 14(b). The recommendations of Fig. 14(b) correspond to the new probabilistic relationships (for $P_{L}=15 \%$ ), except at very high CSR (CSR $>0.4$ ). At these very high CSR; (1) there is virtually no conclusive field data and (2) the very dense soils $\left(N_{1,60} \geqslant 30\right.$ blows/ft $)$ of the boundary region are strongly dilatent and have only very limited postliquefaction strain potential. Behavior in this region is thus not conducive to large liquefaction-related displacements, and the heavy dashed lines shown in the upper portion of Fig. 14(b) represent the authors' recommendations in this region based on data available at this time.

Finally, it should be noted that these new liquefaction hazard assessment correlations are based on both direct calculation of in situ CSR as well as "simplified" CSR estimates based on improved $r_{d}$ correlations for the back-analyzed field performance case histories. As such, these are compatible either with direct seismic response analyses, or use of the new $r_{d}$ recommendations presented herein [and Eq. (8)], and without systematic bias. They are not, however, compatible with use of previous $r_{d}$ recommendations for "simplified" estimation of in situ CSR.

\section{Summary and Conclusions}

This paper has presented the development of recommended new probabilistic and deterministic relationships for assessment of likelihood of initiation of liquefaction. Stochastic models for as- sessment of seismic soil liquefaction initiation risk have been developed within a Bayesian framework. In the course of developing the proposed stochastic models, the relevant uncertainties including (1) measurement/estimation errors, (2) model imperfection, (3) statistical uncertainty, and (4) those arising from inherent variables were addressed.

Improved treatment of $r_{d}$ in "simplified" assessment of in situ CSR results in triggering relationships that are unbiased with respect to use in conjunction with either (1) direct seismic response analyses for evaluation of in situ CSR, or (2) improved "simplified" assessment of in situ CSR. This is an important step forward, as these studies also show that all previous, widely used correlations are unconservatively biased when used in conjunction with direct response analyses for assessment of CSR, as a result of bias in previous "simplified" $r_{d}$ recommendations.

The new models provide a significantly improved basis for engineering assessment of the likelihood of liquefaction initiation, relative to previously available models, as shown in Fig. 2. The new models presented and described in this paper deal explicitly with the issues of: (1) FC, (2) magnitude-correlated $\left(\mathrm{DWF}_{M}\right)$, and (3) effective overburden stress ( $K_{\sigma}$ effects), and they provide both: (1) an unbiased basis for evaluation of liquefaction initiation hazard and (2) significantly reduced overall model uncertainty. Indeed, model uncertainty is now reduced sufficiently that overall uncertainty in application of these new correlations to field problems is now driven strongly by the difficulties/uncertainties associated with project-specific engineering assessment of the necessary "loading" and "resistance" variables, rather than uncertainty associated with the correlations themselves. This, in turn, allows/ encourages the devotion of attention and resources to improved evaluation of these project-specific parameters. As illustrated in Figs. 2 and 14(a and b), this represents a significant overall improvement in our ability to accurately and reliably assess liquefaction hazard.

\section{Acknowledgments}

Funding for these studies was provided by PG\&E, through the PG\&E/PEER Center Research Program, under Contract No. Z-19-2-133, and this support is gratefully acknowledged. The writers also wish to thank M. J. Bennett, and Dr. J. C. Tinsley, Dr. S. Toprak, and Dr. T. L. Holzer, all from the U.S. Geological Survey (USGS), for their assistance in collecting and interpreting case histories, and for their valuable suggestions. Similarly, the writers are grateful to Dr. T. L. Youd both for his assistance in obtaining and evaluating case history data, as well as for his insight and comments. They are also grateful to Dr. Anne Kammerer and Dr. Robert E. S. Moss for useful discussion and checking of the new correlations proposed, as well as assistance in representing these in a tractable form for use by working engineers.

\section{References}

Bennett, M. J. (1989). "Liquefaction analysis of the 1971 ground failure at the San Fernando Valley Juvenile Hall, California." Bull. Assoc. Eng. Geol., 26(2), 209-226.

Bennett, M. J., McLaughlin, P. V., Sarmiento, J. S., and Youd, T. L. (1984). "Geotechnical investigation of liquefaction sites, Imperial Valley, California." Open File Rep. No. 84-252, U.S. Dept. of Interior Geological Survey, Washington, D.C. 
Bennett, M. J., Ponti, D. J., Tinsley, J. C., Holzer, T. L., and Conaway, C. H. (1998). "Subsurface geotechnical investigations near sites of ground deformations caused by the January 17, 1994, Northridge, California, Earthquake." U.S. Dept. of Interior Geological Survey, Open File Rep. No. 98-373, Washington, D.C.

Bennett, M. J., Tinsley, J. C. (1995). "Geotechnical data from surface and subsurface samples outside of and within liquefaction-related ground failure of the October 17, 1989, Loma Prieta Earthquake, Santa Cruz and Monterey Counties, California." U.S. Dept. of Interior Geological Survey, Open File Rep. No. 95-663, Washington, D.C.

Boulanger, R. W., Mejia, L. H., and Idriss, I. M. (1997). "Liquefaction at Moss Landing during Loma Prieta Earthquake." J. Geotech. Eng., 123(5), 453-467.

Cetin, K. O. (2000). "Reliability-based assessment of seismic soil liquefaction initiation hazard," PhD dissertation, Univ. of California, Berkeley, Calif.

Cetin, K. O., Der Kiureghian, A., and Seed, R. B. (2002). "Probabilistic models for the initiation of seismic soil liquefaction." Struct. Safety, 24(1), 67-82.

Cetin, K. O., and Seed, R. B. (2000). "Earthquake-induced nonlinear shear mass participation factor $\left(r_{d}\right)$." Geotechnical Research Rep. No. $U C B / G T-2000 / 08$, Dept. of Civil and Environmental Engineering, Univ. of California, Berkeley, Calif.

Cetin, K. O., and Seed, R. B. (2004). "Nonlinear shear mass participation factor, $r_{d}$ for cyclic shear stress ratio evaluation." Soil Dyn. Earthquake Eng. 24(2) 103-113.

Cetin, K. O., Seed, R. B., Moss, R. E. S., Der Kiureghian, A. K., Tokimatsu, K., Harder, L. F., Jr., Kayen, R. E., and Idriss, I. M. (2000). "Field performance case histories for SPT-based evaluation of soil liquefaction triggering hazard." Geotechnical Research Rep. No. $U C B / G T-2000 / 09$, Dept. of Civil and Environmental Engineering, Univ. of California, Berkeley, Calif.

Geyskens, P., Der Kiureghian, A., and Monteiro, P. (1993). "Bayesian udating of model parameters." Research Rep. No. UCB/SEMM-93/06, Dept. of Civil and Environmental Engineering, Univ. of California, Berkeley, Calif.

Golesorkhi, R. (1989). "Factors influencing the computational determination of earthquake-induced shear stresses in sandy soils." $\mathrm{PhD}$ dissertation, Univ. of California, Berkeley, Calif.

Hamada, M., and O’Rourke, T. D. (1992). "1983 Nihonkai Chubu Earthquake." Proc., 4th Japan-U.S. Workshop on Earthquake Resistant Design of Lifeline Facilities and Countermeasures for Soil Liquefaction, Technical Rep. No. NCEER-92-0019, August 12.

Holzer, T. L., Tinsley, J. C., Bennett, M. J., and Mueller, C. S. (1994). "Observed and predicted ground deformation-Miller Farm lateral spread, Watsonville, California." Proc., 5th U.S._Japan Workshop on Earthquake Resistant Design of Lifeline Facilities and Countermeasures for Soil Liquefaction, Technical Rep. No. NCEER-94-0026, 7999.

Iai, S. et al. (1994). "Effects of remedial measures against liquefaction at 1993 Kushiro-Oki Earthquake.” Proc., 5th Japan-U.S. Workshop on Earthquake Resistant Design of Lifeline Facilities and Countermeasures Against Soil Liquefaction, Technical Rep. No. NCEER-94-0026, November 7.

Idriss, I. M. (1997). "Evaluation of liquefaction potential and consequences: Historical perspective and updated procedures." Proc., 3rd Seismic Short Course on Evaluation and Mitigation of Earthquake Induced Liquefaction Hazards. T. D'Orazio, ed., Cowell Theater of Fort Mason, San Francisco.

Idriss, I. M., Arango, I., and Brogan, G. (1979). "Study of liquefaction in November 23, 1977 Earthquake San Juan Province, Argentina.” Final Rep., Woodward-Clyde Consultants.

Idriss, I. M., and Sun, J. I. (1992). Users manual for SHAKE91, A computer program for conducting equivalent linear seismic response analyses of horizontally layered soil deposits, program modified based on the original SHAKE program published in December 1972, Schnabel, Lysmer, and Seed.

Imai, T., Tonouchi, K., and Kanemori, T. (1981). "The simple evaluation method of shear stress generated by earthquakes in soil ground." Rep. No. 3, Bureau of Practical Geological Investigation, 39-58.

Ishihara, K. (1977). "Simple method of analysis for liquefaction of sand deposits during earthquakes." Soils Found., 17(3), 1-17.

Ishihara, K., Kawase, Y., and Nakajima, M. (1980). "Liquefaction characteristics of sand deposits at an oil tank site during the 1978 Miyagiken-Oki earthquake.” Soils Found., 20(2), 97-111.

Ishihara, K., Silver, M. L., and Kitagawa, H. (1979). "Cyclic strength of undisturbed sands obtained by a piston sampler.” Soils Found., 19(3), 61-76.

Ishihara, K., Shimuzu, K., and Yamada, Y. (1981). "Pore water pressures measured in sand deposits during an earthquake." Soils Found., 21(4), 85-100.

Iwasaki, T., Tatsuoka, F., Tokida, K. I., and Yasuda, S. (1978). “A practical method for assessing soil liquefaction potential based on case studies at various sites in Japan." Proc., 2nd Int. Conf. on Microzonation for Safer Construction-Research and Application, Vol. II, San Francisco, 885-896.

Juang, C. H., Jiang, T., and Andrus, R. D. (2002). "Assessing the probability-based methods for liquefaction potential evaluation." $J$. Geotech. Geoenviron. Eng., 128(7), 580-589.

Kishida, H. (1966). "Damage to reinforced concrete buildings in Niigata City with special reference to foundation engineering." Soils Found., VI(1), 71-88.

Kishida, H. (1969). "Characteristics of liquefied sands during MinoOwari, Tohnankai and Fukui earthquakes." Soils Found., 9(1), 75-92.

Kishida, H. (1970). "Characteristics of liquefaction of level sandy ground during the Tokachi-Oki earthquake." Soils Found., 10(2), 103-111.

Koizumi, Y (1964). "Changes in density of sand subsoil caused by the Niigata earthquake." Proc., Symp. on Niigata Earthquake, Japanese Society of Soil Mechanics and Foundation Engineering, Tokyo, November 11.

Koizumi, Y. (1966). "Change of density of sand subsoil caused by the Niigata Earthquake." Soils Found., VII(2), 38-44.

Liao, S. S. C., and Lum, K. Y. (1998). "Statistical analysis and application of the magnitude scaling factor in liquefaction analysis." Proc., ASCE 3rd Specialty Conf. in Geotechnical Earthquake Engineering and Soil Dynamics, Vol. 1, 410-421.

Liao, S. S. C., and Whitman, R. V. (1986). "Overburden correction factor OS for SPT in sand.” J. Geotech. Eng., 112(3), 373-377.

Liao, S. S. C., Veneziano, D., and Whitman, R. V. (1988). "Regression models for evaluating liquefaction probability." J. Geotech. Eng., 114(4), 389-411.

Matsuo, O. (1996). "Damage to river dikes." Special Issue of Soils and Foundations on Geotechnical Aspects of the January 17, 1995 Hyogoken-Nambu Earthquake, January, 235-240.

Mitchell, J. K., Lodge, A., Coutinho, R., Kayen, R., Seed, R. B., Nishio, S., Stokoe, K. H. (1994), "In situ test results from Four Loma Prieta earthquake liquefaction sites: SPT, CPT, DMT, and shear wave velocity." Earthquake Engineering Research Center Rep. No. UCB/EERC94/04, Univ. of California at Berkeley, Berkeley, Calif., April.

National Center for Earthquake Engineering Research, (NCEER). (1997). "Proceedings of the NCEER workshop on evaluation of liquefaction resistance of soils," Technical Rep. No. NCEER-97-0022, T. L Youd and I. M. Idriss, eds., SUNY, Buffalo, N.Y.

Ohsaki, Y. (1966). "Niigata Earthquakes, 1964, building damage and soil conditions." Soils Found., VI(2), 14-37.

Schnabel, P. B., Lysmer, J., and Seed, H. B. (1972). "SHAKE: A computer program for earthquake response analysis of horizontally layered sites." Rep. No. EERC/72-12, Earthquake Engineering Research Center, Univ. of California, Berkeley, Calif.

Seed, H. B., Arango, I., Chan, C. K., Gomez-Masso, A., and Ascoli, R. G. (1979). "Earthquake-induced liquefaction near Lake Ametitlan, Guatemala." Earthquake Engineering Research Center Rep. No. $U C B / E E R C-79 / 27$, Univ. of California at Berkeley, Berkeley, Calif.

Seed, H. B., and Idriss, I. M. (1971). "Simplified procedure for evaluating soil liquefaction potential." J. Soil Mech. Found. Div., 97(SM9), $1249-1273$. 
Seed, H. B., Tokimatsu, K., Harder, L. F., and Chung, R. M. (1984). "The influence of SPT procedures in soil liquefaction resistance evaluations." Earthquake Engineering Research Center Rep. No. UCB/ EERC-84/15, Univ. of California, Berkeley, Calif.

Seed, H. B., Tokimatsu, K., Harder, L. F., and Chung, R. M. (1985). "The influence of SPT procedures in soil liquefaction resistance evaluations." J. Geotech. Eng., 111(12), 1425-1445.

Shengcong, F., and Tatsuoka, F. (1983). Rep. of Japan-China Cooperative Research on Engineering Lessons from Recent Chinese Earthquakes, Including the 1976 Tangshan Earthquake (Part 1), C. Tamura, T. Katayama, and F. Tatsuoka, eds., Institute of Industrial Science, Univ. of Tokyo, Tokyo.

Shibata, T., Oka, F., and Ozawa, Y. (1996). "Characteristics of ground deformation due to liquefaction." Special Issue of Soils and Foundations on Geotechnical Aspects of the January 17, 1995, HyogokenNambu Earthquake, January, 65-79.

Tohno, I., and Yasuda, S. (1981). "Liquefaction of the ground during the 1978 Miyagiken-Oki earthquake." Soils Found., 21(3), 18-34.

Tokimatsu, K., Mizuno, H., and Kakurai, M. (1996). "Building damage associated with geotechnical problems." Special Issue of Soils and Foundations on Geotechnical Aspects of the January 17, 1995, Hyogoken-Nambu Earthquake, January, 219-234.

Toprak, S., Holzer, T. L., Bennett, M. J., and Tinsley, J. C. (1999). "CPTand SPT-based probabilistic assessment of liquefaction potential." Proc., 7th U.S.-Japan Workshop on Earthquake Resistant Design of Lifeline Facilities and Countermeasures Against Liquefaction, Seattle.

Tsuchida, H. (1979). "The damage to port structures by the 1978 Miyagiken-Oki earthquake." Technical Note No. 325, The Port and Harbor Research Institute, Ministry of Transportation, Tokyo (in Japanese).

Tsuchida, H., Iai, S., and Hayashi, S. (1980). “Analysis of liquefaction during the 1978 off Miyagi prefecture earthquake." Proc., of the 7th World Conference on Earthquake Engineering, Istanbul, Vol. 3, 211 218.

Wakamatsu, T. (1992). "1990 Luzon earthquake.” Proc., 4th Japan-U.S. Workshop on Earthquake Resistant Design of Lifeline Facilities and Countermeasures for Soil Liquefaction, Technical Rep. No. NCEER92-0019, August 12.

Yasuda, S., Ishihara, K., Harada, K., and Shinkawa, N. (1996). "Effect of soil improvement on ground subsidence due to liquefaction." Special Issue of Soils and Foundations on Geotechnical Aspects of the January 17, 1995, Hyogoken-Nambu Earthquake, January, 99-107.

Yasuda, S., and Tohno, I. (1988). "Sites of reliquefaction caused by the 1983 Nihonkai-Chubu earthquake." Soils Found., 28(2), 61-72.

Yoshimi, Y., Tokimatsu, K., and Ohara, J. (1994). "In-situ liquefaction resistance of clean sands over a wide density range." Geotechnique, 44(3), 479-494.

Youd, T. L., and Bennett, M. J. (1983). "Liquefaction sites, Imperial Valley California." J. Geotech. Eng., 109(3), 440-457.

Youd, T. L., and Noble, S. K. (1997). "Liquefaction criteria based on statistical and probabilistic analyses." Proc., NCEER Workshop on Evaluation of Liquefaction Resistance of Soils, NCEER Technical Rep. No: NCEER-97-0022, 201-205.

Youd, T. L., et al. (2001). "Liquefaction resistance of soils; summary report from the 1996 NCEER and 1998 NCEER/NSF workshops on evaluation of liquefaction resistance of soils." J. Geotech. Geoenviron. Eng., 127(10), 817-833.

Youd, T. L., and Shakal (1994).

Youd, T. L., and Wieczorek, G. F. (1982). "Liquefaction and secondary ground failure in the Imperial Valley, California earthquake of October 15, 1979." U.S. Geological Survey Professional Paper No. 1254, 223-246. 